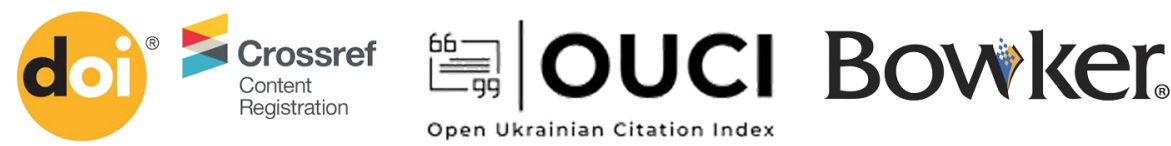

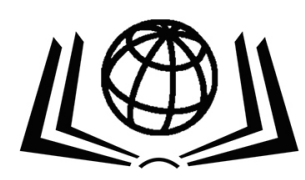

International Science Group ISG-KONF.COM

\section{MODERN MEDICINE AND PHARMACOLOGY, INNOVATIONS AND PERSPECTIVES}

Collective monograph

ISBN 978-1-63972-069-9

DOI 10.46299/ISG.2021.MONO.MED.III BOSTON(USA)-2021 
ISBN - 978-1-63972-069-9

DOL- 10.46299/ISG.2021.MONO.MED.III

Modern Medicine and

Pharmacology, Innovations and Perspectives

Collective monograph

Boston 2021 
Library of Congress Cataloging-in-Publication Data

ISBN - 978-1-63972-069-9

DOI- 10.46299/ISG.2021.MONO.MED.III

Authors - Mohammed V.O.S., Nesterovska R., Serhiyenko V., Serhiyenko L., Hotsko M., Serhiyenko A., Tashchuk V., Al Salama M.W., Amelina T., Ivanchuk P., Nesterovska R., Ахмедова Н., Ахмедова Д., Мельников О.Ф., Самбур М.Б., Тимченко С.В., Тимченко М.Д., Фараон I.В., Лахтадир Т. В., Дзевульська I.В., Камінський Р.Ф., Турбал Л.Л., Muliarchuk O., Derpak Y., Vydyborets S., Suleimanova E., Tymchenko A., Vovk S., Vashcenko V., Vovk T., Коляда H., Остапенко А., Скоробогатий B., Hladkykh F., Chyzh M.

\section{REVIEWER}

Vydyborets Stanislav - Head of the Department of Hematology and Transfusiology of the National Medical Academy of Postgraduate Education named after P.L. Shupyk.

Slabkyi Hennadii - Doctor of Medical Sciences, Head of the Department of Health Sciences, Uzhhorod National University.

\section{Published by Primedia eLaunch https://primediaelaunch.com/}

Text Copyright (C) 2021 by the International Science Group(isg-konf.com) and authors. Illustrations (C) 2021 by the International Science Group and authors. Cover design: International Science Group(isg-konf.com). (C) Cover art: International Science Group(isg-konf.com). (C)

All rights reserved. Printed in the United States of America. No part of this publication may be reproduced, distributed, or transmitted, in any form or by any means, or stored in a data base or retrieval system, without the prior written permission of the publisher. The content and reliability of the articles are the responsibility of the authors. When using and borrowing materials reference to the publication is required.

Collection of scientific articles published is the scientific and practical publication, which contains scientific articles of students, graduate students, Candidates and Doctors of Sciences, research workers and practitioners from Europe and Ukraine. The articles contain the study, reflecting the processes and changes in the structure of modern science.

The recommended citation for this publication is:

Modern medicine and pharmacology, innovations and perspectives: collective monograph Mohammed V.O.S., Nesterovska R., - etc. - International Science Group. Boston : Primedia eLaunch, 2021. 140 p. Available at : DOI- 10.46299/ISG.2021.MONO.MED.III 


\section{TABLE OF CONTENTS}

\begin{tabular}{|c|c|c|}
\hline 1. & CLINICAL MEDICINE & \\
\hline 1.1 & $\begin{array}{l}\text { Mohammed V.O.S. }{ }^{1} \text {, Nesterovska R. }{ }^{1} \\
\text { TACTICS OF MANAGING A YOUNG PATIENT WITH REDUCED } \\
\text { LEFT VENTRICULAR EJECTION FRACTION. RANOLAZINE AS } \\
\text { A COMPONENT OF THERAPY } \\
{ }^{1} \text { Department of Internal Medicine, Physical Rehabilitation and Sports Medicine } \\
\text { Bukovinian State Medical University }\end{array}$ & 6 \\
\hline 1.2 & $\begin{array}{l}\text { Serhiyenko V. }{ }^{1} \text {, Serhiyenko L. }{ }^{1}, \text { Hotsko M. }{ }^{1}, \text { Serhiyenko A. }{ }^{1} \\
\text { DIABETIC CARDIAC AUTONOMIC NEUROPATHY: } \\
\text { BENFOTIAMINE, INSULIN RESISTANCE AND SOME PRO- } \\
\text { AND ANTI-INFLAMMATORY PARAMETERS } \\
{ }^{1} \text { Department of Endocrinology, Danylo Halitsky Lviv National Medical University }\end{array}$ & 14 \\
\hline 1.3 & $\begin{array}{l}\text { Tashchuk V. }{ }^{1} \text {, Al Salama M.W. }{ }^{1}, \text { Amelina T. }{ }^{1} \text {, Ivanchuk P. }{ }^{1} \\
\text { INFLUENCE OF HYPERURICEMIA ON CHANGES OF CARDIAC } \\
\text { MARKERS, FUNCTIONAL AND CORONARY RESERVES IN } \\
\text { PATIENTS WITH STABLE ANGINA PECTORIS } \\
{ }^{1} \text { Department of Internal Medicine, Physical Rehabilitation and Sports Medicine, } \\
\text { Bukovinian State Medical University }\end{array}$ & 23 \\
\hline 1.4 & $\begin{array}{l}\text { Tashchuk V. }{ }^{1} \text {, Nesterovska R. }{ }^{1} \\
\text { CLINICAL PICTURE AND LABORATORY DISORDERS IN } \\
\text { PATIENTS WITH COVID-19 INFECTION AND ISCHEMIC } \\
\text { HEART DISEASE } \\
{ }^{1} \text { Department of Internal Medicine, Physical Rehabilitation and Sports Medicine } \\
\text { Bukovinian State Medical University }\end{array}$ & 29 \\
\hline 1.5 & 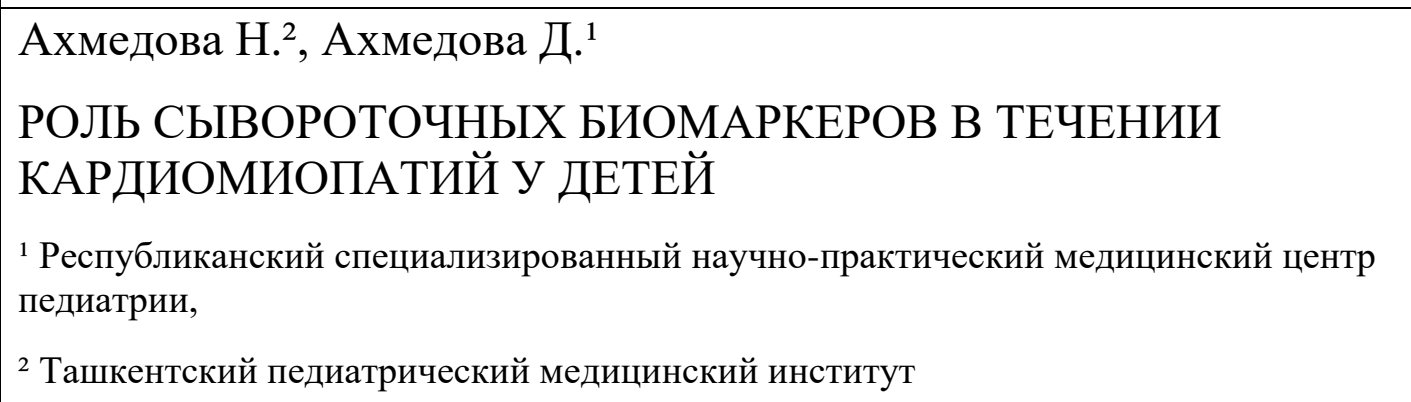 & 38 \\
\hline 1.5 .1 & $\begin{array}{l}\text { РОЛЬ МАРКЕРОВ ПОВРЕЖДЕНИЯ КАРДИОМИОЦИТОВ В } \\
\text { РАЗВИТИИ И ПРОГНОЗЕ СЕРДЕЧНОЙ НЕДОСТАТОЧНОСТИ } \\
\text { ПРИ КАРДИОМИОПАТИЯХ У ДЕТЕЙ }\end{array}$ & 40 \\
\hline 1.5 .2 & $\begin{array}{l}\text { РОЛЬ НЕЙРОГОРМОНАЛЬНОГО МАРКЕРА - ПЕПТИДА } \\
\text { ЭНДОТЕЛИН } 1 \text { В РАЗВИТИИ СЕРДЕЧНОЙ } \\
\text { НЕДОСТАТОЧНОСТИ ПРИ КАРДИОМИОПАТИЯХ У ДЕТЕЙ }\end{array}$ & 42 \\
\hline
\end{tabular}




\begin{tabular}{|c|c|c|}
\hline 1.5 .3 & $\begin{array}{l}\text { ИММУНОЛОГИЧЕСКИЕ АСПЕКТЫ В ПРОГРЕССИРОВАНИИ } \\
\text { СЕРДЕЧНОЙ НЕДОСТАТОЧНОСТИ ПРИ } \\
\text { КАРДИОМИОПАТИЯХ У ДЕТЕЙ }\end{array}$ & 46 \\
\hline 1.6 & $\begin{array}{l}\text { Мельников О.Ф. }{ }^{1} \text {, Самбур М.Б. }{ }^{1}, \text { Тимченко С.В. }{ }^{1}, \text { Тимченко М.Д. }{ }^{1}, \\
\text { Фараон І.В. } \\
\text { ВПЛИВ ПІДНЕБІННИХ МИГДАЛИКІВ НА СТАН } \\
\text { ГУМОРАЛЬНИХ ЧИННИКІВ ЛОКАЛЬНОГО ІМУНІТЕТУ В } \\
\text { ОБЛАСТІ РОТОГЛОТКИ У ХВОРИХ НА ХРОНІЧНІ ЗАПАЛЬНІ } \\
\text { ЗАХВОРЮВАННЯ ВЕРХНІХ ДИХАЛЬНИХ ШЛЯХІВ ПРИ } \\
\text { ІНФІКУВАННІ ВІРУСАМИ РЕСПІРАТОРНОЇ ГРУПИ } \\
\text { ' Лабораторія патофізіологї̈ та імунології, Державна установа «Інститут } \\
\text { отоларингології ім. проф. О.С. Коломійченка Національної Академії Медичних Наук } \\
\text { України», Київ, Україна } \\
{ }^{1} \text { State institution «О. S. Kolomiychenko Institute of otolaryngology } \\
\text { of National academу of medical sciences of Ukraine» }\end{array}$ & 57 \\
\hline \multicolumn{3}{|c|}{ MEDICAL PSYCHOLOGY } \\
\hline 2.1 & $\begin{array}{l}\text { Лахтадир Т. В. }{ }^{1}, \text { Дзевульська І.В. }{ }^{1}, \text { Камінський Р. Ф. }{ }^{1}, \text { Турбал Л.Л. } \\
\text { ПСИХОЛОГІЧНІ РЕКОМЕНДАЦІЇ } \\
\text { ВІЙСЬКОВОСЛУЖБОВЦЯМ, ЯКІ ОПИНИЛИСЯ В ГРУПІ } \\
\text { РИЗИКУ ВИНИКНЕННЯ ПОСТТРАВМАТИЧНОГО } \\
\text { СИНДРОМУ } \\
{ }^{1} \text { Кафедра описової та клінічної анатомії, Національний медичний університет імені } \\
\text { О.О. Богомольця, м. Київ }\end{array}$ & 68 \\
\hline 3. & PUBLIC HEALTH AND HEALTHCARE & \\
\hline 3.1 & $\begin{array}{l}\text { Muliarchuk O. }{ }^{1} \text {, Derpak Y. }{ }^{1}, \text { Vydyborets S. }{ }^{1}, \text { Suleimanova E. } \\
\text { Tymchenko A. } \\
\text { PATTERN OF ACTIVE BLOOD DONORS DONATING FOR } \\
\text { MORE THAN } 10 \text { YEARS BASED ON THE RESULTS OF } \\
\text { LABORATORY, MORPHOLOGIC, BIOCHEMICAL AND } \\
\text { BIOPHYSICAL BLOOD TEST OF PERIFERAL BLOOD } \\
{ }^{1} \text { Department of Hematology and Transfusiology } \\
\text { Shupyk National Healthcare University of Ukraine, Kyiv, Ukraine } \\
{ }^{2} \text { Ceneral university department physical education, sports and human health } \\
\text { Taurida National V.I. Vernadsky University, Kyiv, Ukraine }\end{array}$ & 74 \\
\hline
\end{tabular}




\begin{tabular}{|c|c|c|}
\hline 3.2 & $\begin{array}{l}\text { Vovk S. }{ }^{1} \text {, Vashcenko V. }{ }^{1}, \text { Vovk T. }{ }^{2} \\
\text { PROBLEMS OF FORMATION OF THE PUBLIC HEALTH } \\
\text { SYSTEM IN UKRAINE } \\
{ }^{1} \text { Department of higher education organization, health and hygiene management Donetsk } \\
\text { National Medical University } \\
{ }^{2} \text { departments of non-industrial management Donetsk State University of management }\end{array}$ & 102 \\
\hline \multicolumn{3}{|l|}{4.} \\
\hline 4.1 & $\begin{array}{l}\text { Коляда Н.․, Остапенко А. }{ }^{2}, \text { Скоробогатий В. }{ }^{1} \\
\text { НОВІ ПІДХОДИ ДО ДІАГНОСТИКИ ТА КОМПЛЕКСНОГО } \\
\text { ЛІКУВАННЯ АЛЕРГІЧНИХ РИНІТІВ, АДЕНОЇДИТУ В } \\
\text { ДИТЯЧОМУ ВІЦІ } \\
{ }^{1} \text { Кафедра оториноларингологї̈, Запоріжжя, Державний заклад "Запорізька медична } \\
\text { Аакадемія післядипломної освіти МОЗ України" } \\
\text { ² Кафедра клінічної лабораторної діагностики та лабораторної імунології, } \\
\text { Запоріжжя, Державний заклад «Запорізька медична академія післядипломної освіти } \\
\text { МОЗ Україн» }\end{array}$ & 110 \\
\hline \multicolumn{3}{|c|}{ 5. THEORETICAL MEDICINE } \\
\hline 5.1 & $\begin{array}{l}\text { Hladkykh F. }{ }^{1}{ }^{2}, \text { Chyzh M. } \\
\text { CORRECTION OF ULCEROGENIC ACTION OF } \\
\text { NONSTEROIDAL ANTI-INFLAMMATORY DRUGS BY USING } \\
\text { OF CRYOPRESERVED PLACENTA EXTRACT } \\
{ }^{1} \text { Department of Experimental Cryomedicine, Institute for Problems of Cryobiology and } \\
\text { Cryomedicine of the National Academy of Sciences of Ukraine, Kharkiv, Ukraine } \\
{ }^{2} \text { Radiology Department, State Organization «Grigoriev Institute for medical Radiology } \\
\text { and Oncology National Academy of Medical Sciences of Ukraine», Kharkiv, Ukraine }\end{array}$ & 117 \\
\hline & REFERENCES & 122 \\
\hline
\end{tabular}




\section{SECTION 1. CLINICAL MEDICINE}

DOI 10.46299/ISG.2021.MONO.MED.III.1.1

\subsection{Tactics of managing a young patient with reduced left ventricular ejection fraction. ranolazine as a component of therapy}

Dilated cardiomyopathy (DCM) - myocardial disease, characterized by an increase in the volume of the cavities of the heart, systolic dysfunction, but without an increase in wall thickness, in the absence of the established etiological factor as well as significant damage to the coronary arteries [1]. The basis for the development of cardiac dysfunction in DCM are genetic factors, direct damaging effect of infection, toxic agents, endocrine disorders, metabolic and immune-mediated processes, peripartum cardiomyopathy [2]. DCM is characterized by the appearance of progressive heart failure (HF), rhythm and conduction disturbances, thromboembolism and sudden of death. DCM is also the third most common cause of HF, this pathology occurs at any age, but most often men aged 30-45 are ill years old [1].

Ranolazine is a new antianginal and anti-ischemic drug that does not has a significant effect on blood pressure (BP) and heart rate (HR), as well as peripheral vascular resistance [3]. Ranolazine inhibits the late flow of $\mathrm{Na}$, reduces the concentration of intracellular $\mathrm{Ca}$ than improves diastolic relaxation. A decrease in diastolic tension contributes to a quality and easier filling of coronary vessels, improves myocardial blood supply and indirectly prevents the development of arrhythmias and progression of heart failure, improves myocardial contractility, increases ejection fraction (EF) [3].

\section{Own clinical experience.}

A 32-year-old patient turned to a medical institution with complaints of severe choking, heart interruptions, headaches and constricting pain in chest. Objectively: general condition of moderate severity. The pulse rate is 98 beats per minute, arrhythmic - (atrial fibrillation- (AF)); BP- 105/75 mmHg. Heart border are displaced to the left by $1.5 \mathrm{~cm}$. Heart sounds are weakened. Liver is enlarged by $2 \mathrm{~cm}$. He is swelling in the lower legs and feet. 
Diagnosis: Dilated cardiomyopathy. Persistent atrial fibrillation, tachysystolic form. Heart Failure II-A stage with left ventricular systolic dysfunction, III FC.

Echocardiography (EchoCG): EF - 35\%, pulmonary arterial pressure (PAP) $=35$ $\mathrm{mmHg}$, aortic valve insufficiency, minor aortic stenosis, enlargement of the left atrium $(4.8 \mathrm{~cm})$, significantly enlarged left ventricle, severe hypokinesia of all walls of the left ventricle, left ventricular myocardial contractility significantly reduced, left ventricular diastolic dysfunction, atrial tachyarrhythmia.

Blood test: erythrocytes $5.15^{*} 10^{12}\left(\mathrm{~N}=4.0-5.0 * 10^{12}\right)$, hemoglobin $165 \mathrm{~g} / \mathrm{L}(\mathrm{N}=130$ $160 \mathrm{~g} / \mathrm{L})$.

Biochemical blood analysis: uric acid $-423.7 \mathrm{mcmol} / \mathrm{l}(\mathrm{N}=202.3-415.5 \mathrm{mcmol} / \mathrm{l})$, low density lipoproteins $2.85 \mathrm{mmol} / \mathrm{L}(\mathrm{N}=$ up to $2.59 \mathrm{mmol} / \mathrm{L})$.

\section{Treatment scheme 1:}

Potassium orotate $500 \mathrm{mg}$ - 1 tab 3 times a day (8.00-15.00-21.00) use for 3-5 weeks. Eplerenone $50 \mathrm{mg}-1$ tab 2 times a day (8.00-18.00)

Carvedilol $6.25 \mathrm{mg}$ - 1 tab 2 times a day (10.00-21.00)

Dabigatran $150 \mathrm{mg}$ - 1 tab 1 times a day

Trimetazidine dihydrochloride $35 \mathrm{mg}$ - 1 tab 2 times a day (9.00-21.00)

Echocardiography (Fig. 1): EF - 42\%, EchoCG signs of DCM, aortic valve insufficiency, minor aortic stenosis, pulmonary hypertension (PAP $=39 \mathrm{mmHg}$ ). The left heart is significantly enlarged, slight left ventricular hypertrophy, left ventricular hypokinesia.

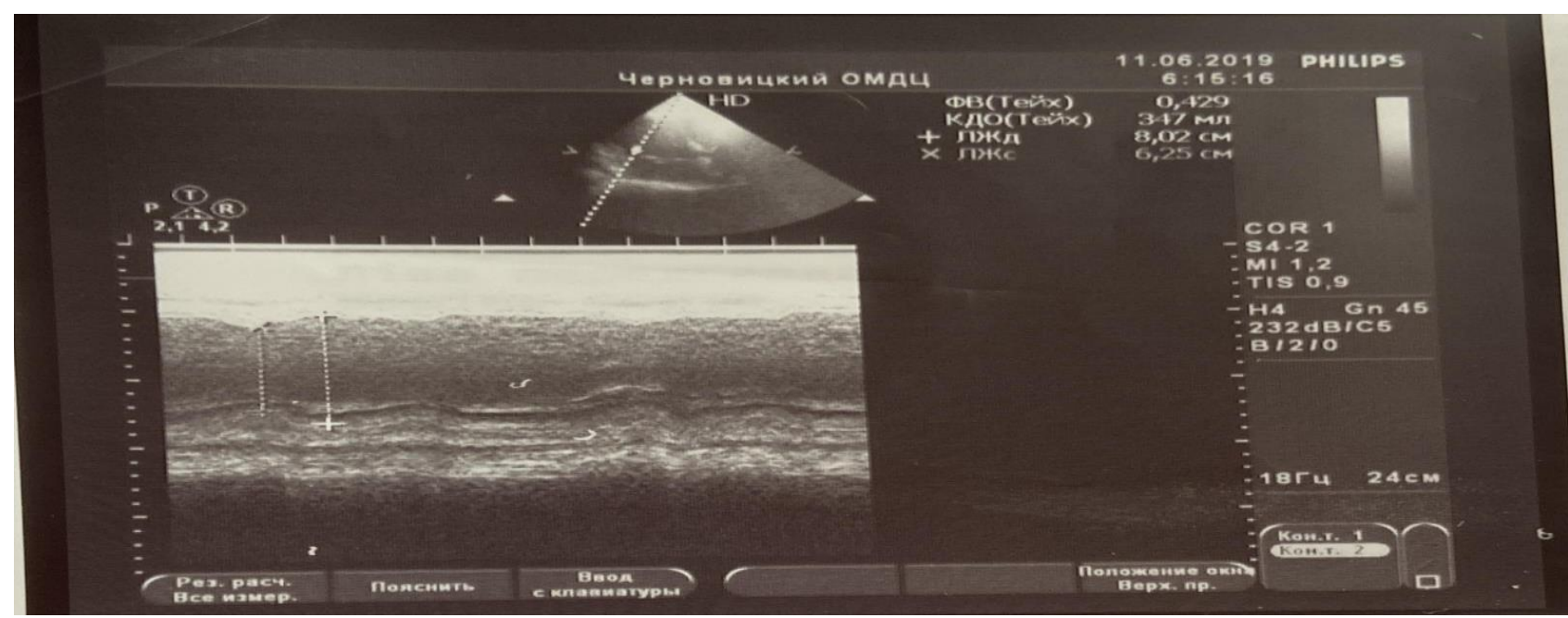

Fig.1. Echocardiography 


\section{Treatment scheme 2:}

Ramipril 5 mg - 1/4 tab 2 times a day $(9.00+21.00)$

Potassium orotate $500 \mathrm{mg}-1$ tab 3 times a day $(8.00+15.00+21.00)$

Eplerenone $50 \mathrm{mg}-1 / 2$ tab 2 times a day $(8.00+18.00)$

Carvedilol $6.25 \mathrm{mg}-1$ tab 2 times a day $(10.00+22.00)$

Rivaroxaban $20 \mathrm{mg}-1$ tab 1 times a day (14.00)

Torasemide $5 \mathrm{mg}-1 / 2$ tab 1 times a day (12.00)

Sildenafil $50 \mathrm{mg}-1 / 2$ tab 2 times a day $(9.00+21.00)$

Ranolazine 1000 mg - 1 tab 1 times a day (22.00) - was used for a period of 3 months

Echocardiography: EF - 43\%, EchoCG signs of DCM, aortic valve insufficiency, minor aortic stenosis, pulmonary hypertension $(\mathrm{PAP}=39 \mathrm{mmHg})$, enlarged left atrium, hypokinesia in the left ventricular of posterior wall, arrhythmia.

Blood test: erythrocytes $4.58 * 10^{12}$, hemoglobin $147 \mathrm{~g} / \mathrm{L}$.

Biochemical blood analysis: uric acid $-437.3 \mathrm{mcmol} / 1$, low density lipoproteins = $3.18 \mathrm{mmol} / \mathrm{L}$.

\section{Treatment scheme 3:}

Valsartan $25.7 \mathrm{mg}+$ Sacubitril $24.3 \mathrm{mg}-50 \mathrm{mg} 1 / 2 \mathrm{tab} 2$ times a day $(9.00+21.00)$

Bisoprolol $2.5 \mathrm{mg}-1 \mathrm{tab} .2$ times a day $(9.00+21.00)$

Eplerenone $50 \mathrm{mg}-1 / 2$ tab 2 times a day $(8.00+18.00)$

Acetylsalicylic acid $75 \mathrm{mg}-1 \mathrm{tab} 1$ times a day (19.00)

Rivaroxaban $20 \mathrm{mg}-1$ tab 1 times a day (14.00)

Torasemide $5 \mathrm{mg}-1 / 2$ tab 1 times a day (12.00)

Febuxostat $80 \mathrm{mg}$ - 1 tab 1 times a day (9.00)

Ranolazine $1000 \mathrm{mg}$ - 1 tab $1 \mathrm{~g} /$ day - continued intake (was used for a period of 3 months).

Holter ECG monitoring: throughout the study, constant AF, mainly from ventricular normosystole. 3 singles was recording, polytopic ventricular extrasystoles and one case of paired ventricular extrasystoles. Ventricular premature beats are (B Lown and Wolf IVA Classes) (Fig. 1). The frequency of occurrence of extrasystoles is 0-2 per hour (rare), all during the active period. The average heart rate for the entire period is 78 / 
min, 82 / min during the active period and 67 / min during the passive period. Circadian index 1.21 (reduced). There aren't reliable signs of ischemia fixed. The "T" wave ranges from $1 / 2$ of the height $\mathrm{R}$. When analyzing the heart rate variability, there is an increase in all time and frequency indicators. The sympathetic-parasympathetic balance is reduced. Elongation the QT interval is observed $47 \%$ of the time.

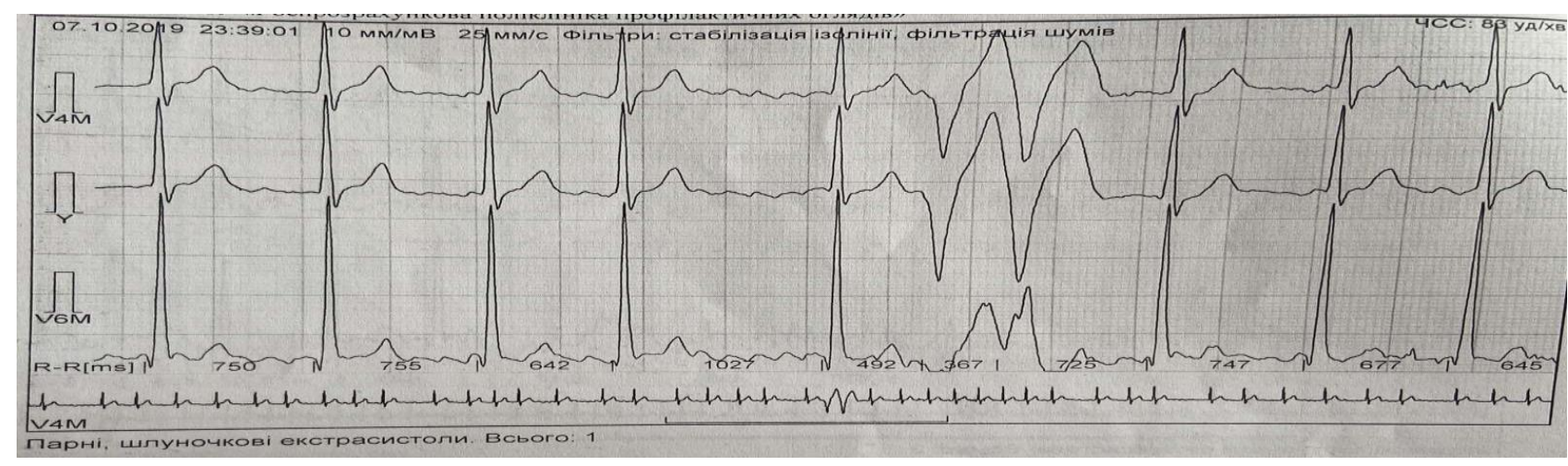

Fig.2. Paired ventricular extrasystoles

\section{Treatment scheme 4:}

Valsartan $25.7 \mathrm{mg}+$ Sacubitril $24.3 \mathrm{mg}-50 \mathrm{mg} 1 / 2 \mathrm{tab} 2$ times a day $(9.00+21.00)$

Sotalol $80 \mathrm{mg}-1 / 4-1 / 2$ tab 2 times a day $(7.00+22.00)$

Eplerenone $50 \mathrm{mg}-1 / 2$ tab 2 times a day $(8.00+18.00)$

Dabigatran 110 mg - 1 tab 1 times a day (14.00)

L-arginine - 1 effervescent tablet 1 times a day (10.00)

Only once a week: Torasemide $10 \mathrm{mg}+$ Combined drug (magnesium asparagine + potassium asparagine) 3 tab (At 8.00 magnesium asparagine + potassium asparagine; at 12.00 magnesium asparagine + potassium asparagine + torasemide; at 18.00 magnesium asparagine + potassium asparagine).

Dabigatran 100 mg - 1 tab1 times a day (14.00).

Echocardiography: EF - 45\%, left atrial enlargement, moderate left ventricular dysfunction and left ventricular enlargement, aortic valve insufficiency type II, moderate diffuse hypokinesia left ventricular.

Blood test: erythrocytes $4.99 * 10^{12}$, hemoglobin $161 \mathrm{~g} / \mathrm{L}$. 
Biochemical blood analysis: uric acid $-364 \mathrm{mcmol} / \mathrm{l}$, low density lipoproteins = $3.21 \mathrm{mmol} / \mathrm{L}$.

Phonocardiography (Fig. 3) are irregular heart rhythms 93-120 / min, atrial tachyarrhythmia, the amplitude of I and II tones is different in different cardiac cycles $\mathrm{I}: \mathrm{II}=1: 2$. Maximum II tone above the aorta II: $\mathrm{I}=1: 2$. At all points systolic noise is registered. Systolic noise is medium-amplitude, medium and high frequency, erratic shape, volatile in duration. Diastolic noise at Botkin's point, on the basis of a xiphoid process, on an aorta, on the pulmonary artery, unstable in duration, medium and high frequency, unstable forms. Conclusion: phonocardiography signal processing you can think about aortic valve insufficiency and aortic valve stenosis.

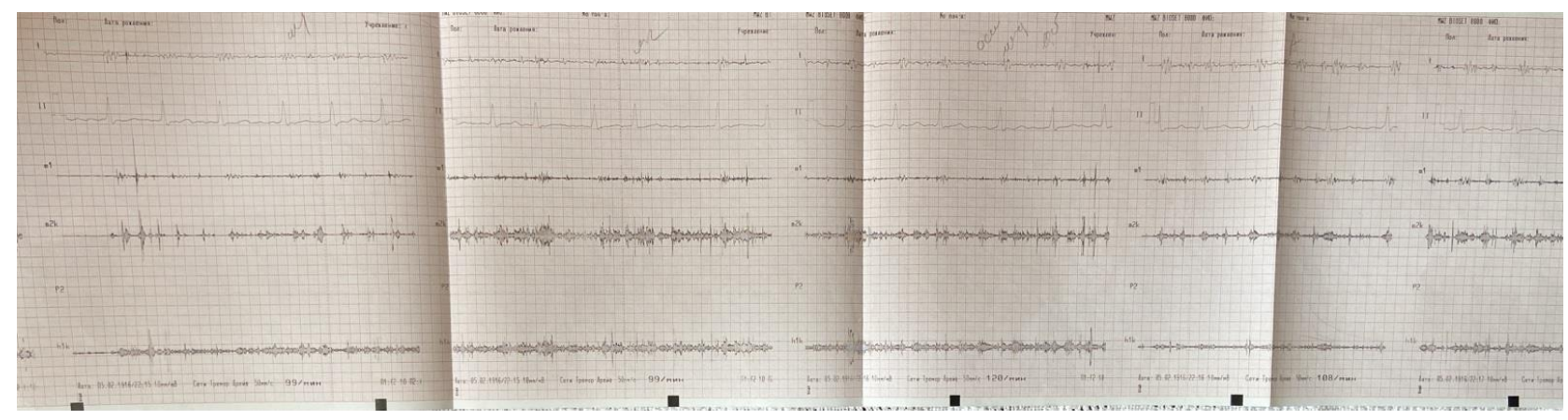

Fig. 3. Phonocardiography

\section{Treatment scheme 5:}

Valsartan $25.7 \mathrm{mg}+$ Sacubitril $24.3 \mathrm{mg}-50 \mathrm{mg} 1 / 2$ tab 4 times a day $(9.00$ $+13.00+18.00+21.00)$

Bisoprolol $2.5 \mathrm{mg}-1 \mathrm{tab} .2$ times a day $(7.00+22.00)$

Eplerenone $50 \mathrm{mg}-1 / 2$ tab 2 times a day $(8.00+18.00)$

Dabigatran $110 \mathrm{mg}$ - 1 tab 1 times a day (14.00)

Torasemide $5 \mathrm{mg}-1 / 2$ tab 1 times a day (12.00)

Etatsizin $50 \mathrm{mg}-1 \mathrm{tab}$ times a day $(7.00+22.00)$

Echocardiography: EF - 47\%, EchoCG are signs of DCM, aortic valve insufficiency, minor aortic stenosis, pulmonary hypertension (PAP $=39 \mathrm{mmHg}$ ). The left heart is significantly enlarged the contractile capacity of the left ventricular myocardium is reduced, arrhythmia. 


\section{Treatment scheme 6:}

Valsartan $25.7 \mathrm{mg}+$ Sacubitril $24.3 \mathrm{mg}-50 \mathrm{mg} 1 / 2 \mathrm{tab} 2$ times a day $(9.00+21.00)$

Nebivolol $5 \mathrm{mg}-1 / 4-1 / 22$ times a day $(7.00+22.00)$

Amiodarone $200 \mathrm{mg}-1 / 2$ tab - 1 tab 2 times a day $(12.00+18.00)$

Dabigatran $110 \mathrm{mg}$ - 1 tab 1 times a day (14.00)

Torasemide $5 \mathrm{mg}-1 / 2$ tab 1 times a day (12.00)

L-arginine - 1 effervescent tablet 1 times a day (10.00)

Only once a week: Torasemide $10 \mathrm{mg}+$ Combined drug (magnesium asparagine + potassium asparagine) 3 tab (At 8.00 magnesium asparagine + potassium asparagine; at 12.00 magnesium asparagine + potassium asparagine + torasemide; at 18.00 magnesium asparagine + potassium asparagine).

Dabigatran 100 mg - 1 tab1 times a day (14.00).

Blood test: erythrocytes $4.89 * 10^{12}$, hemoglobin $155 \mathrm{~g} / \mathrm{L}$.

Biochemical blood analysis: uric acid $-349.8 \mathrm{mcmol} / \mathrm{l}$, low density lipoproteins = $2.92 \mathrm{mmol} / \mathrm{L}$.

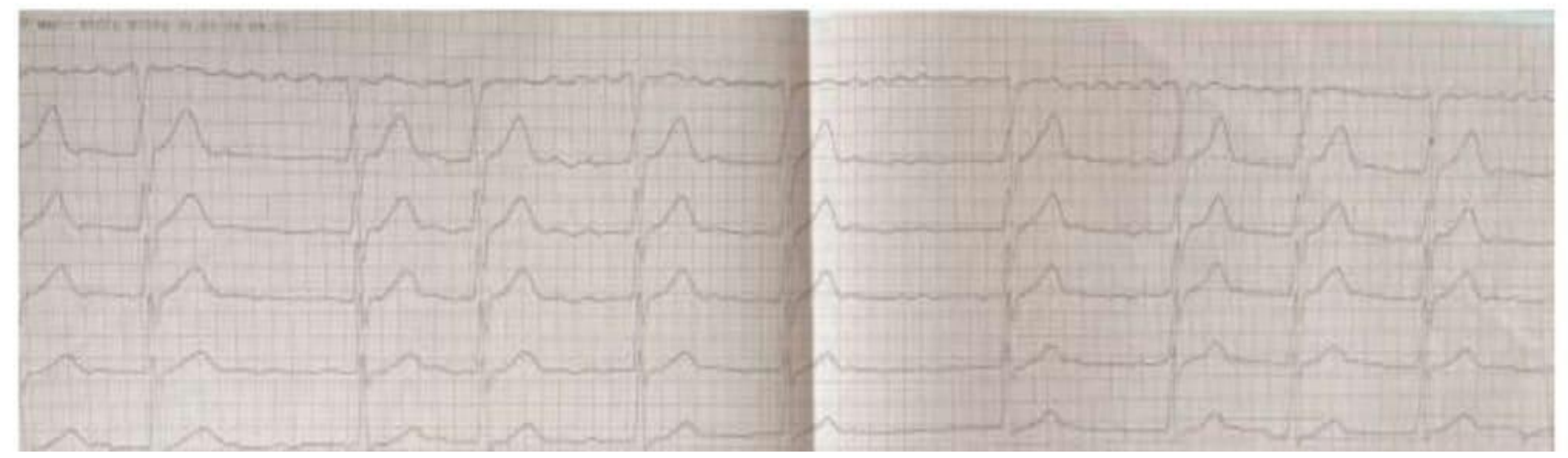

Fig. 4. Episodes of atrial fibrillation

\section{Treatment scheme 7:}

Valsartan $25.7 \mathrm{mg}+$ Sacubitril $24.3 \mathrm{mg}-50 \mathrm{mg} 1 / 2 \mathrm{tab} 2$ times a day $(9.00+21.00)$

Nebivolol $5 \mathrm{mg}-1 / 4-1 / 2$ tab. 2 times a day $(7.00+22.00)$

Amiodarone $200 \mathrm{mg}-1$ tab 2 times a day $(12.00+18.00)$

Dabigatran $110 \mathrm{mg}$ - 1 tab 1 times a day (14.00) 
Torasemide $5 \mathrm{mg}$ - 1tab 1 times a day (12.00)

L-arginine + L-carnitine + inosine -1 tab 2 times a day $(9.00+21.00)$

Only once a week: Torasemide $10 \mathrm{mg}+$ Combined drug (magnesium asparagine + potassium asparagine) 3 tab (At 8.00 magnesium asparagine + potassium asparagine; at 12.00 magnesium asparagine + potassium asparagine + torasemide; at 18.00 magnesium asparagine + potassium asparagine).

Dabigatran $100 \mathrm{mg}$ - 1 tab1 times a day (14.00).

Echocardiography: EF - 49\%, pulmonary hypertension (PAP = $39 \mathrm{mmHg})$.

Treatment scheme 8:

Valsartan $25.7 \mathrm{mg}+$ Sacubitril $24.3 \mathrm{mg}-50 \mathrm{mg} 1 \mathrm{tab} 2$ times a day $(8.00+21.00)$

Nebivolol $5 \mathrm{mg}-1 / 2$ tab. 2 times a day $(9.00+22.00)$

Eplepres $25 \mathrm{mg}-1$ tab 1 times a day (9.00)

Torasemide $5 \mathrm{mg}$ - 1 tab 1 times a day (12.00)

Rivaroxaban $20 \mathrm{mg}$ - 1 tab 1 times a day (14.00)

Trimetazidine dihydrochloride $35 \mathrm{mg}-1$ tab 2 times a day $(9.00+21.00)$

Only once a week: Torasemide $10 \mathrm{mg}+$ Combined drug (magnesium asparagine + potassium asparagine) 3 tab (At 8.00 magnesium asparagine + potassium asparagine; at 12.00 magnesium asparagine + potassium asparagine + torasemide; at 18.00 magnesium asparagine + potassium asparagine).

Echocardiography: EF - 50\%, pulmonary hypertension (PAP = $39 \mathrm{mmHg})$.

\section{Treatment scheme 9:}

Valsartan $25.7 \mathrm{mg}+$ Sacubitril $24.3 \mathrm{mg}-50 \mathrm{mg} 1 \mathrm{tab} .2$ times a day $(8.00+21.00)$

Nebivolol $5 \mathrm{mg}-1 / 2 \mathrm{tab} .2$ times a day $(9.00+22.00)$

Eplerenone $25 \mathrm{mg}$ - 1 tab 1 times a day (9.00)

Ivabradine $7.5 \mathrm{mg}-1 / 2$ tab 1 times a day (15.00)

Torasemide $10 \mathrm{mg}$ - 1 tab 1 times a day (12.00)

Rivaroxaban $20 \mathrm{mg}-1$ tab 1 times a day (14.00)

Potassium chloride $600 \mathrm{mg}-1$ tab 2 times a day $(8.00+22.00)$

Ethyl ester of omega-3-unsaturated fatty acids $1000 \mathrm{mg} 1$ times a day before meals $(7.45)$ 
Only once a week: Torasemide $10 \mathrm{mg}+$ Combined drug (magnesium asparagine + potassium asparagine) 3 tab (At 8.00 magnesium asparagine + potassium asparagine; at 12.00 magnesium asparagine + potassium asparagine + torasemide; at 18.00 magnesium asparagine + potassium asparagine).

The presented clinical case demonstrates the difficulty of managing a patient with DCM and reduced left ventricular ejection fraction. The patient's improved general condition, EF increased from $35 \%$ to $50 \%$, the number of arrhythmic episodes decreased. Ranolazine is recommended for inclusion in algorithms therapy while taking other antiarrhythmic drugs (amiodarone, beta blockers), therefore, in our clinical practice, a case is presented effective treatment of a patient with a combination of ranolazine with beta-blockers, which today it is considered as a highly effective antiarrhythmic tandem $[4,5]$. Thus, a comprehensive long-term approach to treatment patients with DCM allows you to expand the range of treatment options difficult patient and improve his quality of life. 


\subsection{Diabetic cardiac autonomic neuropathy: benfotiamine, insulin resistance and some pro- and anti-inflammatory parameters}

Diabetic autonomic neuropathy (DAN) is often underestimated and indeed a serious complication of diabetes mellitus (DM), as can potentially affect any circuit/tract of autonomic nervous system (ANS). The most studied and common form of DAN is cardiac autonomic neuropathy (CAN), owing to its relations with other microangiopathic comorbidities and life-threatening complications. Development of CAN is characterized by lesion of nerve fibers in the parasympathetic and sympathetic divisions of the ANS [6, 7].

The broad term that describes any malfunction or disease of the ANS is dysautonomia. It has been proved that functional changes in the ANS are associated with various forms of mild to moderate vitamin deficiencies. Mild to moderate thiamine deficiency (TD) and/or hypoxia both give rise to exaggeration of centrally controlled mechanisms involved in all survival reflexes, mediated normally through a balanced reaction of the endocrine system and ANS [8]. Due to increased requirements deriving from amplified and accelerated glucose metabolism in non-insulin dependent tissues, DM might be considered as TD state $[8,9]$. The TD in clinical diabetes may increase the fragility of vascular cells to the adverse effects of hyperglycemia and there by the increase of the risk of microvascular complications $[7,8]$. Chronic exposure to moderate and severe hypoxia increases the activity of the sympathetic nervous system and adrenal medulla, and TD induces an early central muscarinic cholinergic lesions [8]. It was showed that prescription of benfotiamine, is associated with reduction of oxidative stress (OS) and diabetic micro-macrovascular complications. OS was considered as the main pathophysiological pathway of CAN development. Elevated intracellular levels of glucose lead to activation of polyol pathway, formation of advanced glycation end-products (AGEs), resulting in subsequent formation of reactive oxygen species (ROS) [9].

The correction of TD must be performed using exogenous vitamin $\mathrm{B}_{1}$, or benfotiamine (high-bioavailable liposoluble vitamin $\mathrm{B}_{1}$ derivatives). Results of experimental and clinical studies suggest a positive effect of BET prescription on 
prevention of diabetic vascular disease progression. Benfotiamine broad therapeutic potential has a good efficiency on medications containing soluble thiamine derivatives for the purpose of regulating the activity of free radical processes; correction of endothelial dysfunction in case of cardiovascular diseases (CVD), stabilization of clinical and antioxidants effects [10].

The aim of this study is to analyze the effect of benfotiamine on the insulin resistance, the content of some pro- and anti-inflammatory factors in patients with type 2 DM (T2DM) and advanced stage of CAN. Forty patients with T2DM and definite CAN, aged between 50-59 years with disease duration 1-6 years, median BMI $27,2 \pm 0,34 \mathrm{~kg} / \mathrm{m}^{2}$ and median glycated hemoglobin A1c (HbA1c) $7.16 \pm 0.19 \%$ were examined. The standard hypoglycemic treatment of DM included dietary regime, appropriate physical activity, and oral antihyperglycemic drugs. Patients with T2DM and CAN were divided into 2 groups. Patients in groups did not differ significantly in age, sex distribution, BMI, duration of the disease which made them as homogeneous as possible. First group received traditional antihyperglycemic therapy $(n=19$, control) for three months; patients in group 2 ( $n=21$, treatment group), received in addition 300 $\mathrm{mg} / \mathrm{q}$.d. benfotiamine for three months. To determine the effects of benfotiamine on the investigated parameters all measurements were performed initially and after the end of treatment period. Each patient examined before the beginning of the study did not take benfotiamine and was on stable regime of hypoglycemic and antihypertensive treatment for 6 months. Inclusion criteria: age: 50-60 years old; T2DM with optimal/suboptimal glycemic control; T2DM patients with advanced stage of CAN; clinical stages of diabetic polyneuropathy; BMI within $20-30 \mathrm{~kg} / \mathrm{m}^{2}$; consent to maintain appropriate physical activity.

T2DM was diagnosed according to [11], and CAN - [6]. All patients underwent screening for CAN that included five cardiovascular autonomic reflex tests (CARTs). Resting 12-lead surface ECG and Holter-ECG [(ECG "EC-3H” ("Labtech,” Hungary)] analysis included measurement of 24 hours ECG, circadian indexes and heart rate variability parameters. The severity of CAN was determined on the condition that all five CARTs were performed. The results were considered according to scores obtained 
in individual tests. Physiological values were evaluated as " 0 " scores, borderline values - as "0.5" scores, pathological values - as " 1 " score [6]. The scores were summed up and the median score for studied patients was $2.8 \pm 0.29$.

The concentration of glucose in the blood was determined by the glucose oxidase method while HbA1c was assessed using a highly sensitive method of ion-exchange liquid chromatography with D-10 analyzer and BIO-RAD reagents (USA). Determination of immunoreactive insulin (IRI) was performed using commercial kits from immunogen insulin immunoradiometric assay reagents (Czech Republic); leptin level-from Immunotech Leptin (Czech Republic) test kits; tumor necrosis factor-alpha (TNF-alpha), interleukin (IL)-6, IL-8 and IL-10-from Vector-Best (Russia); highsensitivity C-reactive protein (hs-CRP) - from diagnosis-related group (USA). TNFalpha/IL-10 ratio and homeostasis model assessment (HOMA) insulin resistance (IR) index (HOMA-IR) were calculated. The work was done according to the principles of the Declaration of Helsinki (2004). All patients signed an informed consent prior their inclusion in the study.

The normality of presented data were checked by using Shapiro-Wilk test, all the studied variables had a normal distribution. Absolute values were compared with calculation of mean values, errors of means, using Student's t-test. Data are presented as mean \pm standard error of the mean ( $\Delta \%, \mathrm{Mean} \pm \mathrm{SEM})$. Statistical significance was set at $\mathrm{p}<0.05$. All tests were performed using the ANOVA (MicroCal Origin v. 8.0) software.

\section{Results}

The level of HbA1c in patients with T2DM and definite CAN did not change significantly after treatment $(p>0.05)$. Changes of glucose, IRI concentrations and HOMA-IR parameters in patients with T2DM and definite CAN after 3-months of benfotiamine therapy are given in table 1 . 
Table 1

The glucose, IRI concentrations and HOMA-IR parameters after 3-months of benfotiamine therapy $(\Delta \%$, Mean \pm SEM)

\begin{tabular}{|c|c|c|c|c|c|}
\hline \multirow[t]{2}{*}{ Parameter } & \multicolumn{5}{|c|}{ Patients with T2DM and definite CAN $(n=40)$} \\
\hline & Groups & $\begin{array}{l}\text { Before } \\
\text { treatment }\end{array}$ & $\begin{array}{l}\text { After } \\
\text { treatment }\end{array}$ & $\%$ change & $\mathrm{p}$ \\
\hline $\begin{array}{l}\text { Fasting } \\
\text { blood }\end{array}$ & $\begin{array}{l}\text { Control } \\
(n=19)\end{array}$ & $7.03 \pm 0.26$ & $7.05 \pm 0.30$ & $+0.89 \% \pm 3.1 \%$ & $>0.05$ \\
\hline $\begin{array}{l}\text { glucose } \\
(\mathrm{mmol} / \mathrm{L})\end{array}$ & $\begin{array}{l}\text { Treatment } \\
(\mathrm{n}=21)\end{array}$ & $6.64 \pm 0.42$ & $6.69 \pm 0.38$ & $+2.19 \% \pm 2.96 \%$ & $>0.05$ \\
\hline \multirow[t]{2}{*}{$\begin{array}{l}\text { Fasting IRI } \\
(\mu \mathrm{IU} / \mathrm{mL})\end{array}$} & $\begin{array}{l}\text { Control } \\
(\mathrm{n}=19)\end{array}$ & $27.76 \pm 2.11$ & $26.01 \pm 2.19$ & $-6.7 \% \pm 2.0 \%$ & $>0.05$ \\
\hline & $\begin{array}{l}\text { Treatment } \\
(\mathrm{n}=21)\end{array}$ & $26.84 \pm 1.39$ & $23.21 \pm 0.86$ & $\begin{array}{c}- \\
12.74 \% \pm 1.42 \%\end{array}$ & $<0.05$ \\
\hline \multirow[t]{2}{*}{ HOMA-IR } & $\begin{array}{l}\text { Control } \\
(n=19)\end{array}$ & $9.03 \pm 0.98$ & $8.39 \pm 0.91$ & $-7.15 \% \pm 1.8 \%$ & $>0.05$ \\
\hline & $\begin{array}{l}\text { Treatment } \\
(\mathrm{n}=21)\end{array}$ & $8.06 \pm 0.89$ & $6.99 \pm 0.6$ & $\begin{array}{c}- \\
11.91 \% \pm 2.68 \%\end{array}$ & $>0.05$ \\
\hline
\end{tabular}

The results are presented as absolute values and as $\%$ change from baseline. $\Delta \%$, Mean \pm SEM; $p<0.05$, compared to baseline.

As can be seen from table 1 prescription of benfotiamine to patients with T2DM and definite CAN contributes to a statistically significant reduction in IRI levels [ $\Delta=-$ $12.74 \% \pm 1.42 \%(\mathrm{p}<0.05)]$. At the same time, prescription of benfotiamine does not affect the concentration of fasting glucose and HOMA-IR parameters ( $>0.05)$. Investigated parameters did not change significantly in the control group $(\mathrm{p}>0.05)$.

Changes of hs-CRP, leptin and TNF-alpha concentrations in blood of patients with T2DM and CAN after 3-months of benfotiamine therapy are given in table 2. 
Table 2

Changes of the hs-CRP, leptin and TNF-alpha concentrations after 3-months of benfotiamine therapy $(\Delta \%$, Mean \pm SEM)

\begin{tabular}{llllll}
\hline Parameter & \multicolumn{5}{l}{ Patients with T2DM and definite CAN (n=40) } \\
\cline { 2 - 6 } & Groups & $\begin{array}{l}\text { Before } \\
\text { treatment }\end{array}$ & $\begin{array}{l}\text { After } \\
\text { treatment }\end{array}$ & \% change & $\mathrm{p}$ \\
\hline hs-CRP & Control & $2.88 \pm 0.48$ & $2.69 \pm 0.48$ & $-7.2 \% \pm 1.64 \%$ & $>0.05$ \\
$(\mathrm{mg} / \mathrm{L})$ & $(\mathrm{n}=19)$ & & & & \\
& Treatment & $2.91 \pm 0.19$ & $2.48 \pm 0.1$ & - & $<0.05$ \\
& $(\mathrm{n}=21)$ & & & $13.62 \% \pm 1.96 \%$ & \\
Leptin & Control & $21.06 \pm 1.69$ & $19.52 \pm 1.58$ & $-7.1 \% \pm 1.81 \%$ & $>0.05$ \\
$(\mu \mathrm{g} / \mathrm{L})$ & $(\mathrm{n}=19)$ & & & & \\
& Treatment & $20.87 \pm 1.85$ & $19.61 \pm 1.84$ & $-6.41 \% \pm 1.33 \%$ & $>0.05$ \\
& $(\mathrm{n}=21)$ & & & & $>0.05$ \\
TNF-alpha & Control & $5.82 \pm 0.44$ & $5.49 \pm 0.42$ & $-6.1 \% \pm 1.02 \%$ & \\
$(\mathrm{pg} / \mathrm{mL})$ & $(\mathrm{n}=19)$ & & & & $<0.05$ \\
& Treatment & $5.38 \pm 0.2$ & $4.75 \pm 0.13$ & - & \\
& $(\mathrm{n}=21)$ & & & $10.24 \% \pm 1.54 \%$ & \\
\hline
\end{tabular}

The results are presented as absolute values and as $\%$ change from baseline. $\Delta \%$, Mean \pm SEM; $p<0.05$, compared to baseline.

It is shown in table 2 that the outcome of treatment group was better than of control group. In particular, benfotiamine prescription to patients with T2DM and definite CAN contributes to a statistically significant reduction in hs-CRP [ $\Delta=-$ $13.62 \% \pm 1.96 \% \quad(\mathrm{p}<0.05)]$ and TNF-alpha $[\Delta=-10.24 \% \pm 1.54 \% \quad(\mathrm{p}<0.05)]$ levels compared to the control group. Prescription of benfotiamine does not affect on the concentration of leptin ( $\mathrm{p}>0.05)$.

Changes of some IL's concentrations and TNF-alpha/IL-10 ratio of patients with T2DM and definite CAN after 3-months of benfotiamine therapy are given in table 3 . 
Table 3

IL-6, IL-8, IL-10 concentrations and TNF-alpha/IL-10 ratio after 3-months of benfotiamine therapy $(\Delta \%$, Mean \pm SEM)

\begin{tabular}{|c|c|c|c|c|c|}
\hline \multirow[t]{2}{*}{ Parameter } & \multicolumn{5}{|c|}{ Patients with T2DM and definite CAN $(n=40)$} \\
\hline & Groups & $\begin{array}{l}\text { Before } \\
\text { treatment }\end{array}$ & $\begin{array}{l}\text { After } \\
\text { treatment }\end{array}$ & $\%$ change & $\mathrm{p}$ \\
\hline \multirow[t]{2}{*}{$\begin{array}{l}\text { IL-6 } \\
\text { (pg/mL) }\end{array}$} & $\begin{array}{l}\text { Control } \\
(\mathrm{n}=19)\end{array}$ & $5.54 \pm 0.52$ & $5.14 \pm 0.44$ & $-5.81 \% \pm 1.79 \%$ & $>0.05$ \\
\hline & $\begin{array}{l}\text { Treatment } \\
(\mathrm{n}=21)\end{array}$ & $5.74 \pm 0.31$ & $4.79 \pm 0.22$ & $\begin{array}{c}- \\
15.41 \% \pm 2.03 \%\end{array}$ & $<0.05$ \\
\hline \multirow[t]{2}{*}{$\begin{array}{l}\text { IL-8 } \\
(\mathrm{pg} / \mathrm{mL})\end{array}$} & $\begin{array}{l}\text { Control } \\
(n=19)\end{array}$ & $7.26 \pm 0.49$ & $6.94 \pm 0.48$ & $-3.9 \% \pm 1.59 \%$ & $>0.05$ \\
\hline & $\begin{array}{l}\text { Treatment } \\
(n=21)\end{array}$ & $7.12 \pm 0.48$ & $6.64 \pm 0.43$ & $-6.32 \% \pm 2.03 \%$ & $>0.05$ \\
\hline \multirow[t]{2}{*}{$\begin{array}{l}\text { IL-10 } \\
(\mathrm{pg} / \mathrm{mL})\end{array}$} & $\begin{array}{l}\text { Control } \\
(n=19)\end{array}$ & $16.73 \pm 2.53$ & $15.66 \pm 2.28$ & $-3.7 \% \pm 2.33 \%$ & $>0.05$ \\
\hline & $\begin{array}{l}\text { Treatment } \\
(\mathrm{n}=21)\end{array}$ & $16.17 \pm 1.86$ & $14.78 \pm 1.49$ & $-6.19 \% \pm 2.73 \%$ & $>0.05$ \\
\hline $\begin{array}{l}\text { TNF- } \\
\text { alpha/IL- }\end{array}$ & $\begin{array}{l}\text { Control } \\
(n=19)\end{array}$ & $42.51 \pm 5.49$ & $41.5 \pm 4.79$ & $-0.51 \% \pm 2.32 \%$ & $>0.05$ \\
\hline $10(\%)$ & $\begin{array}{l}\text { Treatment } \\
(n=21)\end{array}$ & $38.61 \pm 4.27$ & $35.91 \pm 3.33$ & $-4.34 \% \pm 2.77 \%$ & $>0.05$ \\
\hline
\end{tabular}

The results are presented as absolute values and as $\%$ change from baseline. $\Delta \%$. Mean \pm SEM; $p<0.05$. compared to baseline.

As can be seen from table 3 prescription of benfotiamine to patients with T2DM and definite $\mathrm{CAN}$ is accompanied by the statistically significant decrease in the content of IL-6 $[\Delta=-15,41 \% \pm 2,03 \%(\mathrm{p}<0.05)]$, and, at the same time, does not affect on the concentration of IL-8 (p<0.05), IL-10 (p>0.05) and TNF-alpha/IL-10 ratio parameters 
( $>$ >0.05). In the control group no positive dynamics of the concentration of the studied parameters was found ( $\mathrm{p}>0.05)$.

The protective effect of high-dose thiamine on detrusor contractility and on progression of diabetic cystopathy in streptozotocin-diabetic rats was some of the findings directed to the effect of thiamine on DAN. The deficiency of thiamine in clinical DM may increase the fragility of vascular cells to the adverse effects of hyperglycemia and there by the increase of the risk of developing microvascular complications. A suppression of transketolase (TKT) activity, and subsequent downregulation of the hexose monophosphate (HMP) shunt, resulting in accumulation of glyceraldehyde 3-phosphate, fructose 6-phosphate, and dihydroxyacetone phosphate may be at least one mechanism in the development of diabetes-induced vascular damage and other comorbidities [12, 13].

Thiamine and its derivatives have been demonstrated to prevent the activation of the biochemical pathways [increased flux through the polyol pathway, formation of AGEs, activation of protein kinase $\mathrm{C}$ (PKC), and increased flux through the hexosamine biosynthesis pathway (HBP)] induced by hyperglycemia in DM. TD plays a role in the diabetic endothelial vascular diseases, such as, neuropathy [13, 14]. In vitro studies with benfotiamine have shown a reduction in PKC activation in the glomeruli and decreased glomerular AGEs levels. Benfotiamine has been shown to prevent increased markers of HBP activity, intracellular AGEs formation, intracellular PKC activity and nuclear factor kappa-light-chain-enhancer of activated B cells (NF$\kappa \mathrm{B})$ activation seen with in vitro hyperglycemic damage. High-dose therapy of thiamine and benfotiamine suppressed AGEs accumulation in the peripheral nerve and reversed diabetic neuropathies (DN's) potentially by reducing the levels of triose phosphates via activation of TKT [14].

Cardiac OS is involved in heart failure that is induced by thiamine deprivation in rats. These findings suggest that thiamine modulates OS $[14,15]$. Endothelial nitric oxide synthase (eNOS) and nitric oxide (NO) may play an important role in attenuating cardiac remodeling and apoptosis. BFT reduces OS and activates eNOS to enhance the generation and bioavailability of NO, and it subsequently improves the integrity of 
vascular endothelium to prevent sodium arsenite-induced experimental vascular endothelial dysfunction [15].

The nerve tissues in DM undergo a proinflammatory process that presents symptoms and develops DN. The levels of CRP and TNF-alpha correlate with the incidence of DN's. Production of the initiating inflammatory mediators such as TNFalpha, transforming growth factor-beta, and NF- $\kappa \mathrm{B}$ results from several glucoseinduced pathways. Cyclooxygenase- 2 (COX-2) is an important enzyme that is upregulated by NF- $\kappa \mathrm{B}$ in diabetic peripheral nerves and consecutively generates prostaglandin E2 and ROS that trigger NF- $\kappa$ B. Inducible nitric oxide synthase (iNOS) is an additional inflammatory enzyme which is regulated by NF- $\kappa \mathrm{B}$. Similar to COX2 , iNOS either induces NF- $\kappa \mathrm{B}$ or is induced by it. This gives the impression that chronic NF- $\kappa \mathrm{B}$ activation is in the center of all the inflammatory elements operating in DN's. The cytokines which are induced by NF- $\kappa$ B in Schwann cells, endothelial cells, and neurons lead to absorption of macrophages in the diabetic nerves. Macrophages promote DN's via a variety of mechanisms, including making of cytokines, ROS, and proteases, which all result in cellular oxidative damage and myelin breakdown [15, $16]$.

Benfotiamine can promote neuronal and vascular deficiency correction through participation of NO processes, which have a significant therapeutic potential for the treatment of CVD. Benfotiamine significantly decreased production of proinflammatory mediators such as inducible form of iNOS and NO; COX-2, heat-shock protein 70, TNF-alpha, IL-6, whereas it increased anti-inflammatory IL-10 production in lipopolysaccharide (LPS)-stimulated BV-2 microglia. Moreover, benfotiamine suppressed the phosphorylation of extracellular signal-regulated kinases 1/2 (ERK1/2), c-Jun N-terminal kinases (JNK) and a serine/threonine protein kinase (Akt/PKB). Treatment with specific inhibitors revealed that benfotiamine-mediated suppression of NO production was via JNK1/2 and Akt pathway, while the cytokine suppression includes ERK1/2, JNK1/2 and Akt pathways. In murine macrophages, benfotiamine also blocked the expression of COX-2 and its product, prostaglandin E2, by LPSinduces cytotoxicity. In addition, benfotiamine significantly prevented LPS-induced 
macrophage death and monocyte adhesion to endothelial cells. These antiinflammatory effects of benfotiamine are mediated through the regulation of the arachidonic acid pathway in macrophages. Therefore, benfotiamine may have therapeutic potential for neurological diseases by inhibiting inflammatory mediators and enhancing anti-inflammatory factor production $[12,17]$.

The mechanism of benfotiamine influence on diabetic CAN pathogenesis is not well-known. There is moderate evidence from preclinical experimental models that high-dose thiamine and benfotiamine (1) inhibit the HMP, AGEs formation, and diacylglycerol-PKC through the TKT activation; (2) target at various surrogate markers of hyperglycemia-induced pathological processes and (3) can delay the progression of microangiopathic complications [17]. Therefore, the positive influences of benfotiamine is partly confirmed by its neurotropic, cardioprotective, angioprotective and cytoprotective properties [18, 19]; suggests the feasibility of its usage in the complex treatment of patients with T2DM and definite CAN. The results obtained in our study indicate that benfotiamine contributed to a decrease in the hs-CRP, TNFalpha and IL-6 levels. Obtained results could witness, that prescription of benfotiamine may lead to decrease of the proinflammatory immune response. The obtained data suggest that prescription of benfotiamine is associated with reduction of proinflammatory component of the immune response and make it possible to regard benfotiamine as a promising pharmacological agent in a complex therapy of the definite stage of CAN in T2DM. Thus, further investigations aimed to understand the mechanism of action and confirmation of the beneficial effect of benfotiamine on biochemical parameters, dynamics of independent CARTs, Holter-ECG, arterial wall stiffness parameters among patients with T2DM and CAN, and its associated comorbidities may be needed to validate this clinical findings. 


\subsection{Influence of hyperuricemia on changes of cardiac markers, functional and coronary reserves in patients with stable angina pectoris}

Analysis of the literature shows the relationship between hyperuricemia and cardiovascular disease. Epidemiological and experimental studies over 10 years have shown that hyperuricemia is not only a risk factor for gout and nephrolithiasis, but is often accompanied by hypertension, type 2 diabetes, obesity, metabolic syndrome, chronic kidney disease and cardiovascular disease. In addition, comorbid pathology, such as renal failure or insulin resistance, leads to increased levels of uric acid in the serum, thereby contributing to the development of gout [23, 31]. It is recognized that gout forms a group with an increased risk of cardiovascular disease [27], in turn, atherosclerosis induces an increase of uric acid, which leads to an unfavorable prognosis in patients with acute heart failure.

As mentioned [25], the levels of C-reactive protein and N-terminal pro B-type natriuretic peptide, associated with an increase of serum uric acid $(1 \mathrm{mg} / \mathrm{dL}$, are independent indicators of 1-year mortality. Hyperuricemia increases the risk of hypertension (2-3 times in 5-7 years), renal damage (5 times in 2 years at plasma uric acid levels $>330 \mu \mathrm{mol} / 1$ ), progression of IgA nephropathy, associated with obstructive pulmonary syndrome sleep apnea, vascular diseases (carotid, peripheral and coronary arteries), stroke and vascular dementia, preeclampsia, inflammation, endothelial dysfunction, oxidative stress, sex [27, 28, 29]. Thus, the study of the mechanisms of interdependence of these indicators is relevant against the background of hyperuricemia and coronary heart disease.

We examined 120 patients with an objectified diagnosis of stable angina depending on the distribution of uric acid levels and manifestations of hyperuricemia without its symptoms (34 patients, $28.33 \%$ of cases) and with elevated uric acid levels (86 people, $71.67 \%$ of cases).

At the beginning of inpatient treatment [21] and after 6 months at the outpatient stage, patients were examined for uric acid, $\mathrm{N}$-terminal pro B-type natriuretic peptide and C-reactive protein, with the evaluation of echocardiographic results in comparing 
changes in left ventricular ejection fraction and the achieved threshold load at Bicycle ergometer test.

A study of the set of detection of correlation between the studied values with the estimation of correlation coefficients, two-dimensional descriptive statistics measuring the total variability of two or more variables represented by correlation coefficients, including Pearson's linear correlation coefficient, subsequent construction of sets of equations.

In the group of hyperuricemia more often diagnosed with stable angina III functional class $(87.21 \pm 3.60$ against $41.18 \pm 8.44 \%$ of cases of stable angina III functional class, $\mathrm{p}<0.001$ ), as well as the probability of a history of Q-Myocardial infarction, $60 \pm 6.81$ vs. $32.84 \pm 8.05 \%$ of cases, $p<0.05$ ), and when the uric acid level exceeds $467.9 \mu \mathrm{mol} / 1$, the left ventricular ejection fraction probably decreased (51.17 \pm 1.37 vs. $55.77 \pm 0.73 \%, p<0.01$ ), which was also realized by Bicycle ergometer test tests with probably lower threshold load values $(53.65 \pm 2.89 \mathrm{~W}$ in the hyperuricemia group against $72.74 \pm 5.18 \mathrm{~W}$ in the group with normal uric acid levels, $\mathrm{p}<0,01$ ) and was accompanied by an excess of uric acid levels above $467.9 \mu \mathrm{mol} / 1$, the predominance of C-reactive protein levels $(12.07 \pm 0.97$ vs. $5.37 \pm 0.60 \mathrm{mg} / 1, \mathrm{p}$ $<0.001)$ and N-terminal pro B-type natriuretic peptide $(413.44 \pm 63.14$ vs. $206.42 \pm$ $31.43 \mathrm{pg} / \mathrm{ml}, \mathrm{p}<0.01)$, as noted in previous publications $[22,30]$.

The following analysis is performed, as a separate case of stochastic connection, the study of correlation, in which the change in the mean value of the effective (changing under the influence of factor features) due to changes in factor (under their influence change other, dependent on them) features with model construction pair regression in the form of the equation of the relationship of two indicators $\mathrm{Y}$ (feature) and $\mathrm{X}$ (factor) to determine the effect of changes in one indicator on another, when the equation of the pairwise regression model is presented as $\mathrm{Y}=\mathrm{f}(\mathrm{X})$, where $\mathrm{Y}$ is the dependent indicator (effective sign), $\mathrm{X}$ is an independent (explanatory) factor.

The estimated regression equation (based on sample survey data at first entry to compare uric acid $(\mathrm{Y})$ and $\mathrm{N}$-terminal pro $\mathrm{B}$-type natriuretic peptide $(\mathrm{X})$ ) will be $\mathrm{Y}=$ $0.6501 * \mathrm{X}-38.0834$, correlation according to the Chaddock's scale between sign Y 
factor $X$ is noticeable and direct $\left(r_{X Y}=0.552\right)$. Since $\left|t_{\text {observ }}\right|>t_{c r i t}-$ we reject the hypothesis of equality 0 of the correlation coefficient, and the correlation coefficient itself is statistically significant, the study of the F-criterion (R. Fisher) shows that since the actual value of $F>F_{\text {table, }}$, the coefficient of determination is also statistically significant and regression is statistically reliable.

The correlation between uric acid $(\mathrm{Y})$ and $\mathrm{C}$-reactive protein level $(\mathrm{X})$ is described by the equation $\mathrm{Y}=0.02142 * \mathrm{X}-0.26$, is high and direct $(\mathrm{rXY}=0.701)$, according to the F-test is statistically reliable. In the equation with the estimate of the ratio of uric acid $(\mathrm{Y})$ and $\mathrm{PV} L V(\mathrm{X})$ by the formula $\mathrm{Y}=0.0134 * \mathrm{X}+45.0824$, but the relationship is weak $\left(r_{X Y}=0.224\right)$ and statistically unreliable by the F-test. The relationship between uric acid (Y) and threshold load (X) according to the equation $\mathrm{Y}$ $=-0.03104 * \mathrm{X}+41.0479$ and according to the F-test is statistically unreliable.

Thus, the comparison of the correlation of two indicators, one of which is effective, which changes under the influence of factor traits and is actually uric acid (Y) shows a high and direct relationship between assessment factors for C-reactive protein, noticeable and direct - for N-terminal pro B-type natriuretic peptide, both according to the F-criterion are statistically reliable, in contrast to the weak and statistically unreliable - for left ventricular ejection fraction and threshold load.

The next task of the study is to build multiple regression with the creation of a model with a large number of factors, determining the impact of each of them separately, as well as their combined impact on the simulated indicator, because multiple regression can analyze the relationship between several independent variables (predictors) and the dependent variable (Y), which in its own work is the content of uric acid in the first receipt, while the influencing factors, where $\mathrm{X}=\mathrm{X}\left(\mathrm{X}_{1}, \mathrm{X}_{2}, \ldots, \mathrm{X}_{\mathrm{m}}\right)$ - a vector of independent (explanatory) variables, it is proposed to evaluate the indicators: $\mathrm{X}_{1}$ - N-terminal pro B-type natriuretic peptide at the first admission and $\mathrm{X}_{2}$ - its content at the second, $\mathrm{X}_{3}-\mathrm{C}$-reactive protein at the first admission and $\mathrm{X}_{4}$ - its content at the second, $\mathrm{X}_{5}-$ left ventricular ejection fraction at the first admission and $\mathrm{X}_{6}$ - its level at repeated, $\mathrm{X}_{7}$ - threshold load at the first receipt and $\mathrm{X}_{8}$ - its achievement at repeated inspection in 6 months. The multiple regression equation is presented as: 


$$
\mathrm{Y}=-12.0028+0.3893 * \mathrm{X}_{1}-0.08975 * \mathrm{X}_{2}+13.4637 * \mathrm{X}_{3}-3.9902 * \mathrm{X}_{4}+
$$
$8.8012 * \mathrm{X}_{5}-2.0567 * \mathrm{X}_{6}-6.233 * \mathrm{X}_{7}+3.594 * \mathrm{X}_{8}$

The observed values of $t$-statistics for ryX1-8 are calculated and defined table, $t_{c r i t}$ $(n-m-1 ; \alpha / 2)$. Since $t_{\text {observ }}>t_{\text {crit }}$, we reject the hypothesis of equality 0 of the correlation coefficient and the correlation coefficient is statistically significant, which is registered for factors $\mathrm{X}_{1}\left(\mathrm{~N}\right.$-terminal pro B-type natriuretic peptide $\left.{ }_{1}\right) \mathrm{t}_{\mathrm{observ}}=4.5 ; \mathrm{t}_{\text {crit }}(\mathrm{n}-\mathrm{m}-1 ; \alpha /$ $2)=(46 ; 0.025)=2.009 ; \mathrm{X}_{3}\left(\mathrm{C}\right.$-reactive protein $\left.{ }_{1}\right)$ statistically significant, $\mathrm{t}_{\text {observ }}=4.5$; $\mathrm{X}_{6}$ (left ventricular ejection fraction ${ }_{2}$ ) statistically significant, $\mathrm{t}_{\mathrm{observ}}=3.52$.

Interestingly, no significant dependence of uric acid content on the indicators $\mathrm{X}_{5}$

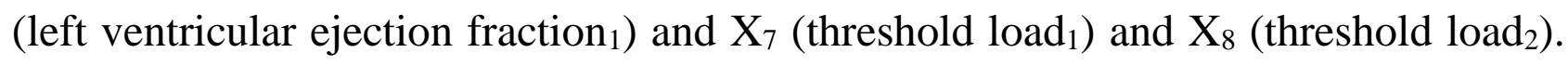
At the same time, the initial level of uric acid was not expected to be affected by the factor of the second intake $\mathrm{X}_{2}$ (N-terminal pro B-type natriuretic peptide $\left.\mathrm{N}_{2}\right), \mathrm{X}_{4}(\mathrm{C}$ reactive $\left.\operatorname{protein}_{2}\right)$. Checking the overall quality of the multiple regression equation using F-statistics (Fisher's test) with the assessment of the relationship for the predominance of the actual value of $\mathrm{F}>\mathrm{F}_{\mathrm{kp}}$, and therefore in this case the coefficient of determination was statistically significant and the regression equation was statistically reliable.

It was found that factor $\mathrm{X}_{1}\left(\mathrm{~N}\right.$-terminal pro B-type natriuretic peptide $\left.{ }_{1}\right) \mathrm{F}_{\mathrm{X} 1}$ (50.094)> 2.25, therefore, factor $X_{1}$ should be included in the model after the introduction of factors $X_{j}$, with a similar dependence for $X_{3}\left(C\right.$-reactive protein $\left.{ }_{1}\right) F_{X 3}$ (55.276)> 2.25; $\mathrm{X}_{4}(\mathrm{C}$-reactive protein 2$) \mathrm{F}_{\mathrm{X} 4}(6.848)>2.25 ; \mathrm{X}_{5}$ (left ventricular ejection fraction $\left._{1}\right) F_{X 5}(22.6)>2.25$ and $X_{7}\left(\right.$ threshold load $\left._{1}\right) F_{X 7}$ (37.024)> 2.25.

Since the density of the combined influence of factors on the result allows to determine the multiple correlation index - the study was subjected to a multiple correlation coefficient through a matrix of paired correlation coefficients, it was determined that when approaching $\mathrm{R}$ to 1 (in our own study $\mathrm{R}=0,8933$ ), the regression equation better describes actual data affect the result.

Finally: defined as the correlation coefficient between variables belonging to the ordinal scale with a score for variable scale variables, parametric Pearson correlation coefficient - r-Pearson - a correlation measure for two continuous (metric variables) 
measured on the same sample, the score relationships between two series of indicators in the quantitative scale) [20].

It was found that the level of uric acid in the first examination shows a direct moderate relationship with $\mathrm{N}$-terminal pro B-type natriuretic peptide ${ }_{1}$ (r-Pearson 0,363, $\mathrm{p}<0,01$ ), a direct moderate relationship with C-reactive $\operatorname{protein}_{1}$ (r-Pearson $0,454, p<0$ , 01), inverse moderate with left ventricular ejection fraction ${ }_{1}$ (r-Pearson $-0,351, p$ $<0,01)$, acquires a direct high connection with $\mathrm{C}$-reactive protein $_{2}$ of the second admission ( $\mathrm{r}$-Pearson $0,765, \mathrm{p}<0,01$ ), direct moderate communication tongue with $\mathrm{N}$ terminal pro B-type natriuretic peptide 2 ( $\mathrm{r}$-Pearson $0.438, \mathrm{p}<0.01$ ), inverse moderate with left ventricular ejection fraction $2(r-P e a r s o n-0.351, p<0.01)$.

In turn, $\mathrm{N}$-terminal pro B-type natriuretic peptide of the first admission showed a direct appreciable connection with C-reactive $\operatorname{protein}_{1}$ (r-Pearson 0,533, p <0,01), inverse moderate with left ventricular ejection fraction $_{1}$ ( $r$-Pearson $-0,561, p<0,01$ ), further N-terminal pro B-type natriuretic peptide of the second admission showed an even more pronounced direct visible relationship with C-reactive protein 2 (r-Pearson $0.619, \mathrm{p}<0.01)$ and the reverse noticeable with left ventricular ejection fraction 2 ( $r$ Pearson -0.611, $\mathrm{p}<0.01)$.

The relationship between C-reactive protein and left ventricular ejection fraction was inverse moderate in the first ( $\mathrm{r}$-Pearson $-0.340, \mathrm{p}<0.01)$ and inverse moderate in the second ( $\mathrm{r}$-Pearson $-0.504, \mathrm{p}<0.01$ ) surveys. Noteworthy is the lack of Pearson correlation in the assessment of the achieved load in Bicycle ergometer test except for the weak feedback in the second survey with $\mathrm{N}$-terminal pro B-type natriuretic peptide 2 (r-Pearson -0.319, $\mathrm{p}<0.05)$.

Therefore, the study of changes in the Pearson correlation coefficient depending on the levels of uric acid, N-terminal pro B-type natriuretic peptide and C-reactive protein showed a predominantly direct moderate relationship at admission, which reached a noticeable and even high relationship in the second survey, with the inverse moderate for left ventricular ejection fraction, in contrast from the achieved load at Bicycle ergometer test. 
In conclusion, the following can be noted:

1. Hyperuricemia causes coronary reserve limitation with increasing functional class of angina and reduction of threshold load, decreased left ventricular ejection fraction, increased levels of C-reactive protein, N-terminal pro B-type natriuretic peptide, with the reverse reaction of total testosterone in general.

2. The estimated regression equation, according to the sample survey data, at the first admission to compare uric acid with the N-terminal pro B-type natriuretic peptide indicates a noticeable and direct connection, C-reactive protein - high and direct, according to the F-test is statistically reliable, in contrast to the weak and statistically unreliable - for the fraction of left ventricular ejection according to echocardiography and threshold load during bicycle ergometer test.

3. Construction of multiple regression equation with dependent variable uric acid content and influencing factors - C-reactive protein, N-terminal pro B-type natriuretic peptide, left ventricular ejection fraction, threshold load is statistically reliable with a high coefficient of multiple correlation $(r=0,89)$.

4. The Pearson correlation coefficient depending on the levels of uric acid, $\mathrm{N}$-terminal pro B-type natriuretic peptide and $\mathrm{C}$-reactive protein indicates a predominantly direct moderate binding on admission, with a noticeable and even high binding on re-examination, with a moderate feedback for left ventricular ejection fraction, in contrast to the achieved load during bicycle ergometer test. 


\subsection{Clinical picture and laboratory disorders in patients with COVID-19 infection and ischemic heart disease}

Since December 2019, cases of disease related severe acute respiratory syndrome coronavirus 2 (SARS-CoV-2), now known as COVID-19 (coronavirus disease 2019), have rapidly spread from Hubei Province in China to the whole world. The World Health Organization (WHO) has officially recognised COVID-19 as a pandemic and countries worldwide are now facing huge challenges trying to prevent its further spread as well as treating the growing number of COVID-19 patients. In fact, although the majority of cases are usually self-limiting with mild symptoms such as low-grade fever and cough, the disease can be fatal [32].

The pathophysiology of COVID-19 is associated with an enhanced inflammatory response of the patient's body, which leads to damage not only to lung tissue but also to other body systems, including the cardiovascular system [33].

A multicenter study of 44,672 cases of COVID-19 showed a fivefold increase in mortality in patients with cardiovascular disease compared with no pathology $(10.5 \%$ vs. 2.3\%) [34], the presence of cardiovascular disease in history helps patients become more susceptible to the virus. A study of 5700 patients have reported hypertension (56.6\%), ischemic heart disease (IHD) (11.1\%) and congestive cardiac failure (6.9\%) as common underlying co-morbidities in confirmed COVID-19 cases [35].

Today, most researchers are inclined to believe that the predictors of an unfavorable IHD prognosis in patients with COVID-19 are inflammatory processes in the vascular wall caused by activation of the cascade of proinflammatory reactions, complement system and proinflammatory cytokines through to "cytokine storm". Myocardial inflammation and endothelial dysfunction caused by SARS-CoV-2 cause an imbalance between myocardial perfusion and its metabolic processes in patients with coronary heart disease, which contributes to the rupture of atherosclerotic plaque. It is known that the level of pro-inflammatory cytokines (IL-1, IL-6, tumor necrosis factor- $\alpha$ (TNF- $\alpha$ ) and others) can be used to assess patients at risk of adverse disease with COVID -19 with cardiovascular pathology [36]. However, in routine practice it is 
not always possible to quickly obtain the results of the study of the above markers of inflammation. However, it is known that the total effect of most pro-inflammatory cytokines leads to changes in general clinical blood testing, in particular, IL-6 affects leuko- and lymphopoiesis.

Thus, the identification of inflammatory markers as prognostic predictors of mortality in patients with COVID-19 and CVD may be useful in assessing the severity of the disease and making optimal treatment decisions.

The aim of the work - to investigate the connection between hospital mortality and markers of systemic inflammation in COVID-19 patients with IHD and to assess hematological indices under the influence of the inclusion of quercetin and arginine in complex therapy at the inpatient stage of treatment.

A retrospective analysis of 63 medical records of COVID-19 patients with IHD who were inpatient treatment from February to April 2021 was carried out. The diagnosis of coronary heart disease was verified on the basis of clinical data and results of laboratory and instrumental research methods in accordance with the recommendations of the European Society of Cardiology (ESC), the Association of Cardiologists of Ukraine, and protocols of the Ministry of Health of Ukraine. The presence of COVID-19 was established using polymerase chain reaction (PCR) to detect SARS-CoV-2 RNA in the test samples.

3 patients with incomplete survey data, 6 patients who died from non-COVID-19related diseases, and 2 patients with a history of malignancy were excluded from the clinical trials. A total of 52 COVID-19 patients with IHD were included in the study, including 30 males (57.69\%) and 22 females (42.31\%). The average age of the surveyed was $66.23 \pm 11.41$ years $(\mathrm{M} \pm \mathrm{m})$.

To achieve this goal, patients were divided into two groups: the first consisted of $40(76.92 \%)$ patients who were discharged with recovery; the second group included $12(23.08 \%)$ patients who died. Evaluation of hematological indices under the influence of inclusion in the complex therapy of metabolic drugs was determined in 25 patients of group I, divided into 2 subgroups. Subgroup I A, which consisted of 17 patients, received water-soluble quercetin (Corvitin, "Borshchahivskiy Chemical - 
Pharmaceutical Plant", and subgroup IB (8 patients) - arginine hydrochloride (Tivortin, "Yuria-Pharm"). The severity of the systemic inflammation syndrome in the selected groups of patients was assessed by the number of leukocytes and the cellular composition of peripheral blood upon admission to the hospital and, based on the data obtained; the value of hematological integral indices was calculated: 1) blood leukocytes shift index (BLSI) with N.I. Yabluchansky (1983): BLSI $=(E+B+S+$ $\mathrm{RS}+\mathrm{Y}+\mathrm{M}) /(\mathrm{Mo}+\mathrm{L})$, where E - eosinophils, B - basophils, S - segmented neutrophils, RS - rod-shaped, Y - young neutrophils, M - myelocytes, Mo - monocytes, L - lymphocytes. Normally, the BLSI indicator averages (1.96 \pm 0.17 ) conv. unit; 2) index of the neutrophil-to-lymphocyte ratio (NLR), under physiological conditions, the value of NLR is $(2.47 \pm 0.65)$ conv. unit; 3$)$ intoxication leukocyte index (ILI), with Kalf-Kalif formula: $\mathrm{ILI}=(2 \times \mathrm{RS}+\mathrm{S}) /(\mathrm{Mo}+\mathrm{L}) \times(\mathrm{E}+1)$, № (0.3-1.5) conv. unit; 4) nuclear intoxication index (NII) was calculated by GA Dashtayantsom (1978): NII = (Mo +RS) / S, normally averages (0.05-0.1) conv. unit; 5) the ratio of neutrophils to monocytes $(\mathrm{N} / \mathrm{Mo}): \mathrm{N} / \mathrm{Mo}=(\mathrm{S}+\mathrm{RS}+\mathrm{Y}) /$ Mo (Mustafina JG et al., 1999), norm $(11.83 \pm 1.31)$ conv. unit; 6$)$ the ratio lymphocyte to eosinophil (L/E) standard value $(8.73 \pm 1.26)$ conv. unit; 7$)$ the ratio of lymphocytes to monocytes (L / Mo), standard value $(5.34 \pm 0.59)$ conv. unit; 8$)$ the allergization index $(\mathrm{AI})$ : $(\mathrm{L}+10 \times(\mathrm{E}+1)) /(\mathrm{RS}$ $+\mathrm{S}+\mathrm{Mo})$, normally the indicator is (0.79-1.08) conv. unit.

The study did not include patients who underwent coronary artery bypass graft (CABG) surgery, invasive interventions with newly diagnosed coronary heart disease, cases of severe HF (functional class IV), acute cerebrovascular disease, those who died of infectious diseases other than COVID-19, and who have not reached 18 years of age.

Material processing was performed using a standard Microsoft Office Excel software package. The obtained results are presented in the form of mean value and mean error $(M \pm m)$. Student's t-test was used to determine the difference in values. Data were considered reliable under conditions $\mathrm{p}<0.05$.

According to the results of the analysis of inpatient cards, stable angina was diagnosed in $86.54 \%$ of patients, $13.46 \%$ of patients had a history of myocardial 
infarction; recurrent cases of myocardial infarction were detected in $3.84 \%$. A history of diffuse cardiosclerosis was found in $73.07 \%$ of the examined patients, postinfarction cardiosclerosis was diagnosed in $13.46 \%$ of cases.

In patients admitted to the hospital, the indicators of "red" blood were within normal range without statistical differences in the study groups.

When analysis the leukocyte of hematopoiesis, it was revealed that in patients of group II who died from cardiovascular complications associated with COVID-19, there is a significantly higher value of the number of leukocytes $(16.85 \pm 5.25) \times 10^{9} / 1$, in contrast to patients group I, who were discharged with recovery $(5.81 \pm 1.75) \times 10^{9} / 1$ $(\mathrm{p}<0.05)$. There were also statistical differences in the population of white blood cells. In particular, the number of neutrophils in group I was $(67.71 \pm 9.85) \%$, and in patients of group II $(88.09 \pm 2.99) \%$ and lymphocytes $(18.13 \pm 4.25) \%$ in group I versus $(6.25$ $\pm 1.42) \%$ in group II $(\mathrm{p}<0.05)$ (Table 1). The identified clinical features in patients of group II were accompanied by higher rates of inflammatory activity (higher total content of white blood cells and an increase in the percentage of neutrophils), with a decrease in the percentage of peripheral blood lymphocytes.

Table 1.

\section{Indicators of a general blood test in patients of the observation groups}

\begin{tabular}{|c|c|c|c|c|c|c|c|}
\hline $\begin{array}{l}\text { Clinical } \\
\text { groups }\end{array}$ & Erythrocytes & Hemoglobin & Leukocytes & $\begin{array}{c}\text { Eosinophils, } \\
\%\end{array}$ & $\begin{array}{c}\text { Neutrophils, } \\
\%\end{array}$ & $\begin{array}{c}\text { Lymphocytes, } \\
\%\end{array}$ & $\begin{array}{l}\text { Monocyt } \\
\text { es, \% }\end{array}$ \\
\hline $\begin{array}{c}\text { I } \\
\text { Group } \\
(\mathbf{n}=\mathbf{4 0})\end{array}$ & $4.61 \pm 0.57$ & $\begin{array}{c}136.51 \pm \\
16.48\end{array}$ & $5.81 \pm 1.75$ & $2.13 \pm 1.89$ & $67.71 \pm 9.85$ & $18.13 \pm 4.25$ & $\begin{array}{l}12.03 \pm \\
4.25\end{array}$ \\
\hline $\begin{array}{c}\text { II } \\
\text { Group } \\
(\mathbf{n}=12)\end{array}$ & $4.39 \pm 0.72$ & $\begin{array}{c}131.75 \pm \\
18.75\end{array}$ & $16.85 \pm 5.25$ & $1.69 \pm 0.91$ & $88.09 \pm 2.99$ & $6.25 \pm 1.42$ & $\begin{array}{c}6.29 \pm 1.4 \\
2\end{array}$ \\
\hline $\mathbf{p}$ & $>0.05$ & $>0.05$ & $<0.05$ & $>0.05$ & $<0.05$ & $<0.05$ & $>0.05$ \\
\hline
\end{tabular}


The analysis of integral hematological indices showed that in both groups of patients the indicators of ILI, NLR, ILI, NII were higher than normal. There was also a significantly higher level of N / Mo in patients of group II. The above indices reflect the body's systemic response to inflammation. In both groups there were below the norm of L / Mo, AI, lower levels of L / E in patients of group II, which indicates the suppression of the immune system.

The comparative analysis of hematological indices revealed significant differences, in particular, indices BLSI, N / L, N / Mo (Figure 1).

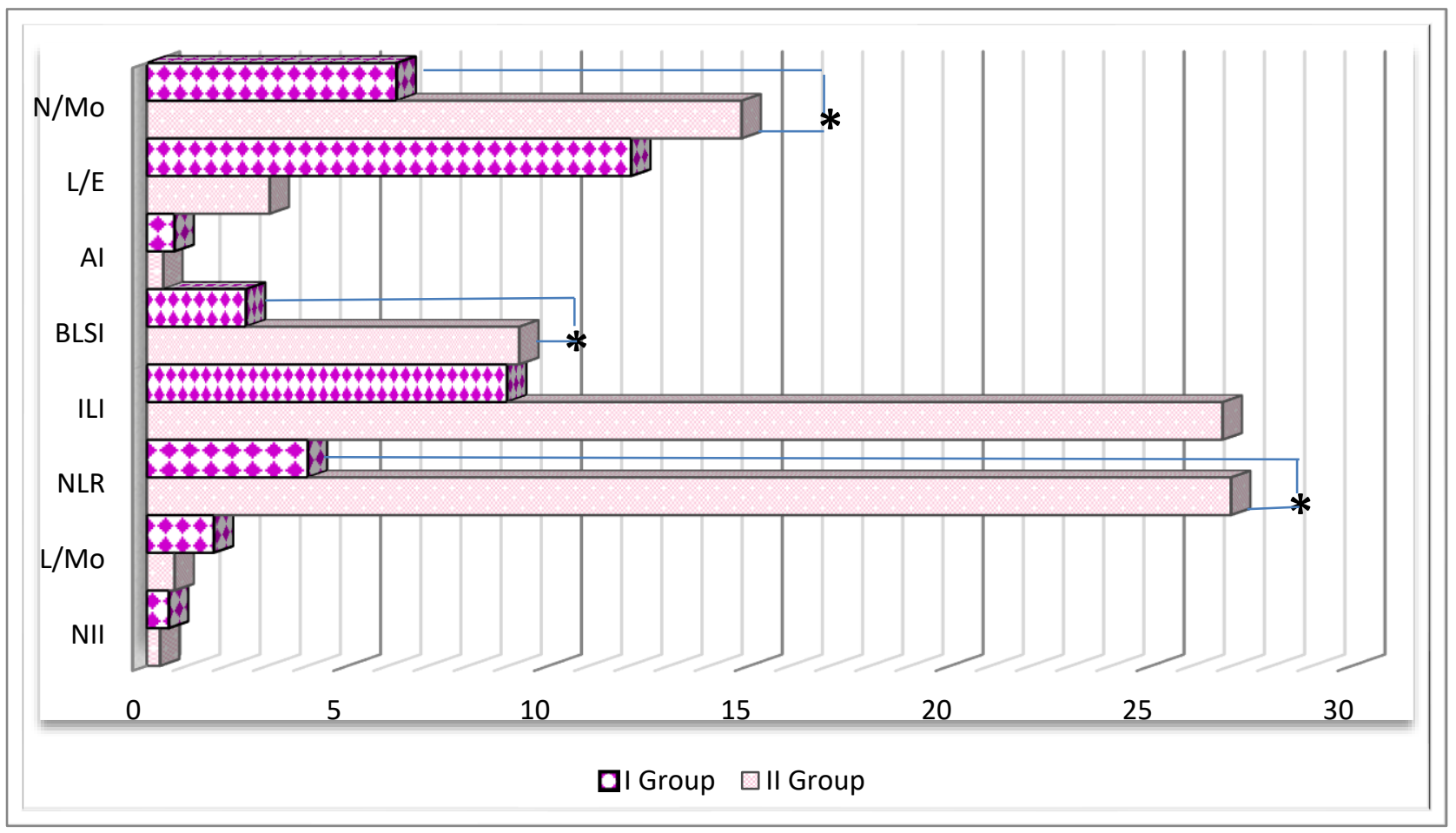

Notes: the significance of the difference between the indicators: $* \mathrm{p}<0.05$.

Figure 1. Indicators of hematological blood indices in patients of the observation groups

An increase in the BLSI index indicates an active inflammatory process and the presence of changes in immunological reactivity, which is mainly associated with an increase in the number of neutrophils and a decrease in the number of lymphocytes. A significant difference in the increase of the index BLSI in group II $(9.28 \pm 2.16)$ compared with group I $(2.47 \pm 0.95)(p<0.05)$, which is probably through to the above processes, and confirmed hemogram (Table 1). Therefore, an increase in this indicator 
can serve as an indirect criterion for an unfavorable course of the disease and its prognosis. In patients of the II clinical group, there was an increase in a number of hematological indices - N / L: $(26.99 \pm 11.11)$ versus group I $(4.01 \pm 2.36)$ and N / Mo: $(14.81 \pm 3.49)$ versus $(6.22 \pm 2.18)(\mathrm{p}<0.05)$.

The analysis of the obtained results of the distribution of hematological indices in patients of subgroup I A and I B on inpatient treatment showed that there is no significant difference between the indicators (Table 2).

Table 2.

\section{Features of distribution of hematological indices at patients on}

COVID-19 from IHD subgroups I A and I B

\begin{tabular}{|c|c|c|c|c|c|c|c|c|}
\hline $\begin{array}{l}\text { Clinical } \\
\text { groups }\end{array}$ & N/Mo & $L / E$ & $I A$ & $B L S I$ & $I L I$ & $N / L$ & $L / M o$ & NII \\
\hline $\begin{array}{c}\text { Subgroup } \\
\text { I A } \\
\text { (Corvitin + } \\
\text { complex } \\
\text { therapy), } \\
\text { n=17 }\end{array}$ & $\begin{array}{c}7.33 \pm 3 . \\
83\end{array}$ & $\begin{array}{c}22.82 \pm 9 \\
.89\end{array}$ & $0.59 \pm 0.21$ & $2.15 \pm 0.86$ & $8.18 \pm 3.48$ & $3.11 \pm 1.28$ & $\begin{array}{c}2.54 \pm 1 . \\
07\end{array}$ & $\begin{array}{l}0.28 \pm 0.0 \\
8\end{array}$ \\
\hline $\begin{array}{c}\text { Subgroup } \\
\text { IB } \\
\text { (Tivortin + } \\
\text { complex } \\
\text { therapy), } \\
\text { n=8 }\end{array}$ & $\begin{array}{c}6.31 \pm 1 . \\
22\end{array}$ & $\begin{array}{c}19.62 \pm 8 \\
.97\end{array}$ & $0.55 \pm 0.08$ & $2.03 \pm 0.48$ & $7.63 \pm 2.52$ & $2.96 \pm 0.79$ & $\begin{array}{c}2.18 \pm 0 . \\
41\end{array}$ & $\begin{array}{c}0.28 \pm 0.0 \\
6\end{array}$ \\
\hline
\end{tabular}

The rationale for the use $\mathrm{N} / \mathrm{L}$ and $\mathrm{N} / \mathrm{Mo}$ to identify patients with severe COVID-19 and mortality is likely to be further explained by the different roles of neutrophils, lymphocytes and monocytes in the immune response. Neutrophils are considered to be one of the most important immune cells in protecting the airway epithelium from SARS-CoV-2 infection by locally stimulating the production of IL$1 \beta$, IL-6, TNF- $\alpha$ and reactive oxygen species. Paradoxically, neutrophil hyperactivation and recruitment intensify the acute inflammatory response and worsen epithelial tissue damage thus leading to disease progression. On the contrary, lymphocytes are very 
important leukocytes in charge of mediating immune tolerance to self-antigens, activation of pathogen-specific adaptive immunity, and, last but not less important, orchestration of immunomodulatory mechanisms [37]. Lymphocytes, including $\mathrm{T}$ and B cells, are able to orchestrate immunomodulatory mechanisms via IL-10 and transforming growth factor-beta 1 (TGF-beta 1) production, a couple of cytokines with key anti-inflammatory and wound-healing actions. In parallel, monocytes are circulating leukocytes that in humans can be sorted into three subpopulations based on the cell surface expression of the cluster of differentiation (CD) 14 and CD16. The classical monocyte subpopulation expresses high CD14 levels with no CD16 expression. Intermediate monocytes show CD14 and CD16 expression; in contrast, non-classical monocytes express very low CD14 levels accompanied by CD16 expression. Intermediate and non-classical monocytes have been shown to produce high levels of IL-1 beta in response to lipopolysaccharide and in patients with metabolic syndrome [38]. Interestingly, reduction in both intermediate and nonclassical monocyte subpopulations has been recently associated with increased severity of the SARS-CoV-2 infection [39]. Additionally, monocytes can differentiate into alternatively activated macrophages and prevent inflammatory responses by promoting tissue repair via IL-10 and TGF-beta 1 production, which may also play a pivotal role in regulating hyperactivation of the inflammatory response described in patients with severe Covid-19 [40].

Thus, it can be assumed that $\mathrm{N} / \mathrm{L}$ and $\mathrm{N} /$ Mo may reflect an imbalance between these immune cells, which in turn is associated with excessive inflammation, severe course, and mortality in group II patients. In addition, in the presence of CVD, acute inflammatory reactions can lead to ischemia. During a systemic inflammatory response, it is observed that inflammatory activity is aggravated in the coronary atherosclerotic plaque, making them more susceptible to rupture. An occlusive thrombus may be formed over a ruptured coronary plaque, caused by inflammation leading to endothelial dysfunction and elevated procoagulant activity of blood and hence it is safe to hypothesize that preexisting cardiovascular disease, in conjunction 
with an aggravated inflammatory response may result in cardiac injury, in patients that are infected with SARS-CoV-2 [36].

L-arginine, hereinafter referred to as arginine, is a semi-essential or conditionally essential amino acid, since it can be synthetized by healthy individuals but not by preterm infants. From a chemical point of view, arginine is a 2-amino-5guanidinopentanoic acid. Arginine is involved in a number of biological processes, it is the substrate for a series of reactions leading to the synthesis of other amino acids, and it is a substrate for two enzymes, namely nitric oxide (NO) synthase (NOS) and arginase, which are fundamental for the generation of NO and urea, respectively. Arginine is known to act as a substrate for NO production by endothelial cells, thus regulating vascular tone and, overall, cardiovascular homeostasis [41] and also prevents the activation and adhesion of lymphocytes and platelets [42]. This substance has antihypoxic, membrane-stabilizing, antioxidant, cytoprotective, antiradical, detoxifying effects [43]. In one study in April 2020, scientists demonstrated that the systemic manifestations observed in COVID-19 may be to endothelial dysfunction and immune inflammation [41].

Therefore, given the positive effect of arginine on endothelial function, it can be assumed that the addition of arginine may be useful in preventing endothelial dysfunction in patients with COVID-19.

Quercetin (3, 3', 4'5, 7 -pentahydroxyflavone) is a widely distributed plant flavonoid, found in several vegetables, leaves, seeds, and grains, where it is conjugated with residual sugars to form quercetin glycosides. Studies suggest that quercetin supplementation may promote antioxidant, anti-inflammatory, antiviral, and immunoprotective effects. Quercetin has been studied in various types and models of viral infection through to its promising antiviral effects in inhibiting polymerases, proteases, reverse transcriptase, suppressing DNA gyrase, and binding viral capsid proteins [44].

The drug also has an immunomodulatory effect, which consists in the suppression of the main proinflammatory cytokines TNF- $\alpha$, IL- 6 and IL- $1 \beta$ under 
conditions of "cytokine storm". The drug is a direct antioxidant, prevents cell apoptosis, and has a cardioprotective effect in ischemic and reperfusion heart disease [45, 46].

Quercetin may be useful in patients with COVID-19 with coronary heart disease through to its immunomodulatory effects and inhibition of inflammatory mediators [46], which may help reduce the "cytokine storm".

Thus, the results of our study not only suggest new markers of mortality from severe COVID-19, but also identify potential treatments aimed at reducing neutrophil hyperactivation and increasing the number of lymphocytes and monocytes.

We can draw conclusions:

1. Patients who died from cardiovascular complications associated with COVID19 had a significantly higher level of systemic inflammatory response, which is manifested by a significant increase in total white blood cell count and an increase in the percentage of neutrophils with significantly higher integrated hematological indices: BLSI, N / L and N / Mo, which is at least partially associated with the risk of disease progression to a critical condition, hospitalization in the intensive care unit and the high mortality rate of such patients.

2. Lymphopenia, excessive activation of the inflammatory cascade and heart disease - all these are the most important features of the disease COVID-19 and have high prognostic value.

3. Drugs containing arginine hydrochloride and quercetin are promising drugs in the complex therapy for the treatment of patients with COVID-19 with IHD. 


\section{5 Роль сывороточных биомаркеров в течении кардиомиопатий у детей}

Болезни сердечно-сосудистой системы имеют особую значимость, связанную не только с их широким распространением, сколько с той ролью, которую эти заболевания играют в смертности, инвалидизации детей и в формировании заболеваемости взрослых [47, 48]. По данным экспертов Всемирной организации здравоохранения, «..отрицательная динамика показателей здоровья населения зафиксирована даже в странах с высоким уровнем жизни: отмечается рост онкологической и эндокринной патологии, а также заболеваний сердечно-сосудистой системы (ССС), среди которых сердечно-сосудистые заболевания занимают 1-е место в структуре смертности среди взрослого населения» $[49,50]$. Согласно независимым многоцентровым исследованиям, дети относятся к группе риска развития кардиоваскулярной патологии, именно в детском возрасте идет формирование основных факторов риска развития сердечно-сосудистых событий, реализация которых ухудшает отдаленный прогноз заболевания, снижая качество жизни и социальную адаптацию в последующие возрастные этапы $[51,52,53]$.

В этом плане одну из лидирующих позиций у детей занимают кардиомиопатии, которые относятся к тяжелым, непрерывно прогрессирующим некоронарогенным заболеваниям миокарда, характеризующимся разнообразием причин, симптомов и проявлений, а также и высокой летальностью $[47,48,54]$.

КМП у детей имеют не только медицинскую и социальную значимость, но и приносят экономический ущерб, связанный с тяжестью заболевания и его последствиями $[55,56,57,58]$

В мире проводятся широкомасштабные научные исследования, направленные на совершенствование диагностики, дифференциации, прогноза и лечения сердечно-сосудистых заболеваний у детей. Кардиомипатии, являясь одной из представительной групп некоронарогенных заболеваний миокарда, отличаются наиболее тяжелым течением с развитием сердечной 
недостаточности, нередко закончивающейся внезапной сердечной смертью [59, $60,61]$.

Повышенный интерес к проблеме изучения заболеваний миокарда объясняется необходимостью дальнейшего изучения этиологии и патогенеза; многообразием и неспецифичностью их клинических проявлений, значительными диагностическими и терапевтическими трудностями на протяжении многих лет, что обусловлено не только высокой смертностью, но и отсутствием единых подходов к диагностике и лечению больных с этой тяжелой патологией. КМП вносят значительный вклад в структуру сердечной недостаточности [55, 62, 63, 64, 65].

В последние годы наметилась тенденция к росту КМП у детей, что объясняется не только истинным увеличением случаев КМП, но и повышением качества диагностики с применением высокотехнологичных методов визуализации сердца, а также, с эволюцией взглядов на кардиомиопатии, как на нозологические единицы $[66,67]$.

У детей при проведении функциональных методов визуализации сердца не всегда возможно определение диагностически значимых признаков КМП. В этом случае для диагностики и прогноза СН в качестве альтернативного и дополнительного диагностического подхода рекомендуется определение в крови биомаркеров. Данный метод широко применяется во взрослой практике и зарекомендовал себя безопасным и объективным средством диагностики и прогноза прогрессирования и осложнений КМП [68, 69, 70, 71, 72, 73].

Braunwald E. в 2008 году предложил классификацию биомаркеров, имеющих значение в диагностике и лечении пациентов с CH: маркеры воспаления (C реактивный протеин, фактор некроза опухоли альфа, аполипопротеин 1, интерлейкины 1, 6 и 18), маркеры оксидативного стресса (окисленные липопротеины низкой плотности, миелопероксидаза, малондиальдегид и др.), маркеры ремоделирования внеклеточного матрикса (металлопротеиназы и их ингибиторы, проколлаген тип I и III и др.), нейрогормоны (катехоламины, ренин, альдостерон, эндотелин 1 и др.), маркеры 
повреждения кардиомиоцитов (тропонины, креатинфосфокиназа МВ (КФК МВ), белок, связывающий жирные кислоты и др.), маркеры миокардиального стресса (натрийуретические пептиды, проадреномедуллин, растворимая форма ST2 рецептора и др.) [74]. В настоящее время используются биомаркеры развития и прогрессирования $\mathrm{CH}$, которые отражают такие патофизиологические процессы, как апоптоз, воспаление и ремоделирование внеклеточного матрикса $[72,75,76$, $77,78]$.

Концепция молекулярных биомаркеров получила широкое развитие в последнее десятилетие. Использование биомаркеров вносит вклад в понимание патогенетических механизмов сердечно-сосудистых заболеваний и сердечной недостаточности [73]. Они являются надежным, безопасным и объективным средством диагностики и стратификации риска неблагоприятных событий, дополняющим клинические и инструментальные данные и отражающим особенности механизмов развития и прогрессирования заболевания у конкретного пациента $[71,79,80,81]$.

С целью изучения значения некоторых сывороточных биомаркеров в развития и прогнозирования КМП и сердечной недостаточности у детей были определены представители 3 групп биомаркеров (повреждения кардиомиоцитов, нейрогормонов и воспаления).

1.5.1. Роль маркеров повреждения кардиомиоцитов в развитии и прогнозе сердечной недостаточности при кардиомиопатиях у детей.

В последние годы в кардиологии все большее значение придается определению компонентов тропонинового комплекса кардиомиоцитов как наиболее чувствительному и специфичному биохимическому маркеру некроза миокарда $[71,82]$. Тропонины (I, T и C) в соотношении 1:1:1 входят в состав тропонинового комплекса, связанного с тропомиозином. Все три тропонина участвуют в кальций-зависимой регуляции акта сокращения-расслабления.

Имеются данные, что наследственные формы ГКМП, ДКМП и РКМП обусловлены мутациями сердечных тропонинов Т, I и С. На сегодняшний день обнаружено более 100 различных мутаций во всех 3 изоформах тропонина и 
число их продолжает расти, описываются новые случаи [69, 83]. У детей относительно недавно обнаружена мутация TNNT2 по типу двойной делеции аминокислот в положении 100 и 101 ( $\Delta \mathrm{N} 100 / \Delta \mathrm{E} 101)$, при которой была повышена чувствительность кардиомиоцитов к ионам кальция и нарушены белок-белковые взаимодействия между миофиламентами [84].

Кардиальный тропонин С в противоположность тропонинам Т и I совершенно идентичен по структуре мышечному тропонину С и, следовательно, не является кардиоспецифичным протеином. В настоящее время определение компонентов тропонинового комплекса кардиомиоцитов уже достаточно широко используется в кардиологической практике в основном для диагностики инфаркта миокарда (ИМ). Установлено, что тропонины $\mathrm{T}$ и I могут расцениваться и как поздние диагностические маркеры, позволяющие выявить «пропущенный» ИМ. Такая чувствительность тропонинов при высокой степени специфичности позволяет рассматривать эти миокардиальные маркеры как «золотые стандарты» в диагностике ИМ, имеющие явные преимущества перед КФК-МВ и ЛДГ. В 2000 г. ведущие кардиологические сообщества Европы и США утвердили тропонин как главный диагностический критерий ИМ [85].

В педиатрии определение тропонинов стали применять в последние несколько лет и, в основном, в неонатологии [86, 87, 88]. Исследования проводились у недоношенных и маловесных новорожденных с патологией ЦНС. Критерием исключения являлись врожденные пороки сердца (ВПС), нарушения сердечного ритма, генетические аномалии. Повышение уровня тропонинов отмечалось у детей в тяжелом состоянии (внутрижелудочковые кровоизлияния, длительная ИВЛ и др.). При СС3 у детей определение тропонина Т проводилось при ВПС. У данной группы пациентов в первые дни жизни отмечены повышенные значения тропонина Т и снижение его уровня на 2-3-й неделе [89]. Выявлено повышение уровня тропонина I у детей в возрасте от 3 до 16 лет с явлениями недостаточности кровообращения (НК) ІІБ-ІІІ степени с летальным исходом $[90,91]$. 
Учитывая, что к биохимическим маркерам повреждения миокарда относят среди прочих кардиоспецифический белок - тропонин-I, мы нашли целесообразным из трех тропонинов (I, T и C), входящих в состав тропонинового комплекса, провести исследования по определению степени значимости тропонина-I в качестве прогностического маркера КМП у детей.

Таблица 1

Показатели тропонина-I в зависимости от варианта КМП

\begin{tabular}{|l|c|c|c|c|c|c|}
\hline \multicolumn{1}{|c|}{ Показатель } & ДКМП & ГКМП & РКМП & $\mathrm{P}_{1}$ & $\mathrm{P}_{2}$ & $\mathrm{P}_{3}$ \\
\hline $\begin{array}{l}\text { Тропонин -I, } \\
(0-0,5 \text { нг/мл) }\end{array}$ & $0,2 \pm 0,019$ & $0,4 \pm 0,038$ & $0,4 \pm 0,05$ & $>0,05$ & $>0,05$ & $>0,05$ \\
\hline
\end{tabular}
допустимыми значениями ( $<0,001)$; $\mathrm{P}_{1}$ - достоверность разницы между показателями детей с ДКМП и ГКМП; Р 2 - достоверность разницы между показателями детей с ДКМП и РКМП; Р 3 - достоверность разницы между показателями детей с ГКМП и РКМП; .

Оценка состояния миокарда, включающая изучение содержания тропонина-I у детей с кардиомиопатиямив зависимости от варианта КМП, показала, что уровень тропонина-I независимо от нозологии достоверно не отличался от нормативных референсных показателей (табл. 1).

Таким образом, полученные результаты свидетельствуют, что тропонин-I не может быть использован в качестве биомаркера для диагностики и оценки течения КМП независимо от варианта КМП.

1.5.2. Роль нейрогормонального маркера - пептида эндотелин 1 в развитии сердечной недостаточности при кардиомиопатиях у детей.

В патогенезе СН при КМП и других СС3 существенную роль играет нейроэндокринная активация катехоламинов, натрийуретических пептидов и компонентов системы ренин-ангиотензина. Установлено, что при СН у больных с ДКМП изменена экспрессия генов многих классов, что ведет к изменению организации цитоскелета и миофибрилл, нарушению передачи сигналов, обмена протеинов и энергетики в миокарде [92, 93, 94, 95]. 
Эндотелин относится к числу биологически активных бициклических полипептидов широкого спектра действия и является одним из наиболее значимых регуляторов функционального состояния эндотелия сосудов [96, 97, 98].

Самым распространенным из семейства эндотелинов, а также самым мощным вазоконстриктором, который в 10 раз сильнее ангиотензина II и в 100 раз превышает эффект норадреналина, является эндотелин-1 [97, 99]. Установлено, что данный белок имеет большое сходство с токсическим компонентом яда пауков и некоторых видов змей. Пептид (сарафотоксин), полученный из яда змеи Atractaspis engaddensis имеет структурное и функциональное сходство с эндотелинами. При попадании сарафотоксина в кровь жертвы возникает коронароспазм, вплоть до остановки сердца [94].

Определение концентрации в плазме крови эндотелина-1 помогает установить диагноз СН на ранних стадиях заболевания, а концентрация церебрального натрийуретического пептида в крови является предиктором риска летального исхода у больных ДКМП [94].

В настоящее время известно, что вазоконстрикторный эффект, увеличение частоты и силы сердечных сокращений (хроно- и инотропные эффекты) эндотелина-1, а также потенцирование им роста и дифференцировки тканей реализуются путем активации двух типов рецепторов - ЭТ-А и ЭТ-В. ЭТ-А обладает высокой аффинностью к эндотелину-1 и эндотелину-2. У ЭТ-В нет предпочтительности, зато он имеет два подтипа - ЭТ-В1 и ЭТ-В2 $[100,101]$. Около десяти лет назад выделен еще один тип рецепторов эндотелина - ЭТ-С. Его структура и роль до конца не изучены. Но предполагается, что действие эндотелина-3 происходит именно через рецепторы ЭТ-С [102]. Подтипы рецепторов по-разному локализованы в сосудистой системе: ЭТ-А обнаруживаются в гладкомышечных клетках сосудов, кардиомиоцитах, в ткани мозга и в желудочно-кишечном тракте; ЭТ-В находятся в гладкомышечных клетках, в венечных сосудах, кардиомиоцитах, клетках юкстагломерулярного аппарата и в подвздошной кишке [94]. 
Существуют прямые и не прямые эффекты эндотелинов. К прямым эффектам относится воздействие на гладкие мышцы сосудов. При их взаимосвязи происходит вазоконстрикция, активация митогенеза, пролиферация клеток и фиброз интимы с повышением жесткости сосудов [97, 103]. К опосредованным - высвобождение из эндотелия вазоактивных факторов (оксида азота, простациклина и натрийуретического пептида предсердий), приводящих к релаксации сосудов [102]. Кроме этого, эндотелины влияют на секрецию гормонов гипофиза и надпочечников, подавляют эффекты вазопрессина в почках, а также увеличивают реакции сердца на симпатические стимулы, повышают сосудистую проницаемость, активируют нейтрофилы и тучные клетки. Эндотелины причастны к иммуномодулирующим эффектам, активируя Т-лимфоциты в вилочковой железе и усиливая иммунный ответ. Следует отметить о роли эндотелина-1 в качестве ингибитора апоптоза $[94,104]$.

Эндотелин-1 рассматривают, прежде всего, как маркер и предиктор тяжести и исхода ИМ и ИБС [101]. Следствием нарушений метаболизма и сократительной функции миокарда являются изменения сердечного ритма, приводящие к развитию фибрилляций [104]. Считается, что эндотелин-1 причастен к легочной гипертензии, атеросклеротическому повреждению сосудов, послеродовым сосудистым осложнениям, поражению почек при гломерулонефрите, ишемическим повреждениям мозга, сахарному диабету [105, $106,107]$.

ЭТ-1 обладает широким спектром провоспалительных эффектов, выходящих за рамки его вазоконстрикторной активности. Показано, что гиперпродукция ЭТ-1 приводит к усилению апоптоза кардиомиоцитов и может способствовать увеличению постнагрузки ЛЖ, снижению сердечного выброса, а также индуцирует процессы ремоделирования миокарда и способствует прогрессированию СН [94].

Подобное многообразие функций эндотелина, а также недостаточная изученность данного пептида позволяет считать исследование по определению 
его в диагностической и прогностической значимости при КМП у детей актуальным.

Эндотелин относится к числу биологически активных бициклических полипептидов широкого спектра действия, различают три изоформы эндотелина: эндотелина-1, эндотелин-2 и эндотелин-3 [48, 94]. На сегодняшний день эндотелин-1 является одним из наиболее значимых регуляторов функционального состояния эндотелия сосудов [94]. Определение концентрации в плазме крови эндотелина-1 помогает установить диагноз сердечной недостаточности на ранних стадиях заболевания.

На основании этих данных мы нашли целесообразным определить степень значимости эндотелина-1 в качестве прогностического биомаркера КМП и сердечной недостаточности у детей.

Результаты наших исследований выявили высокие показатели эндотелина1 у больных с выраженной $\mathrm{CH}$, т.е. уровень эндотелина-1 достоверно увеличивается по мере прогрессирования заболевания, что свидетельствует о значимости данного показателя в прогнозировании течения и исхода КМП у детей (рис.1).

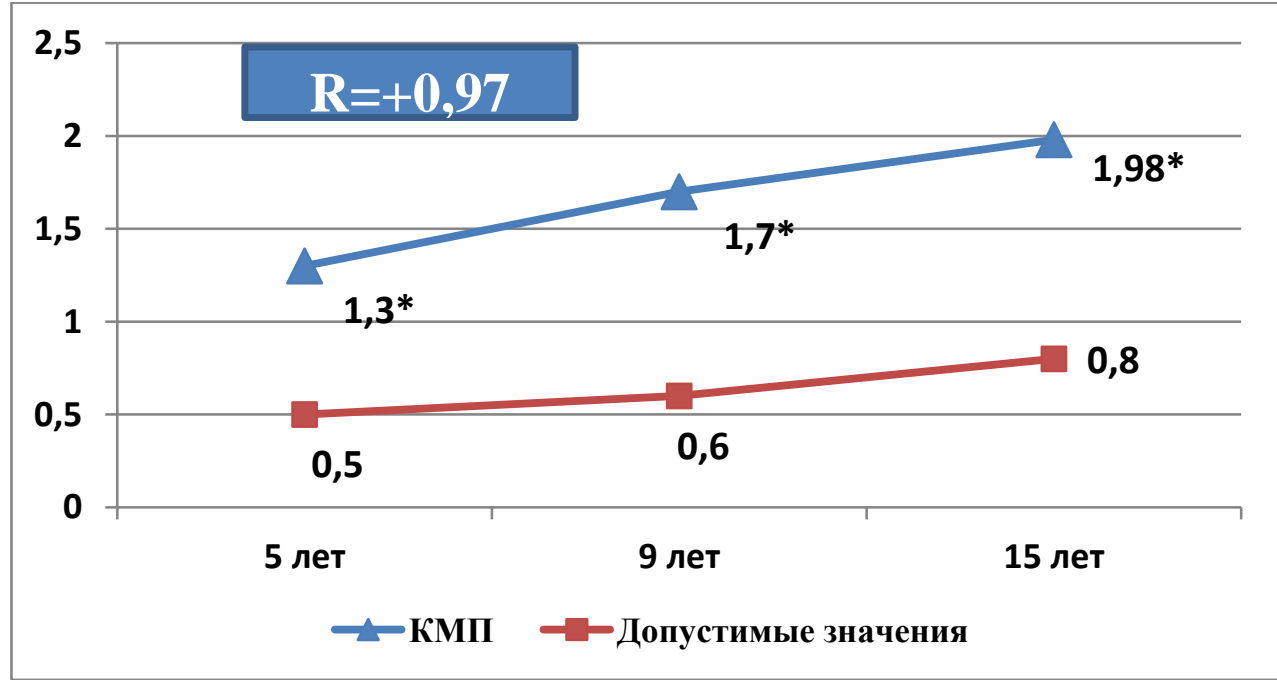

Примечание: *- достоверность разности между показателями детей с КМП и допустимыми значениями.

Рис. 1. Показатели эндотелина-1 в зависимости от давности заболевания.

Как видно из рис.1, у больных с давностью заболевания 5 лет уровень эндотелина-1 в среднем составил 1,3 $\pm 0,08$ фмоль/л, что всего в 1,3 раза 
превышает верхнюю границу допустимых значений, больных с давностью заболевания 9 лет, средний показатель уровня эндотелина-1 составил 1,7士 0,1 фмоль/л и превысил референтные значения в 1,7 раза, а у больных с давностью

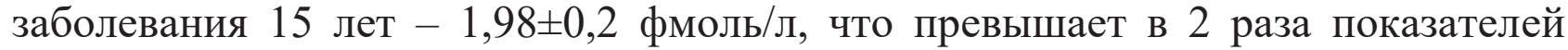
нормы. Корреляционный анализ между давностью КМП, степени тяжести СН и уровнем эндотелина-1 выявил наличие сильной прямой корреляционной связи $(\mathrm{r}=+0,97)$. В связи с этим, уровень эндотелина-1 можно расценивать прогностическим критерием течения и исхода КМП.

В дальнейшем для оценки состояния миокарда у детей с КМП нами был проведен анализ эндотелина-1 в зависимости от варианта КМП свидетельствовал о том, что при кардиомиопатиях уровень эндотелина-1 был повышенным при всех формах кардиомиопатий (табл. 2). Уровень эндотелина-1 был выше у детей с ГКМП (p<0,05), по сравнению с показателем детей с ДКМП и РКМП.

Таблица 2

Показатели эндотелина-1 в зависимости от варианта КМП

\begin{tabular}{|l|c|c|c|c|c|c|}
\hline \multicolumn{1}{|c|}{ Показатели } & ДКМП & ГКМП & РКМП & $\mathrm{P}_{1}$ & $\mathrm{P}_{2}$ & $\mathrm{P}_{3}$ \\
\hline $\begin{array}{l}\text { Эндотелин- } 1, \\
(0,1-1,0 \text { фмоль/л) }\end{array}$ & $1,75 \pm 0,1^{*}$ & $1,61 \pm 0,2^{*}$ & $1,67 \pm 0,3^{*}$ & $<0,05$ & $<0,05$ & $>0,05$ \\
\hline
\end{tabular}

Примечание:*- достоверность различий между показателями детей с КМП и допустимыми значениями $(\mathrm{P}<0,001) ; \mathrm{P}_{1}$ - достоверность разницы между показателями детей с ДКМП и ГКМП; Р 2 - достоверность разницы между показателями детей с ДКМП и РКМП; Р - достоверность разницы между показателями детей с ГКМП и РКМП .

На основании этого можно заключить, что эндотелин-1 можно расценивать высокоспецифичным биомаркером поражения миокарда, а возрастание его активности по мере увеличения давности заболевания - критериями прогрессирования СН и исхода кардиомиопатий у детей.

1.5.3. Иммунологические аспекты в прогрессировании сердечной недостаточности при кардиомиопатиях у детей

В последние годы предложена новая концепция прогрессирования $\mathrm{CH}$, в основе которой лежит представление об иммунной активации и системном воспалении как о маркерах неблагоприятного прогноза и высокого 
кардиоваскулярного риска. Согласно этой концепции, происходит увеличение синтеза провоспалительных цитокинов, определяющих эволюцию дисфункции ЛЖ $[108,109,110,111]$.

Цитокины, являясь регулятором защитных реакций организма, усиливают эффекторные механизмы элиминации чужеродного антигена, регулируют воспаление и регенерацию [112]. Ряд цитокинов обладает способностью инициировать и стимулировать воспалительные реакции (IL-1, IL-6, IL-8, IL-12, IL-16, IL-18, TNF- $\alpha$, IFN- $\alpha$, IFN- $\gamma$ ), тогда как другие (IL-4, IL-10, IL-13) подавляют их $[108,113,114]$. Цитокины способны существовать не только в форме циркулирующих молекул, но и в связанной форме (IL- $1 \alpha$, TNF- $\alpha$ ). В целом цитокины - это сигнальные молекулы, играющие ключевую роль в иммунной системе в норме и при патологии [112]. Формирование и развитие СН тесно связано с нарушением сложных процессов цитокин-индуцированной передачи внеклеточной информации внутрь кардиомиоцита. Цитокины, регулируя синтез белков и фосфолипидов, способны активировать внутриклеточные сигнальные системы, включая апоптоз, систему регуляции внутриклеточного кальция и тем самым, изменять процессы сокращения и расслабления миокарда. $[115,116]$.

Неспецифическая активация макрофагов и моноцитов в плазме и межтканевой жидкости является индуктором синтеза провоспалительных цитокинов, определяющих степень дисфункции ЛЖ. Предполагается, что провоспалительные цитокины играют важную роль в прогрессировании $\mathrm{CH}$, определяя состояние структурных белков миофибрилл и цитоскелет кардиомиоцита $[115,117]$

Содержание цитокинов в плазме крови больных с ХCH, независимо от ее этиологии, значительно превышает нормальные значения [108, 117]. Усиление застоя и нарастающая гипоксия периферических тканей и самого миокарда, свойственные ХCH, вполне могут стать первопричиной активации иммунной системы и приводить к росту TNF- $\alpha$ и других провоспалительных цитокинов. Такая «последовательность» событий косвенно подтверждается прямо пропорциональной зависимостью между уровнем TNF- $\alpha$ и тяжестью XCH: чем 
выше ХCH, тем более выражена реакция иммунной системы и выше уровень цитокинов. И, наоборот, уменьшение степени гипоксии понижает активность иммунного ответа [115, 118$]$.

На сегодняшний день очевидно, что это влияние складывается по крайней мере из четырех ключевых составляющих [118]: 1) отрицательного инотропного действия; 2) ремоделирования сердца (необратимая дилатация полостей и гипертрофия кардиомиоцитов; 3) нарушения эндотелий-зависимой дилатации артериол; 4) усиления процесса апоптоза кардиомиоцитов и клеток периферической мускулатуры.

Известно [118], что цитокины также могут играть важную роль в реализации процессов гиперкоагуляции крови, нарушений регулирования сосудистого тонуса, развития острых коронарных синдромов, индукции метаболических процессов в скелетных мышцах и прогрессирования мышечной дистрофии (развитие синдрома кардиальной кахексии). Предполагается, что негативное действие цитокинов лежит в основе таких характерных гемодинамических признаков ХСН, как низкий сердечный выброс и высокое внутрисердечное давление, а в сочетании с нарушением сосудодвигательной функции эндотелия резистивных сосудов - быть причиной гипотонии, свойственной поздним стадиям сердечной недостаточности, а также снижения толерантности к физической нагрузке и уменьшения силы и выносливости скелетной мускулатуры. Наиболее важными для формирования синдрома ХСН являются «долговременные» эффекты провоспалительных цитокинов, проявляющиеся постепенным разрушением внеклеточного коллагенового матрикса миокарда, дилатацией желудочков и гипертрофией кардиомиоцитов [115, 118$]$.

Таким образом, провоспалительные цитокины являются наиболее важным классом биологически активных веществ, оказывающих иммунное и/или воспалительное действие и имеющих отношение к сердечной недостаточности. К основным провоспалительным цитокинам относятся фактор некроза опухоли$\alpha(\mathrm{TNF}-\alpha)$, интерлейкин 1 (IL-1 $\beta)$ и IL-6 [115, 117, 118]. 
TNF- $\alpha$ является наиболее «важным» маркером развития СН. Прямая связь TNF- $\alpha$ с синдромом CH была установлена в 1990 г. Levine и соавт. [119] впервые показали, что уровень TNF- $\alpha$ в сыворотке больных с тяжелой CH (ФК III-IV по NYHA) на порядок выше, чем у здоровых лиц: Причем повышение активности TNF- $\alpha$ было более выраженным у пациентов с более тяжелыми клиническим и проявлениями декомпенсации, большей степенью кахексии (массой тела $82 \%$ от идеального) и повышенной активностью PAAC $[108,115]$. Влияние TNF- $\alpha$ на прогрессирование СН реализуется путем прямого повреждающего действия на кардиомиоциты, индуцируя процесс их запрограммированной гибели (апоптоз). Кроме того, TNF- $\alpha$ усиливает процессы окислительного стресса кардиомиоцитов [120]. TNF- $\alpha$ проявляет свою биологическую активность после связывания со специфическими мембранными рецепторами $[108,115]$.

Избыточная продукция TNF- $\alpha$ вызывает расстройства гемодинамики и оказывает цитотоксический эффект на клетки организма $[115,121]$.

TNF- $\alpha$ усиливает пролиферацию T- и В-клеток, цитотоксических лимфоцитов, фагоцитоз, индуцирует синтез IL-1 $\beta$, IL-6, IL-2, хемоаттрактантов, адгезивных молекул, острофазных белков, активирует фибробласты, синтез коллагена и коагуляцию. TNF- $\alpha$ стимулирует адгезию моноцитов и лимфоцитов (in vitro) к мезангиальным клеткам, индуцируя экспрессию ICAM-1 [115].

Интерлейкин-1 (IL-1 $\beta$ ) - провоспалительный цитокин, имеющий отношение к $\mathrm{CH}$, играет центральную роль в локальном исистемном, остром и хроническом воспалении. IL-1 $\beta$, кроме эндотелиальных клеток, синтезируется также макрофагами, моноцитами, нейтрофилами, глиальными клетками, фибробластами, Т- и В-лимфоцитами. Как сигнальная молекула, обеспечивает межклеточные взаимодействия, которые в совокупности приводят к формированию воспалительной реакции посредством: экспрессии белков острой фазы воспаления в гепатоцитах, активации нейтрофилов, воздействия на Tхелперы и стимуляции каскада провоспалительных субстанций, прямого провоспалительного влияния на эндотелиальные гладкомышечные клетки и макрофаги, усиления адгезии лейкоцитов к эндотелию, обеспечения ихмиграции 
через сосудистую стенку, стимуляции экспрессии адгезивных молекул $[115,117$, $118]$.

Известно, что провоспалительный цитокин IL-1 $\beta$ продуцируется клетками воспаления, вызывает высвобождение и экспрессию других воспалительных медиаторов (цитокинов/факторов роста, хемокинов, биоактивных липидов, металлопротеиназ и активных радикалов кислорода, адгезивных рецепторов), пролиферацию резидентных клеток, накопление экстрацеллюлярного матрикса $[117,121]$.

У больных с XCH также отмечаются изменения концентрации IL-6. Интерлейкин-6синтезируется многими клетками (макрофаги, моноциты, Т- и Влимфоциты и др.), является одним из мощнейших факторов, вызывающих дисфункцию эндотелия. Его продукция стимулируется IL-1 $\beta$ и TNF- $\alpha$. Гиперэкспрессия IL-6 выявляется в кардиомиоцитах на фоне гипоксического стресса. Кроме того, IL-6 вызывает отрицательный инотропный эффект, гиперэкспрессияIL-6 рецепторов приводит к гипертрофии миокарда. Увеличение концентрации IL-6 являлось маркером неблагоприятного прогноза и коррелировало с функциональным классом ХСН $[115,118,121]$.

Представляются важными и данные о том, что повышенная экспрессия медиаторов воспаления (TNF- $\alpha$, IL-1 $\beta$, IL-6, молекулы адгезии) наблюдается не только в крови, но и в миокарде $[115,117]$. Усиленная миокардиальная экспрессия цитокинов, обнаруживаемая при дисфункции миокарда, предполагает центральную роль цитокинов в развитии процессов ремоделирования миокарда и возникновении ХCH.

Предположение о способности цитокинов, в частности TNF- $\alpha$, индуцировать ремоделирование миокарда с прогрессирующим снижением его сократимости, подтверждается данными литературы [117, 122], в которых установлена взаимосвязь TNF- $\alpha$ c гемодинамическими параметрами и продемонстрирована его гиперэкспрессия у больных с дезадаптивной формой ремоделирования миокарда. 
Молекулярные механизмы развития цитокин-индуцируемого ремоделирования миокарда еще не ясны, но, возможно, определяются синергической активностью цитокинов в отношении экспрессии «индуцируемой» формы синтазы оксида азота (NoS2) в кардиомиоцитах и эндотелиоцитах. Получены данные, что «индуцируемая» синтаза оксида азота ответственна за состояние миокарда, именуемое «гибернацией». В связи с этим определенный интерес представляет изучение роли провоспалительных цитокинов в процессах деструкции миокардиальной ткани у детей на разных стадиях развития СН [118].

Существует несколько взаимосвязанных компонентов иммунной системы, которые могут быть задействованы в патогенезе сердечной недостаточности, и главными из них являются провоспалительные цитокины (TNF- $\alpha$, IL-1 $\beta$, IL-6), молекулы адгезии, аутоантитела, оксид азота, эндотелины [115, 119].

В настоящее время используются биомаркеры развития и прогрессирования сердечной недостаточности, которые отражают такие патофизиологические процессы, как апоптоз, воспаление и ремоделирование внеклеточного матрикса [120]. Наиболее важным классом биологически активных веществ, оказывающих иммуновоспалительное действие, являются провоспалительные цитокины.

Сравнительный анализ содержания провоспалительных цитокинов у больных с кардиомиопатиями выявил выраженные изменения продукции IL-1 $\beta$ и IL-6 в зависимости от стадии сердечной недостаточности. Как видно из табл.3, у обследованных детей получены достоверные отличия концентраций указанных показателей от нормальных значений. Установлена незначительная гиперпродукция IL-1 $\beta$ у пациентов с СН IIБ-III ст. при ДКМП, с CH IIБ ст. при ГКМП. У детей с ДКМП и ГКМП отмечена максимальная концентрация IL-6 и TNF- $\alpha$ при CH IIA стадии и выраженной СН IIБ-III стадии при ДКМП. 
Таблица 3

Содержание интерлейкинов при различных стадиях СН у детей с кардиомиопатиями

\begin{tabular}{|l|c|c|c|}
\hline Группы детей & IL-1 $\beta$, пг/мл & IL-6, пг/мл & TNF- $\alpha$, пг/мл \\
\hline ДКМП,СН І ст. & $1,5 \pm 0,3^{*}$ & $6,8 \pm 1,4^{\wedge}$ & $6,9 \pm 0,2^{* \wedge}$ \\
\hline ДКМП,СНІА & $1,6 \pm 0,4$ & $21,7 \pm 1,8^{*} \wedge$ & $11,5 \pm 0,3^{*}$ \\
\hline ДКМП, СН ІІБ-III ст. & $2,9 \pm 0,2$ & $30,7 \pm 4,3^{* \wedge}$ & $12,6 \pm 0,4^{*}$ \\
\hline ГКМП, СН І ст. & $1,9 \pm 0,2$ & $9,88 \pm 0,8^{*}$ & $9,8 \pm 0,4^{*}$ \\
\hline ГКМП, СН ІІА ст. & $2,8 \pm 0,4$ & $14,75 \pm 1,5^{*}$ & $11,9 \pm 1,1^{*}$ \\
\hline ГКМП, СН ІІБ ст. & $3,1 \pm 0,3^{*}$ & $26,3 \pm 2,3^{*}$ & $13,7 \pm 1,4^{*}$ \\
\hline Референсные значения & $0,00-2,34$ & $0,00-2,13$ & $2,28-7,81$ \\
\hline Корреляционные взаимосвязи & $\mathrm{R}=+0,89$ & $\mathrm{R}=+0,99$ & $\mathrm{R}=+0,73$ \\
\hline
\end{tabular}

Примечание: * - достоверность относительно показателей здоровых детей; ^ достоверность разницы между показателями при различной стадии СН в зависимости от формы КМП.

Высокий уровень провоспалительных цитокинов, особенно TNF- $\alpha$ оказывает повреждающее действие на миокард. Данный цитокин способен индуцировать процесс запрограмированной гибели кардиомиоцитов, под влиянием гиперпродукции TNF- $\alpha$ происходит активация металлопротеиназ, индуцирующих разрушение фибриллярного коллагенового матрикса, что способствует ремоделированию миокарда и формирования отрицательного инотропного эффекта $[120,123]$.

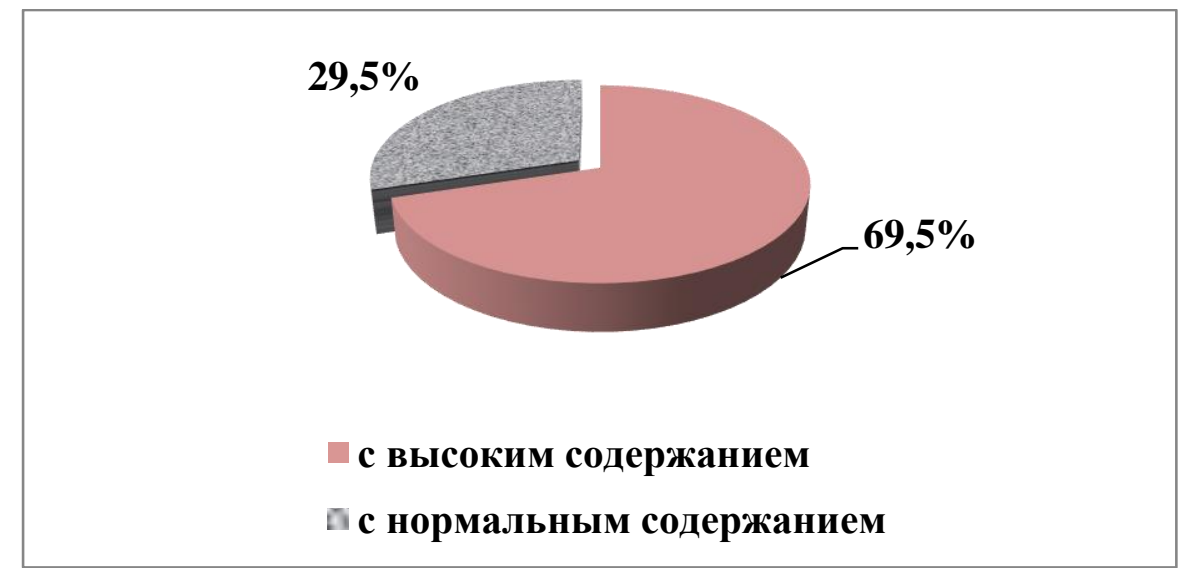

\section{Рис.2. Количество детей с КМП с высоким и нормальным содержанием TNF- $\alpha$ в сыворотке крови}

В исследованиях выявлена способность самих кардиомиоцитов к продукции фактора некроза опухоли (TNF- $\alpha$ ), при этом, количество цитокина находится в прямой зависимости от степени напряжения миокарда. Длительная активация симпатоадреналовой системы приводит к перегрузке митохондрий 
кардиомиоцитов кальцием, что замедляет процессы рефосфорилирования аденозиндифосфата и нарушает процессы сократимости и расслабления [115]. Изучение содержания TNF- $\alpha$ в сыворотке крови у детей с КМП показало его значительное повышение относительно нормы. Высокий уровень содержания TNF- $\alpha$ был выявлен у 69,5\% больных (рис.2).

Так, если умеренная гипоксия сопровождается значительным повышением уровня TNF- $\alpha$ в сыворотке крови, то в случае тяжелой гипоксии у этих детей его уровень был повышен $(\mathrm{p}<0,05)$.

Так, при умеренной гипоксии уровень TNF- $\alpha$ в сыворотке крови колебался от 8 до 12,4 пг/мл и среднее содержание его было выше $(9,2 \pm 0,87$ пг/мл, p<0,001) показателей нормы (2,28-7,81 пг/мл), в случае тяжелой гипоксии у этих детей средний уровень TNF- $\alpha$ был достаточно высоким $(15,7 \pm 1,2$ пг/мл, p $<0,01)$ и колебался в пределах 12,7-17,5 пг/мл (рис.3). Более выраженное повышение TNF- $\alpha$ отмечалось ДКМП с сердечной недостаточностью IIБ - III степени $(17,1 \pm 1,6$ пг/мЛ, $\mathrm{p}<0,01)$.

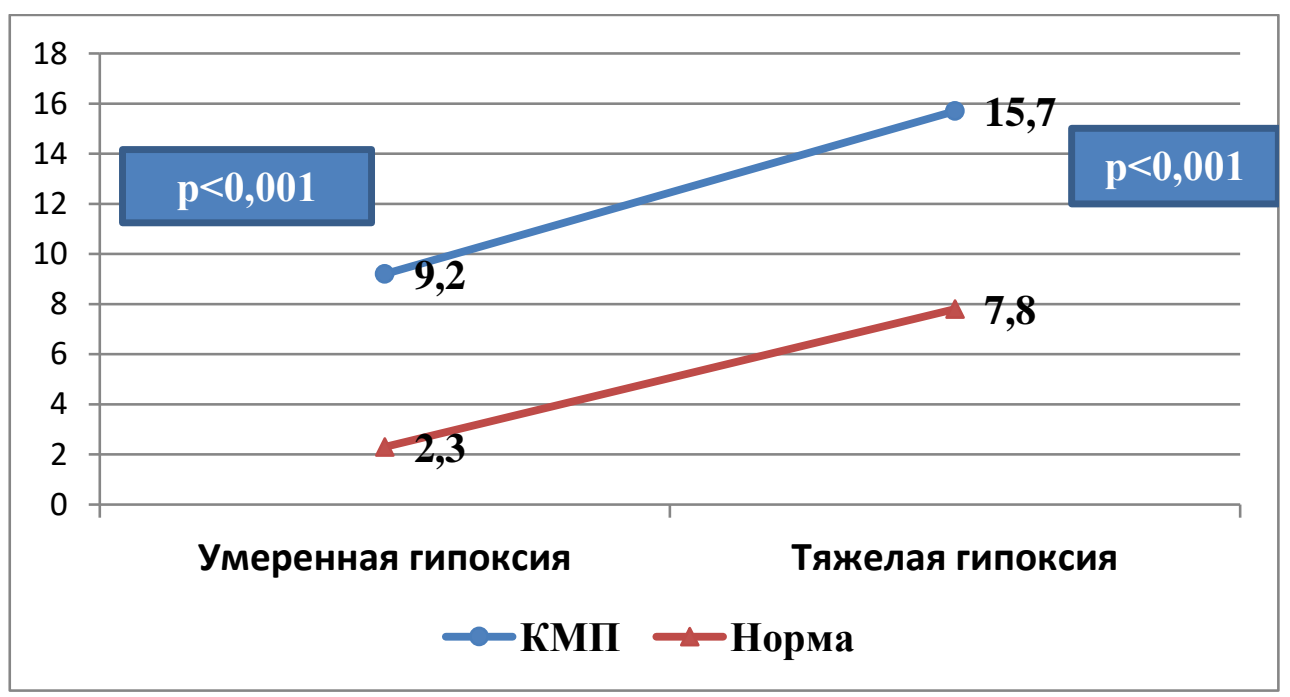

Примечание: р-достоверность различий между показателями детей с КМП и нормой.

\section{Рис.3. Уровень TNF- $\alpha$ у детей с кардиомиопатиями в зависимости от степени гипоксии}

Таким образом, усиление застоя и нарастающая гипоксия периферических тканей и самого миокарда, свойственные $\mathrm{CH}$, вполне могут стать первопричиной активации иммунной системы и приводить к росту TNF- $\alpha$ и других провоспалительных цитокинов. Такая "последовательность" событий косвенно 
подтверждается прямопропорциональной зависимостью между уровнем TNF- $\alpha$ и тяжестью $\mathrm{CH}$ : чем выше стадия $\mathrm{CH}$, тем более выражена реакция иммунной системы и выше уровень цитокинов. И, наоборот, уменьшение степени гипоксии понижает активность иммунного ответа.

Изучение молекулярных механизмов управления процессами неоваскуляризации также представляет собой одну из наиболее актуальных проблем. Многие патологические и физиологические процессы в органах и тканях протекают с участием семейства факторов роста эндотелия сосудов (vascular endothelial growth factor - VEGF), которое включает VEGF A, VEGF B, VEGF C, VEGF D и плацентарный фактор роста [124, 125]. VEGF А играет ведущую роль в регуляции ангиогенеза. Синтез этого фактора активируется в условиях гипоксии за счет увеличения периода полураспада матричной мРНК, а также за счет усиления транскрипции гена. При длительно существующей ишемии происходит накопление как самого фактора, так и мРНК, что доказывает положительную обратную связь между ишемией и синтезом VEGF $[125,126$, $127,128]$.

Повышение VEGF обусловливает повреждение сосудистой стенки, повышая их проницаемость и усиливая пролиферацию эндотелиальных клеток с формированием микроаневризм, а в пролиферативной стадии - рост новообразованных сосудов $[129,130]$. Вышеизложенное дает основание полагать, что экспрессия VEGF проходит последовательные фазы в зависимости от стадии основного заболевания. VEGF А является не только ведущим фактором ангиогенеза, но и критерием прогноза сосудистых катастроф в организме человека [131].

Роль семейства VEGF и TNF- $\alpha$ в развитии различных патологических процессов, в том числе и КМП изучена недостаточно, многие аспекты влияния этих факторов на развитие и течение КМП требуют дальнейшего изучения.

При гипоксии повышается уровень гипоксия-индуцибельного фактора-1альфа (HIF-1 $\alpha)$, который активирует его экспрессию. VEGF повышает 
проницаемость сосудов, ведет к дезорганизации сосудистой стенки $[124,125$, $126,128]$.

Анализ результатов показал, что у детей с КМП уровень VEGF превышал нормальные значения в 2-4,5 раза у 95,5\% больных (рис.4).

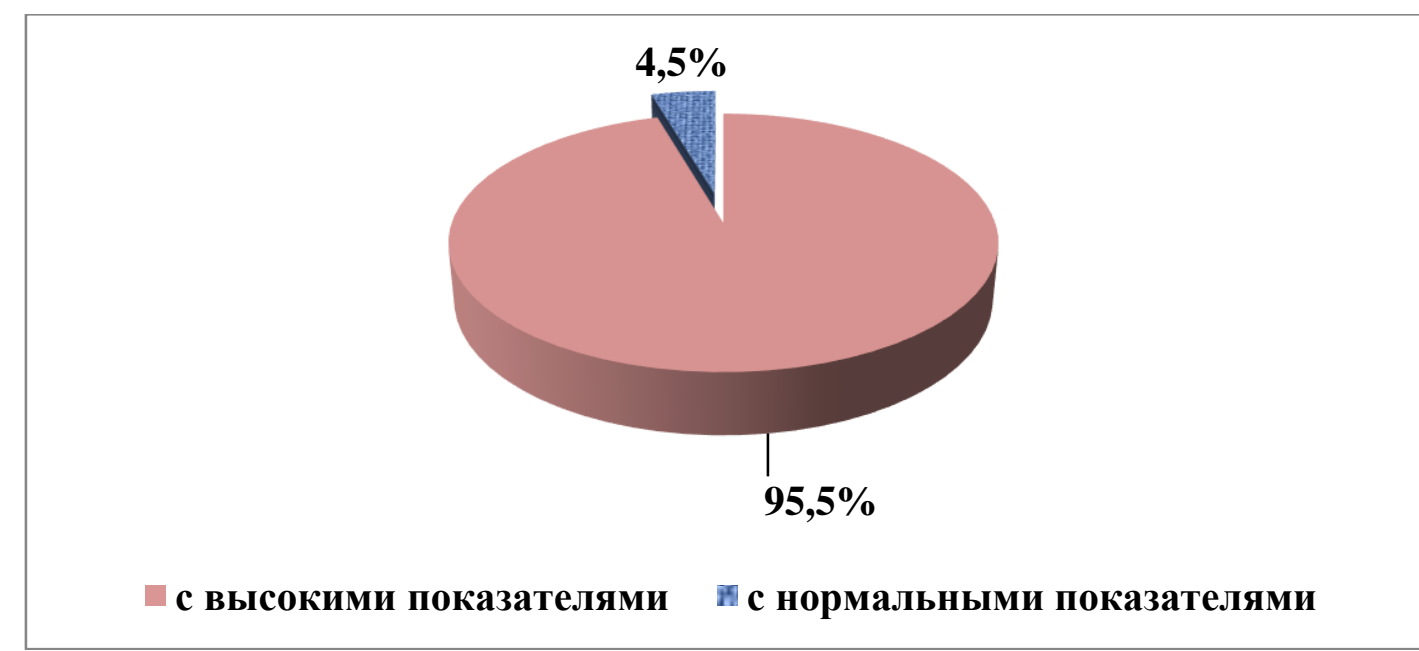

Рис.4. Количество детей с высоким и нормальным содержанием VEGF в сыворотке крови.

С целью определения признаков ремоделирования миокарда нами изучены структурно-функциональные характеристики миокарда ЛЖ у обследованных детей, которые показали сохранность нормальных показателей морфологии миокарда лишь у 7,9\% больных с КМП. Структурно-функциональные изменения миокарда ЛЖ проявлялись развитием асимметричной и симметричной гипертрофией межжелудочковой перегородки, гипертрофией верхушечной, задне-перегородочной или боковой стенки левого желудочка и увеличением массы миокарда у 34,6\% больных, а также уменьшением полости левого желудочка, связанное с гипертрофией миокарда, который является морфологическим признаком ГКМП и одним из факторов, способствующих нарушению гемодинамики за счет недостаточного наполнения левого желудочка во время диастолы. Развитие гипертрофии миокарда ЛЖ сопровождалось снижением величины фракции выброса за счет отсутствия активации компенсаторных возможностей миокарда. Дилатационные изменения левого желудочка выявлены почти у 46\% детей с ДКМП и левого предсердия у 11,5\% детей с ГКМП. Это сопровождалось снижением показателей сократимости 
левого желудочка (ФВ ЛЖ<30—40\%), митральная и трикуспидальная регургитация, нарушение диастолической функции левого желудочка за счет удлинения фазы его изометрического расслабления и повышения конечного диастолического давления в его полости.

Корреляционный анализ сывороточного содержания изученных цитокинов показал тесную корреляционную зависимость их концентраций от степени эхокардиографических изменений сердца. У детей с СН при ДКМП выявлена зависимость степени дилатации ЛЖ от уровня IL-1 $\beta$ и IL-6: конечного диастолического размера (КДР) от концентрации IL-1 $\beta$ (КДР-IL1 $\beta, \mathrm{r}=0,52$; $\mathrm{p}<0,05$. Установлена обратная связь между параметром фракции изгнания и IL-6 $(\mathrm{r}=-0,48)$.

Таким образом, нейрогормональный маркер эндотелин-1, маркеры воспаления IL-1 $\beta$, IL-6, TNF- $\alpha$ и эндотелиальный фактор роста VEGF являются диагностическими и прогностическими критериями развития и прогрессирования кардиомиопатий и сердечной недостаточности независимо от варианта кардиомипатий. Данные биомаркеры играют важную роль в прогрессировании сердечной недостаточности, определяя интенсивность процессов ремоделирования миокарда посредством регулирования уровня апоптоза и следующего за ними заместительного фиброза в сердце, что является причиной нарушения его структуры и несостоятельности сократительного аппарата при прогрессировании сердечной недостаточности. Дальнейшее изучение биомаркеров в развитии и прогнозировании КМП и СН позволит понять их комплексное воздействие на организм и получить данные по определению новых биологических критериев прогнозирования течения и исходов КМП у детей. 
DOI 10.46299/ISG.2021.MONO.MED.III.1.6

\section{6 Вплив піднебінних мигдаликів на стан гуморальних чинників локального імунітету в області ротоглотки у хворих на хронічні запальні захворювання верхніх дихальних шляхів при інфікуванні вірусами респіраторної групи}

Гострі респіраторні захворювання верхніх дихальних шляхів (ВДШ), які у переважній більшості випадків обумовлені вірусами [132], особливо при частому повторенні знижують місцевий і загальний імунітет, послаблюючи специфічні і неспецифічні захисні сили організму, нерідко зумовлюють нашарування бактеріальної інфекції внаслідок активації ендогенної мікрофлори або екзогенного інфікування, що спричиняє розвитку захворювань по типу віруснобактеріальної інфекції [133]. Рецидивуючі респіраторні захворювання сприяють формуванню хронічної патології рото- та носоглотки [134], що в свою чергу підримує порушення захисних механізмів організму [135].

Мигдалики лімфаденоїдного глоткового кільця (ЛГК) виконують функцію імунологічного захисту організму, а відсутність піднебінних мигдаликів (ПМ), які беруть участь у реалізації організмом його захисної функції, негативно впливає на стан як місцевого так і системного імунітету [136].

Метою нашого дослідження було визначення ролі піднебінних мигдаликів в реалізації локальних гуморальних реакцій у хворих на хронічні запальні захворювання (Х33) ВДШ з локалізацією патологічного процесу у слизовій оболонці та лімфоутвореннях глотки - у хворих на хронічний фарингіт та хронічний тонзиліт.

Вираженість реакцій локального імунітету пацієнтів 3 хронічними запальними захворюваннями ротоглотки в стадії ремісії та у осіб контрольної групи оцінювали 3 урахуванням як стану ЛГК, так i наявності в крові анамнестичних противірусних антитіл (АТ) у клінічно значимих концентраціях. Присутність таких АТ розглядалась як прояв відповіді організму на вірусні антигени, з якими пацієнт активно контактував або контактує на час проведення дослідження. Обстежених осіб поділяли на таких, що мали піднебінні мигдалики, і тих, в кого вони були вилучені хірургічним шляхом за медичними 
показаннями не раніше, ніж за п’ять років до проведення дослідження.

Вивчаючи потенційний вплив контактів з респіраторними вірусами на показники локального імунітету ротової частини глотки, пацієнтів 3 наявністю або відсутністю ПМ розподіляли на таких, що мали в крові анамнестичні антитіла до одного або кількох 3 досліджених респіраторних вірусів, а саме: аденовірусу, респіраторно-синцитіального вірусу та вірусу грипу А у клінічно значимому титрі, та таких, у кого такі АТ не виявлялись. Контрольну групу склали клінічно здорові пацієнти без патології з боку ЛОР-органів.

Стан локального гуморального імунітету ротоглотки пацієнтів оцінювався за вмістом в секреті ротоглотки (СР) імунних комплексів (IК) та концентрацій секреторного імуноглобуліну А (sIgA), інтерферонів альфа ( $\alpha$-IFN) та гамма ( $\gamma$ IFN), які визначали імуноферментним методом. Всі обстежені пацієнти мали санований стан ротової порожнини.

Для статистичних розрахунків використовувався пакет ліцензійних програм STATISTICA 6.0 (Ліцензія - Free BSD). Достовірність розбіжностей отриманих даних визначалась за допомогою однобічного непараметричного критерію «U»- Манна-Уітні та критерію ф за методом кутового перетворення Фішера. Результати наводились у вигляді значень середнього арифметичного (M), медіани (Me) та квартілей (Q25-Q75). Кількість проведених досліджень позначалась як $\mathrm{n}$. При оцінці отриманих результатів порівнювались значення Ме. Достовірною вважалась розбіжність при р $<0,05$.

Важливим елементом місцевого імунітету, що захищає слизові оболонки (CO) як від заселення їх патогенними мікроорганізмами, так і від проникнення останніх до внутрішнього середовища організму, є секреторний IgA. Дослідженнями, що визначали вміст sIgA у ротоглотковому секреті хворих на хронічні запальні захворювання ротоглотки в стадії ремісії та клінічно здорових осіб в залежності від стану лімфоглоткового кільця та наявності у крові АТ до одного або кількох респіраторних вірусів, встановлено, що у практично здорових осіб контрольної групи з відсутністю піднебінних мигдаликів концентрація SIgA у секреті ротоглотки була суттєво 
зменшеною в порівнянні з такою у пацієнтів зі збереженими піднебінними мигдаликами (табл. 1).

Таблиця 1.

Вміст $\operatorname{sg}$ A у секреті ротоглотки осіб контрольної групи за наявності або відсутності у них піднебінних мигдаликів та противірусних антитіл

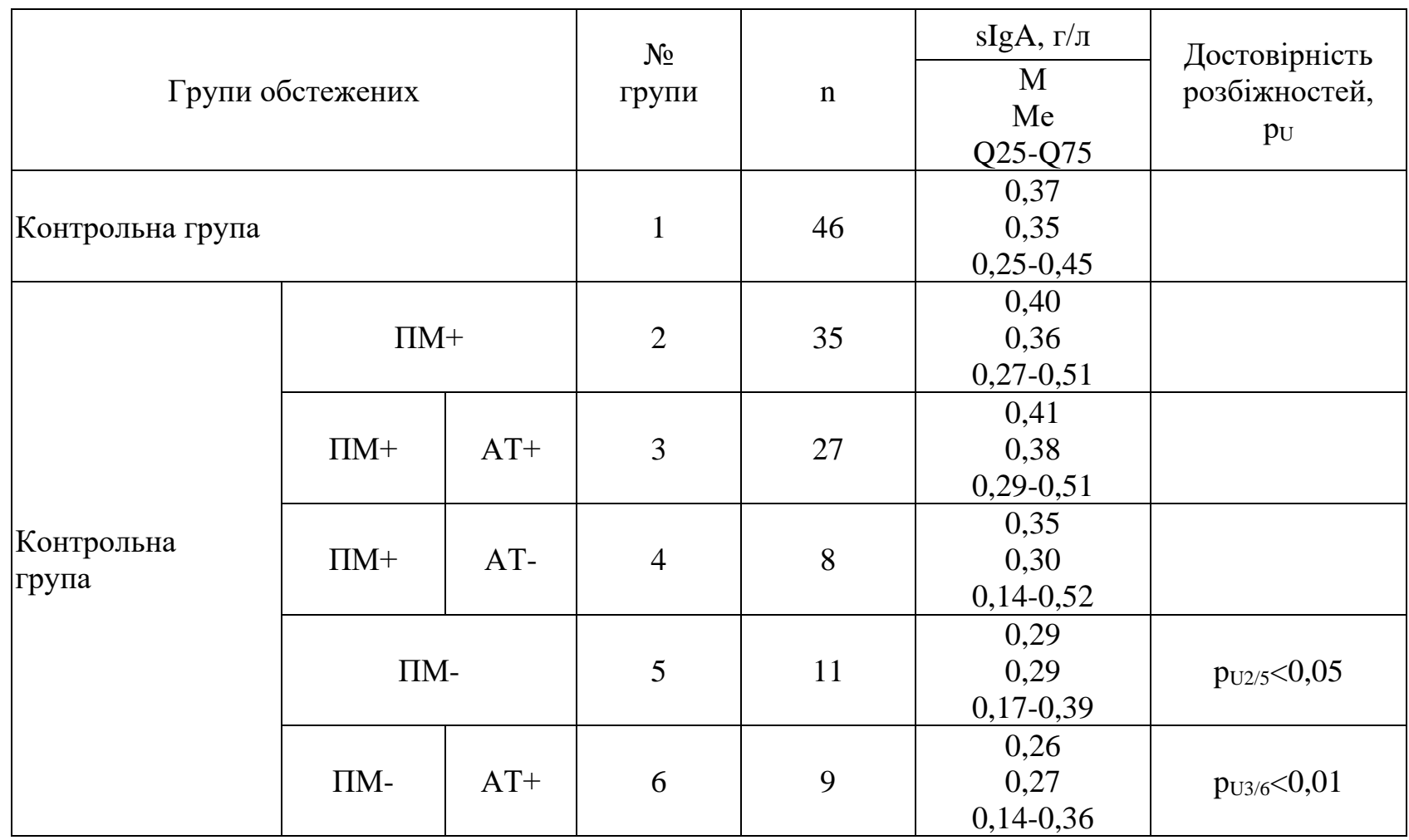

При цьому вміст $\operatorname{sg}$ А у CP тонзилектомованих пацієнтів, у яких в крові визначались противірусні АТ, був вірогідно нижче такого у обстежених осіб 3 наявністю АТ до респіраторних вірусів на тлі незміненого стану піднебінних мигдаликів.

Концентрація SIgA у РС хворих на ХЗ3 РГ суттєво не відрізнялась від такої у клінічно здорових обстежених в усіх групах порівняння (табл. 2). 
Таблиця 2.

Вміст sIgA у секреті ротоглотки хворих на хронічні запальні захворювання ротової частини глотки за наявності або відсутності піднебінних мигдаликів

та противірусних антитіл

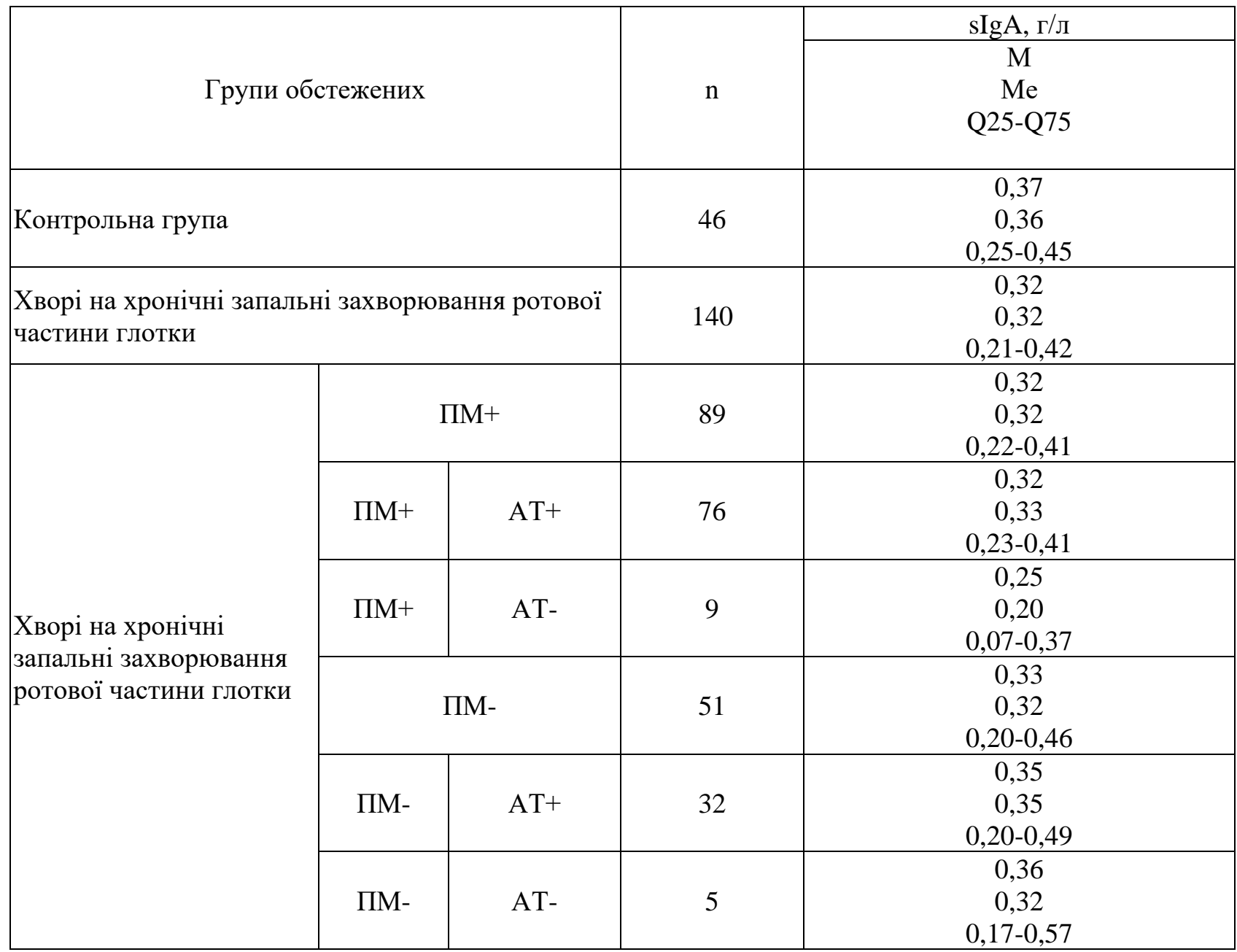

Одним 3 показників стану гуморального імунітету слизової оболонки верхніх дихальних шляхів хворих на хронічні запальні захворювання $\epsilon$ концентрація імунних комплексів в секреті ротоглотки, яка у осіб контрольної групи не змінювалась в залежності від стану ЛГК та наявності в крові обстежених противірусних АТ (табл. 3). 
Таблиця 3.

Вміст імунних комплексів у секреті ротоглотки осіб контрольної групи при різних станах ЛГК та наявності або відсутності в крові анамнестичних антитіл до вірусів респіраторної групи

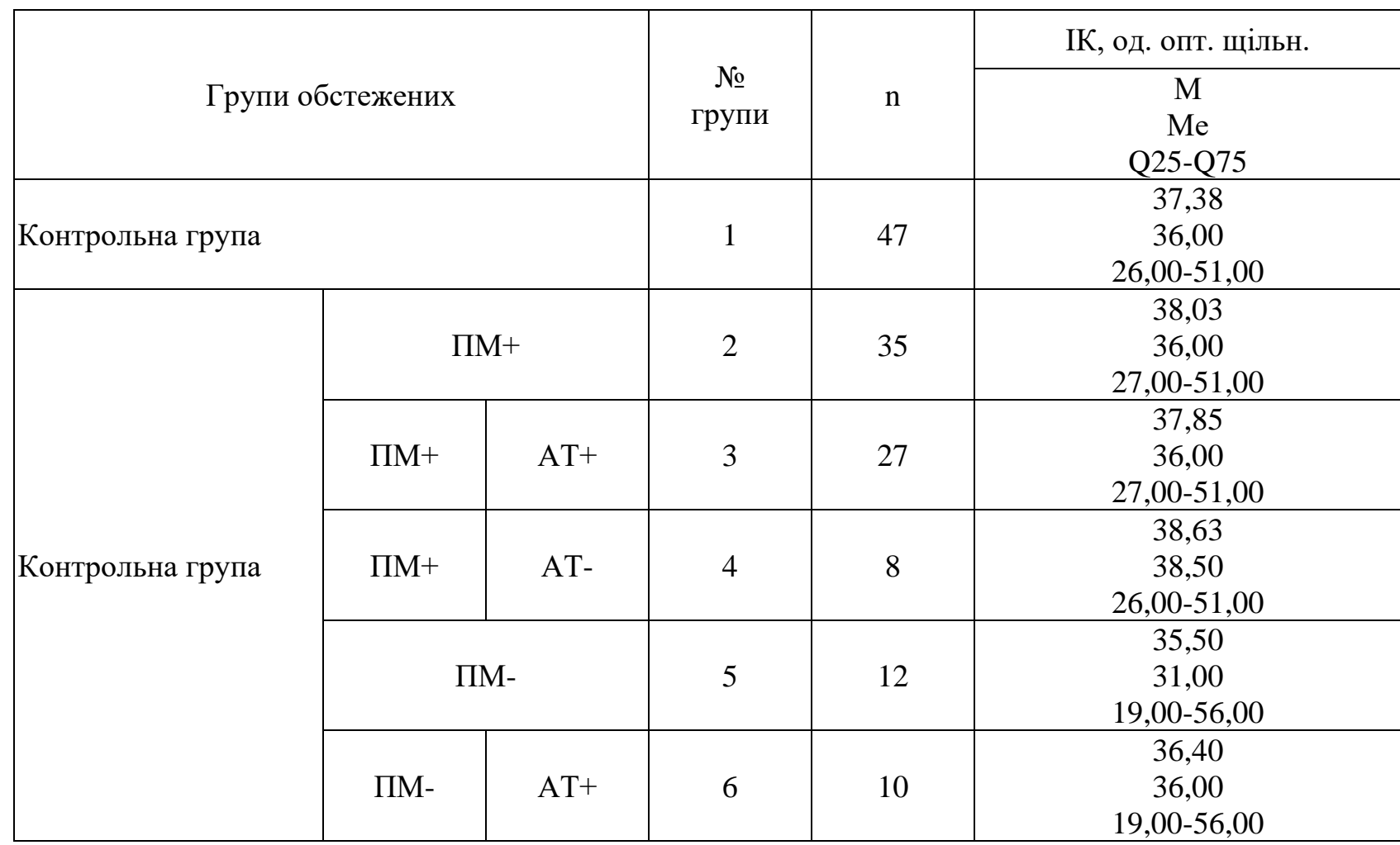

У хворих на хронічні запальні захворювання ротоглотки концентрація ІК в секреті ротоглотки була істотно зниженою в порівнянні з обстеженими із групи контролю як при наявності, так і при відсутності у них піднебінних мигдаликів (табл. 4). При цьому у тонзилектомованих осіб показники концентрації ІК були достовірно зменшеними в порівнянні з такими у обстежених контрольної групи, незалежно від вмісту у них в крові противірусних АТ. Максимально низьким вміст ІК був у секреті ротоглотки тонзилектомованих хворих, які не мали протективних титрів антитіл до вірусів респіраторної групи. 
Таблиця 4.

Вміст імунних комплексів у секреті ротоглотки хворих при різних станах лімфоглоткового кільця та в залежності від присутності в крові анамнестичних антитіл до вірусів респіраторної групи

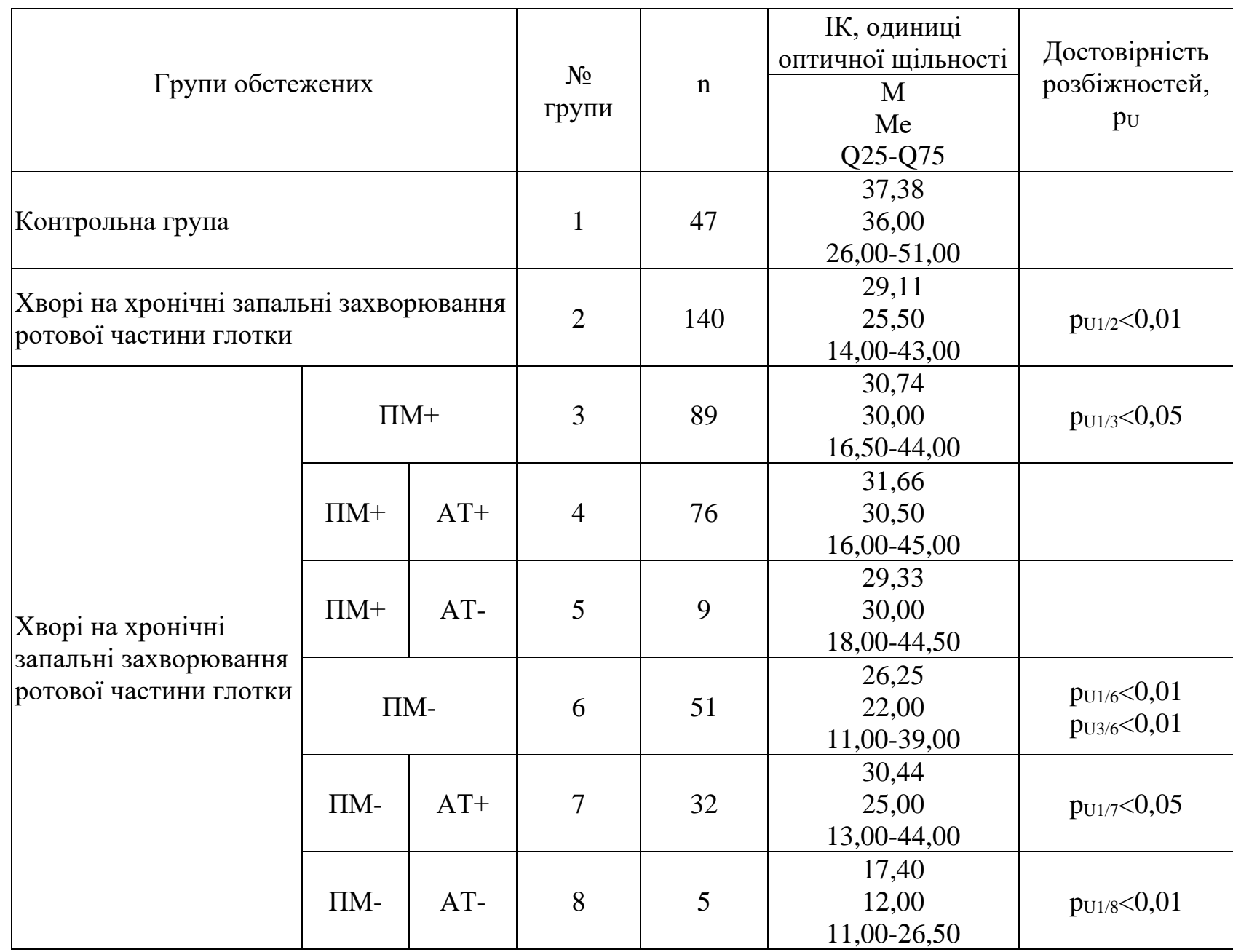

Одним із основних механізмів противірусного захисту є продукція $\alpha$-IFN ключового чинника природної неспецифічної імунної відповіді, що стримує реплікацію вірусів і дозволяє у короткі терміни мобілізувати адаптивну імунну відповідь, необхідну для елімінації інфекційного агента [137].

Проведені дослідження показали, що вміст $\alpha$-IFN в секреті ротоглотки осіб контрольної групи в більшості випадків коливався в межах нормальних значень, не відрізняючись в підгрупах в залежності від наявності в крові противірусних антитіл, проте мав тенденцію до зниження концентрації в підгрупах донорів після тонзилектомії за рахунок більшої кількості обстежених із зниженим вмістом $\alpha$-IFN (табл. 5). 
Таблиця 5.

Вміст $\alpha$-IFN у секреті ротоглотки осіб контрольної групи при різних станах лімфоглоткового кільця та наявності у крові анамнестичних противірусних антитіл

\begin{tabular}{|c|c|c|c|c|c|}
\hline \multirow{2}{*}{\multicolumn{3}{|c|}{ Групи обстежених }} & \multirow[b]{2}{*}{$\begin{array}{c}\text { № } \\
\text { групи }\end{array}$} & \multirow[b]{2}{*}{$\mathrm{n}$} & $\alpha$-IFN, пг/л \\
\hline & & & & & $\begin{array}{c}\mathrm{M} \\
\mathrm{Me} \\
\mathrm{Q} 25-\mathrm{Q} 75\end{array}$ \\
\hline \multicolumn{3}{|l|}{ Контрольна група } & 1 & 24 & $\begin{array}{c}56,62 \\
46,85 \\
24,25-66,70\end{array}$ \\
\hline \multirow{5}{*}{ Контрольна група } & \multicolumn{2}{|c|}{ ПМ+ } & 2 & 15 & $\begin{array}{c}64,85 \\
47,80 \\
25,60-62,20\end{array}$ \\
\hline & ПМ+ & $\mathrm{AT}+$ & 3 & 9 & $\begin{array}{c}58,17 \\
52,20 \\
24,50-84,80 \\
\end{array}$ \\
\hline & ПМ+ & AT- & 4 & 6 & $\begin{array}{c}74,87 \\
31,05 \\
25,60-47,80\end{array}$ \\
\hline & \multicolumn{2}{|c|}{ ПМ- } & 5 & 9 & $\begin{array}{c}42,91 \\
45,90 \\
13,30-71,35\end{array}$ \\
\hline & ПМ- & $\mathrm{AT}+$ & 6 & 7 & $\begin{array}{c}43,71 \\
45,90 \\
16,60-71,20\end{array}$ \\
\hline
\end{tabular}

Аналогічна закономірність спостерігалась і при визначенні рівня $\alpha$-IFN у тонзилектомованих хворих на хронічні запальні захворювання ротоглотки, яка досягала статистично значущої різниці порівняно з показниками вмісту $\alpha$-IFN у осіб контрольної групи (табл. 6).

Найбільшою мірою зменшення концентрації $\alpha$-IFN визначено у пацієнтів із видаленими піднебінними мигдаликами та відсутністю в крові анамнестичних антитіл проти вірусів респіраторної групи, у яких рівень $\alpha$-IFN в секреті ротоглотки був суттєво менший за такий у осіб контрольної групи та хворих на X33 РГ з не видаленими піднебінними мигдаликами, концентрація $\alpha$-IFN в CP яких суттєво не відрізнялась від такої у осіб контрольної групи (табл. 5 та 6). 
Таблиця 6.

Вміст $\alpha$-IFN у секреті ротоглотки хворих при різних станах лімфоглоткового кільця та наявності у крові антитіл до вірусів респіраторної групи

\begin{tabular}{|c|c|c|c|c|c|c|}
\hline \multirow{2}{*}{\multicolumn{3}{|c|}{ Групи обстежених }} & \multirow[b]{2}{*}{$\begin{array}{c}\text { № } \\
\text { групи }\end{array}$} & \multirow[b]{2}{*}{$\mathrm{n}$} & $\alpha$-IFN, пг/л & \multirow[b]{2}{*}{$\begin{array}{c}\text { Достовірність } \\
\text { розбіжностей, } \\
\mathrm{p}_{\mathrm{U}}\end{array}$} \\
\hline & & & & & $\begin{array}{c}\mathrm{M} \\
\mathrm{Me} \\
\mathrm{Q} 25-\mathrm{Q} 75\end{array}$ & \\
\hline \multicolumn{3}{|l|}{ Контрольна група } & 1 & 24 & $\begin{array}{c}56,62 \\
46,85 \\
24,25-66,70\end{array}$ & \\
\hline \multicolumn{3}{|c|}{$\begin{array}{l}\text { Хворі на хронічні запальні захворювання } \\
\text { ротової частини глотки }\end{array}$} & 2 & 59 & $\begin{array}{c}45,26 \\
26,90 \\
15,80-60,60\end{array}$ & \\
\hline \multirow{6}{*}{$\begin{array}{l}\text { Хворі на хронічні } \\
\text { запальні } \\
\text { захворювання } \\
\text { ротової частини } \\
\text { глотки }\end{array}$} & \multicolumn{2}{|c|}{$\Pi \mathrm{M}+$} & 3 & 40 & $\begin{array}{c}51,15 \\
36,40 \\
17,80-63,50 \\
\end{array}$ & \\
\hline & ПМ+ & AT + & 4 & 34 & $\begin{array}{c}49,35 \\
41,55 \\
19,10-66,40 \\
\end{array}$ & \\
\hline & ПМ+ & AT- & 5 & 4 & $\begin{array}{c}13,85 \\
15,10 \\
5,20-20,00 *\end{array}$ & $\begin{array}{l}\mathrm{p}_{\mathrm{U} 1 / 5}<0,01 \\
\mathrm{p}_{\mathrm{U} 4 / 5}<0,05\end{array}$ \\
\hline & \multicolumn{2}{|c|}{ ПМ- } & 6 & 19 & $\begin{array}{c}32,86 \\
22,20 \\
11,40-36,40\end{array}$ & $\mathrm{p}_{\mathrm{U} 1 / 6}<0,05$ \\
\hline & ПМ- & AT + & 7 & 14 & $\begin{array}{c}40,93 \\
24,00 \\
17,60-77,30\end{array}$ & \\
\hline & ПМ- & AT- & 8 & 5 & $\begin{array}{c}10,26 \\
11,10 \\
0,95-19,15\end{array}$ & $\begin{array}{l}p_{\mathrm{U} 1 / 8}<0,01 \\
p_{\mathrm{U} 7 / 8}<0,01\end{array}$ \\
\hline
\end{tabular}

Примітка: * - межі коливань .

Проведені дослідження показали, що концентрація $\alpha$-IFN в секреті ротоглотки залежить також від інфікованості обстежених пацієнтів різних груп вірусами респіраторної групи. Зокрема, у хворих на хронічні запальні захворювання ВДШ з відсутністю противірусних антитіл рівень $\alpha$-IFN в секреті ротоглотки був суттєво нижчим за аналогічні показники у здорових осіб та в підгрупах обстежених 3 клінічно значущими титрами антитіл проти респіраторних вірусів незалежно від наявності або відсутності у них піднебінних мигдаликів (табл. 5 та 6). 
Визначення концентрації $\gamma$-IFN, який зв'язується зі спеціальними рецепторами клітин і впливає на процес репродукції вірусу всередині клітини на стадії синтезу білків, проявляючи імуномодулюючу активність та залучаючи різні клітини імунної системи до регуляції гомеостазу організму [138], показало, що його вміст в секреті ротоглотки осіб контрольної групи суттєво відрізнявся в залежності від наявності або відсутності у них піднебінних мигдаликів і був вірогідно зменшеним у раніше тонзилектомованих пацієнтів (табл. 7).

Таблиця 7

Вміст $\gamma$-IFN у секреті рото глотки осіб контрольної групи за наявності або відсутності у них піднебінних мигдаликів

\begin{tabular}{|c|c|c|c|c|c|c|}
\hline \multirow{2}{*}{\multicolumn{3}{|c|}{ Групи обстежених }} & \multirow[b]{2}{*}{$\begin{array}{c}\text { № } \\
\text { групи }\end{array}$} & \multirow[b]{2}{*}{$\mathrm{n}$} & $\gamma$-IFN, пг/мл & \multirow[b]{2}{*}{$\begin{array}{c}\text { Достовірність } \\
\text { розбіжностей, } \\
\mathrm{p}_{\mathrm{U}}\end{array}$} \\
\hline & & & & & $\begin{array}{c}\mathrm{M} \\
\mathrm{Me} \\
\mathrm{Q} 25-\mathrm{Q} 75\end{array}$ & \\
\hline \multicolumn{3}{|l|}{ Контрольна група } & 1 & 24 & $\begin{array}{c}667,60 \\
306,9 \\
181,45-1173,00\end{array}$ & \\
\hline \multirow{4}{*}{ Контрольна група } & \multicolumn{2}{|c|}{ ПМ+ } & 2 & 15 & $\begin{array}{c}873,89 \\
451,00 \\
104,40-1564,00\end{array}$ & \\
\hline & ПМ+ & $\mathrm{AT}+$ & 3 & 9 & $\begin{array}{c}671,68 \\
311,40 \\
80,90-1328,50\end{array}$ & \\
\hline & \multicolumn{2}{|c|}{ ПМ- } & 5 & 9 & $\begin{array}{c}323,77 \\
261,40 \\
181,45-296,80\end{array}$ & $\mathrm{p}_{\mathrm{U} 2 / 5}<0,05$ \\
\hline & ПМ- & $\mathrm{AT}+$ & 6 & 7 & $\begin{array}{c}364,49 \\
261,40 \\
191,80-302,50\end{array}$ & \\
\hline
\end{tabular}

У хворих на хронічні запальні захворювання ротової частини глотки вміст $\gamma$-IFN не залежав від наявності або відсутності піднебінних мигдаликів і в середньому достовірно не відрізнявся від такого у не тонзилектованих осіб контрольної групі. Разом з тим, звертає увагу значне збільшення концентрації $\gamma$ IFN в секреті ротоглотки хворих зі збереженими ПМ, які не мали контакту 3 вірусами респіраторної групи, хоча цей факт потребує додаткового дослідження в зв'язку з невеликою кількістю спостережень (табл. 8). 
Таблиця 8

Вміст $\gamma$-IFN у секреті ротоглотки хворих при наявності або відсутності у них піднебінних мигдаликів та противірусних антитіл

\begin{tabular}{|c|c|c|c|c|c|c|}
\hline \multirow{2}{*}{\multicolumn{3}{|c|}{ Групи обстежених }} & \multirow[b]{2}{*}{$\begin{array}{c}\text { № } \\
\text { групи }\end{array}$} & \multirow[b]{2}{*}{$\mathrm{n}$} & $\gamma$-IFN, пг/мл & \multirow{2}{*}{$\begin{array}{c}\text { Достовірність } \\
\text { розбіжностей, } \\
\text { pu }\end{array}$} \\
\hline & & & & & $\begin{array}{c}\mathrm{M} \\
\mathrm{Me} \\
\mathrm{Q} 25-\mathrm{Q} 75\end{array}$ & \\
\hline \multicolumn{3}{|l|}{ Контрольна група } & 1 & 24 & $\begin{array}{c}667,60 \\
306,9 \\
181,45-1173,00 \\
\end{array}$ & \\
\hline \multicolumn{3}{|c|}{$\begin{array}{l}\text { Хворі на хронічні запальні захворювання } \\
\text { ротової частини глотки }\end{array}$} & 2 & 58 & $\begin{array}{c}763,14 \\
300,05 \\
135,50-1316,00\end{array}$ & \\
\hline \multirow{6}{*}{$\begin{array}{l}\text { Хворі на хронічні запальні } \\
\text { захворювання ротової } \\
\text { частини глотки }\end{array}$} & \multicolumn{2}{|c|}{ ПМ+ } & 3 & 39 & $\begin{array}{c}752,05 \\
249,60 \\
147,40-1317,00 \\
\end{array}$ & \\
\hline & ПМ+ & $\mathrm{AT}+$ & 4 & 33 & $\begin{array}{c}696,23 \\
233,30 \\
141,45-1316,50 \\
\end{array}$ & \\
\hline & ПМ+ & AT- & 5 & 4 & $\begin{array}{c}1334,68 \\
1403,50 \\
609,70-1922,00^{*}\end{array}$ & $\begin{array}{l}\mathrm{p}_{\mathrm{U} 1 / 5}<0,05 \\
\mathrm{p}_{\mathrm{U} 4 / 5}<0,05\end{array}$ \\
\hline & \multicolumn{2}{|c|}{ ПМ- } & 6 & 19 & $\begin{array}{c}785,40 \\
314,40 \\
107,40-1290,00\end{array}$ & \\
\hline & ПМ- & $\mathrm{AT}+$ & 7 & 14 & $\begin{array}{c}790,60 \\
300,05 \\
107,40-1290,00 \\
\end{array}$ & \\
\hline & ПМ- & AT- & 8 & 5 & $\begin{array}{c}772,72 \\
573,10 \\
164,25-1481,00\end{array}$ & \\
\hline
\end{tabular}

Примітка: * - межі коливань.

Проведені дослідження показали, що структури лімфоглоткового кільця відіграють суттєву роль у формуванні реакцій місцевого імунітету. Отримані результати свідчать про те, що вміст $\operatorname{sg} \mathrm{A}, \alpha$-IFN та $\gamma$-IFN в секреті ротоглотки залежить від піднебінних мигдаликів, зменшуючись у обстежених осіб контрольної групи, які зазнали тонзилектомії. Хронічні запальні захворювання верхніх дихальних шляхів спричиняють зменшення концентрації IK та $\alpha$-IFN в секреті ротоглотки хворих з різним станом піднебінних мигдаликів. Проте у пацієнтів 3 нормальним станом піднебінних мигдаликів, які перехворіли вірусними інфекціями, на відміну від осіб із видаленими піднебінними мигдаликами, показники вмісту $\alpha$-IFN збільшуються, практично не 
відрізняючись від таких у практично здорових донорів. Найбільше пригнічення продукції IК та $\alpha$-IFN визначається у хворих на хронічні запальні захворювання верхніх дихальних шляхів 3 видаленими піднебінними мигдаликами та 3 відсутністю клінічно значимих титрів противірусних антитіл.

Таким чином, дослідження показників місцевого імунітету у хворих на хронічні запальні захворювання верхніх дихальних шляхів 3 різним станом піднебінних мигдаликів, що контактують або мали контакт з респіраторними вірусами, надає можливість виявити найбільш вразливі ланки в системі їх протиінфекційного захисту, на які перш за все варто звертати увагу при обстеженні та лікуванні пацієнтів з хронічними запальними захворюваннями верхніх дихальних шляхів, особливо при умові частого повторення у них гострих респіраторних захворювань. 


\section{SECTION 2. MEDICAL PSYCHOLOGY}

DOI 10.46299/ISG.2021.MONO.MED.III.2.1

\section{1 Психологічні рекомендації військовослужбовцям, які опинилися в групі ризику виникнення посттравматичного синдрому}

У роботі з військовослужбовцями, які пройшли бойові дії, важлива не тільки діагностика посттравматичного стресового розладу, але i його профілактика, лікування та запобігання можливих наслідків. Усвідомлення необхідності проведення спеціальних заходів і створення програм психологічної реабілітації осіб, які потрапили в групу ризику виникнення ПТСР, в даний час стає реальністю для широкого кола фахівців як медичної та психологічної сфери, так і різних громадських організацій [148]. Створення комплексної системи забезпечення охорони фізичного і психічного здоров'я військовослужбовців дозволить ефективно проводити профілактику посттравматичних розладів, сприяти реабілітації військовослужбовців 3 посттравматичним стресовим розладом, підтримувати склад військ у виконанні завдань, як в умовах мирної служби, так і в умовах військових конфліктів.

Формування так званих «груп ризику» може стати першим в довгому списку профілактичних заходів в роботі з військовослужбовцями. Саме «група ризику» може допомогти психологам та іншим фахівцям ефективніше і швидше визначати наявність посттравматичного стресового розладу i iнших патопсихологічних станів[142].

Варто почати 3 визначення поняття «психологічна профілактика». Психологічна профілактика військовослужбовців - це діяльність, спрямована на попередження можливого неблагополуччя в психічному i особистісному розвитку військового та створення психологічних умов, максимально сприятливих для цього розвитку [150]. Особливе місце серед психологічних профілактичних заходів займає профілактика посттравматичного стресового розладу. Даний вид профілактичної роботи досить складний, має ряд особливостей і різнобічність підходів. Найбільш ефективний шлях профілактики 
посттравматичного стресового розладу у військовослужбовців - це індивідуальна та групова підготовка військових до діяльності в екстремальних ситуаціях в поєднанні з можливістю терапії та відновлення осіб, травмованих умовами екстремальної ситуації військового конфлікту. До цього напряму входить застосування арт-терапії [143].

Методи арт-терапії, засновані на грі і творчості, визнані в усьому світі одними 3 найефективніших i, при цьому, захоплюючих видів психологічної допомоги. Завдяки інтерактивним i «живим» заняттям, в короткі терміни вдається поліпшити настрій, загальний психоемоційний стан, зняти напругу i скутість, допомогти позбутися страхів, агресії, тривог, депресії і апатії, підняти життєвий тонус і самооцінку.

Частка «арт» в слові «арт-терапія» перекладається як «мистецтво», що дослівно означає «лікування мистецтвом», тобто застосування терапевтичних методик за допомогою мистецтва або творчості. Даний вид терапії особливо актуальний для психологічної корекції психоемоційного стану людини. Головним завданням арт-терапії в психології вважається досягнення максимальної гармонії психічного стану особистості за допомогою самовираження або самопізнання. Мистецтво, в різних своїх варіаціях, дозволяє висловити i «розкласти по поличках» внутрішні почуття і емоції, переживання i тривоги.

Лікувальна терапія за допомогою мистецтва дозволяє психологам i психотерапевтам в роботі з пацієнтом домогтися наступних результатів:

- дати вихід негативним емоціям або почуттям, які «застрягли»;

- істотно полегшити комплексне психотерапевтичне лікування;

- здійснити розгорнуту психодіагностику стану людини;

- опрацювати стримувані або придушені почуття і думки;

- встановити довірчі відносини з пацієнтом;

- розвинути творчі здібності;

- підвищити самооцінку, особистісний ріст;

- здійснити самопізнання і самовираження; 
- навчити контролювати поведінку і емоції;

- зрозуміти причини емоційних розладів або труднощів [140].

Методика арт-терапії грунтується на твердженні, що внутрішній стан людини неусвідомлено відбивається в зорових образах, а значить і в її малюнках, скульптурах, виробах, інсталяціях, колажі та інших творчих процесах. Арттерапія не має протипоказань, підходить для будь-якого віку і категорій. Подібне лікування проводиться абсолютно добровільно, не викликаючи опору i негативного ставлення. У творчому процесі не важлива якість або художня цінність створюваного арт-об'єкта, головне - зосередитися на завданні і повністю зануритися в сам процес. Аналіз проведеної роботи повинен здійснювати, в першу чергу, автор, намагаючись самостійно розібратися i зрозуміти суть проблемної ситуації. Спеціаліст психолог або психотерапевт лише спрямовує і координує творчий процес.

Таким чином, психологічна профілактика - це комплекс заходів, спрямованих на підтримку психічного i фізичного здоров’я військовослужбовців, стабілізацію їх емоційного стану та розвиток особистісного потенціалу.

Основні принципи психологічної профілактики військовослужбовців:

1. Оперативність проведення;

2. Системність виконання;

3. Гнучкість заходів;

4. Багатоступінчатість комплексу заходів [147].

Ще одним важливим принципом психологічної профілактики посттравматичного стресового розладу є спрямованість профілактичних заходів як на самого військовослужбовця і його діяльність, так і на його соціальне оточення (сім’я, друзі, товариші по службі).

Виходячи 3 усього вищесказаного, можна виділити ряд заходів профілактичного характеру військовослужбовцям, які опинилися в групі ризику виникнення посттравматичного стресового розладу. Перше, і найголовніше, правило - це активне опрацювання травматичного події. Не варто приховувати 
факт участі в події, що травмує характер (військові дії, наприклад). Необхідно негайно звернутися до фахівців (психологів, психотерапевтів, лікарів), які почнуть проводити профілактичні заходи для запобігання, відразу після психічної травматизації в цілях уникнення розвитку посттравматичного стресового розладу [146].

Однак не завжди життєва ситуація дозволяє звернутися до фахівців даного профілю, тому кожен військовослужбовець повинен мати уявлення про правила «швидкої» допомоги самому собі, щоб максимально ефективно уникнути негативних наслідків травматичної ситуації [141].

Важливим моментом в профілактиці посттравматичного стресового розладу є принцип дотримання гігієнічних профілактичних процедур в поведінці військовослужбовця - правильне харчування, відмова від зловживання психоактивних речовин, режим сну і неспання, фізичні навантаження тощо. Наступний пункт - необхідність інформованості військовослужбовця про можливі наслідки екстремальні ситуації, що дозволить уникнути бурхливої реакції на негативні прояви стресової ситуації. У багатьох випадках необхідна корекція помилкових уявлень щодо стресової реакції. Військовослужбовець повинен розуміти, що переживання екстраординарних, неспецифічних почуттів після психічної травматизації - це нормальна реакція на «ненормальні» обставини. Крім того, для профілактики хронічного перебігу посттравматичних розладів військовий повинен знати прояви стресової реакції і характерні симптоми ПТСР для ідентифікації їх у самого себе [149].

Основоположним в підготовці військовослужбовців до умов бойових дій $\epsilon$ формування навичок самодопомоги, навчання методам релаксації та саморегуляції. Одним з таких методів роботи може виступати арт-терапія. Крім участі в профілактичній роботі самого військовослужбовця, його близьке оточення також має бути активно задіяні в даній діяльності.

Родинам і близьким людям, оточуючим військового, необхідно знати наступні стратегії поведінки: 
1. Уважно вислухайте розповіді військовослужбовця про те, що йому довелося пережити. Дуже важливо дати йому виговоритися в комфортній обстановці моральної підтримки близької i коханої людини. Військовослужбовець повинен знати, що його близькі готові допомогти йому психологічно повернутися до нормального, звичного життя.

2. Проявіть терпіння до скарг, тривог і проблем військовослужбовця, які неминуче виникають після бойового стресу. Зверніть увагу на психологічний стан військовослужбовця: чи присутній у нього дискомфорт, підвищена дратівливість, тривалий знижений настрій, тривожний стан і т. д.

3. Необхідно враховувати, що за час служби військовослужбовець відвикає від умов мирного життя, і варто змиритися з деякими змінами, які неминуче з'являються (наприклад, звичка вставати в один і той же час, класти речі чітко на свої місця і т. ін.).

4. Не заохочуйте вживання алкоголю, нікотину та інших негативних речовин. Постарайтеся організувати альтернативні способи розслаблення (масаж, прогулянки, арт-терапія). Придумайте якусь цікаву діяльність для військовослужбовця, не давайте йому «сидіти склавши руки». Вся сім'я повинна дотримуватися однієї моделі поведінки, не повинно виникати протиріч i суперечок. Потрібно уникати конфліктів всередині родини [144].

Таким чином, психологічна профілактика можливості виникнення посттравматичного стресового розладу у військовослужбовців, які пережили досвід участі у військових конфліктах, виявляється необхідною для корекції соціальної поведінки військовослужбовців, поліпшення їх комунікабельності, розвитку здібностей до самореалізації, дозволу психологічних і подолання соціальних конфліктів. Крім того, це допоможе запобігти виснаження, деформування стресом, перевантаженню психіки, навчить військовослужбовців знімати внутрішню напруженість i тривожність, збільшить ресурси i стресостійкість організму. Саме всебічний підхід до психологічної профілактики найбільш ефективний для стабілізації стану військовослужбовців [145]. 
Значущим методом психологічної реабілітації військовослужбовців 3 посттравматичним стресовим розладом є арт-терапія, перевагами якої є широкий вибір видів і методів, використовуваних фахівцями. На арт-заняттях, в процесі сублімації, людина, по суті, перетворює негативний вид енергії (страх, роздратування, агресія) в позитивне творче самовираження. Під час роботи, навіть без корекційних та додаткових занять, несвідомо відбувається трансформація початкової проблеми і настає позитивний терапевтичний ефект. В процесі арт-діяльності людина розслабляється, знімає напругу і скутість, нервова система заспокоюється. Показаннями до лікувальної терапії може стати будь-яке відхилення психоемоційного або психічного стану людини.

Показаннями для застосування арт-терапії під час реабілітації військовослужбовців із посттравматичним стресовим розладом є стрес, депресія, пригнічений настрій, імпульсивність і емоційна нестійкість, страхи, фобії, занижена самооцінка, негативна «Я-концепція», підвищена тривожність. У нашій програмі «Веселка настрою» реабілітаційних занять для зняття негативних симптомів ми застосовували комунікативні ігри, тактильні вправи, малювання за допомогою відбитків листя, дихальна гімнастика, аутотренінги, вгадування емоцій за інтонацією, розгляд піктограми, пластилінографія, малювання олівцями і фарбами, релаксація, розгляд фотографій, розмальовування камінців

Військовослужбовці, які опинилися в ситуації військового конфлікту, потребують психологічної профілактики виникнення посттравматичного стресового розладу. Перш за все, це повинна бути підготовка військовослужбовців до умов бойових дій, формування навичок самодопомоги, навчання методам релаксації та саморегуляції, а також робота 3 сім'ями військовослужбовців, оптимізація стратегій їх поведінки і ставлення до травмованого військовослужбовця [139]. 


\section{SECTION 3. PUBLIC HEALTH AND HEALTHCARE}

DOI 10.46299/ISG.2021.MONO.MED.III.3.1

\subsection{Pattern of active blood donors donating for more than 10 years based on the results of laboratory, morphologic, biochemical and biophysical blood test of periferal blood}

Blood transfusion service and its social component - donorship must be the priority areas of the state policy because the results of its work are of paramount importance. The main task of the blood transfusion service is supply of high quality components for blood transfusion therapy. Quality of blood components is compliance of properties and specifications of the blood component supplied to the recipient with the set standards. Strict order of conformance with the approved regulations and procedures is important at all technological states and is a cornerstone of blood transfusion service products quality. All actions, planned and implemented, starting with planning donorship and ending with the finished product manufacturing and storage conditions, are important for ensuring the quality as the final result [151]. In spite of the lately increasing number of scientific research programs on donor blood storage, integrated solution of this problem remains a challenging open issue. We studied parameters indicative of iron metabolism in donors, and glycolytic processes in peripheral blood erythrocytes depending on history of donations, donors' health at the time of plasma donation via automatic plasmapheresis, issues of donorship optimization, and its medical and social aspects [152]. Potential donors reserve decrease negatively affects the volumes of donor blood collected by the blood transfusion service of Ukraine [153]. Reducing number of donors in contrast to the increasing need for blood components and products is a topical issue of present-day transfusion medicine because the number of donors is decreasing by 10-15\% annually worldwide [151]. Exceedance of regulated number of annual donations and absence of strict control of metabolic processes in the donors can lead to abnormalities of macroand microelement, amino acid, protein and carbohydrate metabolism and enzyme system dysfunction, which ultimately results in iron deficiency and diseases in regular blood donors. First of all, unregulated donations can disturb metabolism of iron and 
microelements ensuring adequate hemoglobin synthesis and erythropoiesis, functioning of metal-dependent enzyme systems and plastic processes [154]. Pathogenic factor of iron deficiency is its negative balance caused by the discrepancy between resorption and intake, or high losses. Iron deficiency leads to erythrocyte transport function impairment (oxygen and carbon dioxide transporting), shortening of their life cycle from 120 to 56 days, and reduction of resistance to different physical and chemical factors, in particular impact on erythrocytes in donors with latent iron deficiency: freezing at ultra-cold temperatures leads to hemolysis increase to over 30 $\%$ when reference rate is $2-5 \%$. Acid resistance of erythrocytes decreases almost 2fold (acid erythrograms demonstrate destruction of the main erythrocyte mass during the first 8 minutes instead of 15-16 minutes). In iron deficiency, erythropoiesis intensity is not accompanied by increased production of erythrocytes, but causes metabolic, functional and morphologic changes in them, which is of particular importance for blood donors because, on an average, 5\% of donors stop donating for the reason of deterioration of the peripheral blood parameters [152]. Erythrocyte destruction caused by metabolic, functional and morphologic changes in them leads to macrophage system overstraining. Besides, the above-mentioned changes in the erythrocytes of the blood donors result in donor blood quality lowering and, consequently, lower quality of blood components containing erythrocytes, which can affect the results of blood transfusion therapy and recipients' health [153]. Iron metabolism evaluation method used for blood donors by the Ukrainian blood transfusion service and approved legally provisions measurement of hemoglobin parameter pathophysiology of which changes only at the stage of overt iron deficiency $[152,156]$. Peripheral blood parameters abnormality detected by the establishments of the blood transfusion service in more than $5 \%$ of blood donors is a cause of denial of donations, while iron deficiency was found in $25-50 \%$ of the active donors [151]. Study of the latent abnormalities of iron metabolism and related changes of physical properties of erythrocytes, rheological abnormalities and energy processes in erythrocytes of blood donors, as well as development of correction and prevention methods is a topical issue for the state blood transfusion service. In spite of paramount 
importance of the energy processes progress in erythrocytes, their impact on functional capacity of peripheral blood erythrocytes in the body of active donors, the study of this problem has just started, which calls for the development of diagnostic methods for detection of the above-mentioned changes and methods of their correction $[152,156]$.

All the above-mentioned defines the important problem of the modern transfusion medicine - determination of theimpact of the changes of laboratory, morphologic, biochemical and biophysical parameters of donor erythrocytes and pathophysiologic grounding of donation safety. Solution of this problem will make available the important data on pathologic states inducing qualitative morphologic changes in erythrocytes in active donors and detection o early symptoms of such abnormalities for timely correction.

However, previous research in this field did not provide clear and unambiguous answer regarding the possibility of evaluation of the latent abnormalities of laboratory, morphologic, biochemical and biophysical parameters of donor blood erythrocytes and pathophysiologic grounding of donation safety, in particular, depending on how long the person has been donating blood.

The study included 459 donors who donated in clinical centers of the Chair of Hematology and Transfusion Medicine of Shupyk National Healthcare University of Ukraine, Kyiv, Ukraine.

All donors were examined pursuant to the Medical Examination Procedure for Donors of Blood and (or) its Components approved by Decree of the Health Ministry of Ukraine no. 385 dated 01.08.2005 - On Infectious Safety o Donor Blood and its Components as donors whose blood is used for production of components. Before donation, blood donors filled questionnaire and were examined by qualified specialists pursuant to the requirements of the applicable Medical Examination Procedure for Donors of Blood and (or) its Components. Hemoglobin was measured for all the donors (RR: M - no less than $130 \mathrm{~g} / \mathrm{l}, \mathrm{F}$ - no less than $120 \mathrm{~g} / \mathrm{l}$ ). Blood donation volume was determined on the basis of hemoglobin test (max volume $-450 \mathrm{ml}$ excluding blood volume drawn for the test (up to $40 \mathrm{ml}$ ). For active blood donors, it is necessary to consider the interval before the donations that should not be less than 60 days from the 
date of the previous donation, as well as number of donations per year - no more than 5 for men and 4 for women. After blood donation, alanine aminotransferase (ALT, RR $0,1-0,68 \mathrm{mmol} / \mathrm{h}-1)$ level was measured in donors' blood; it was also tested for hemotransmissive infections (HIV $1 / 2$, hepatitis $\mathrm{B}$, hepatitis $\mathrm{C}$, syphilis).

459 blood donors ( 231 men and 228 women) were examined, among which 299 were active donors (148 men and 151 women) donating on regular basis, no less than 3 times a year and 160 first-time registered donors (83 men and 77 women). First-time registered donors made the control group of our research. According to age classification (WHO, 1991), first-time donors were divided into three subgroups: young donors -48 (26 men and 22 women aged 20-34), middle-aged donors - 62 (30 men and 32 women aged 35-44) and ripe-age donors - 50 (27 men and 23 women aged 45-59). Mean age of the first-time donors from the control group was 38,90 $\pm 1,31$ (2059 years old). Mean age of the male donors was 39,66 $\pm 1,53$ (22-59 years old). Mean age of female donors was 37,56 $\pm 2,45$ (20-57 years old). All 160 first-time donors were practically healthy and eligible for donation subsequent to the result of survey, examination by specialists and hemoglobin level. Markers of hemotransmissive infections were all negative. ALT level was within the normal limits.

Since the control group was made by first-time donors, for convenience of systematization and reflection of the results of scientific research, objectivation in research data comparison, all the examined active donors were divided into three groups depending on the number of years they were donating and, consequently, increasing risk of latent metabolic abnormalities: group I - 146 donors (76 men and 70 women) donating from 2 to 5 years (number of donations in men was 10,41 $\pm 0,96$ (from 3 to 24 ), in women - 10,41 $\pm 0,96$ (from 3 to 18). Mean age of group I active donors

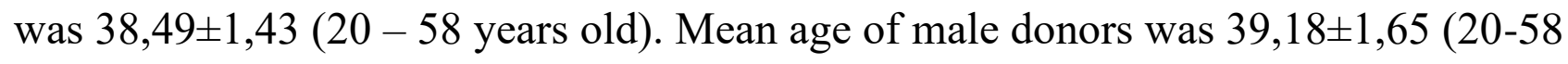
years old). Mean age of female donors was 36,25 $\pm 2,89$ (22-58 years old). Group II 98 donors (43 men and 55 women) donating from 6 to 9 years (number of donations in

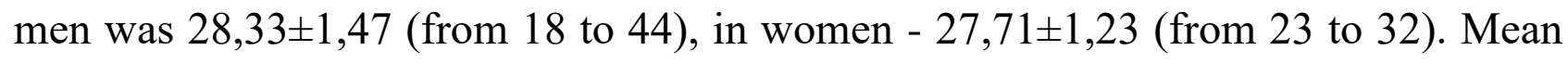
age of group II active donors was 41,32 $\pm 1,71$ (26 - 59 years old). Mean age of male 


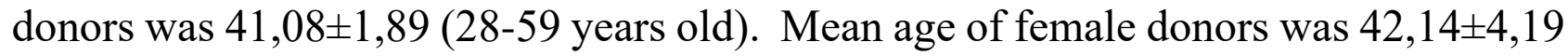
(26-57 years old).

Group III -55 donors ( 29 men and 26 women) donating for more than years

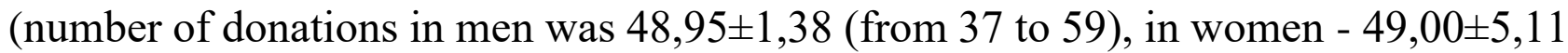

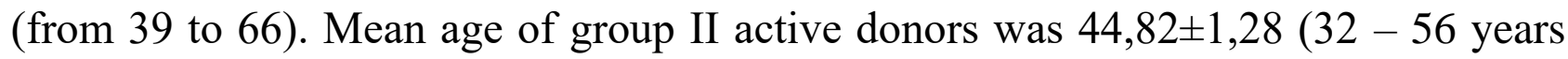
old). Mean age of male donors was 44,27 $\pm 1,44$ (32-54 years old). Mean age of female donors was 46,83 $\pm 2,86$ (40-56 years old). Mean age of the examined active donors was

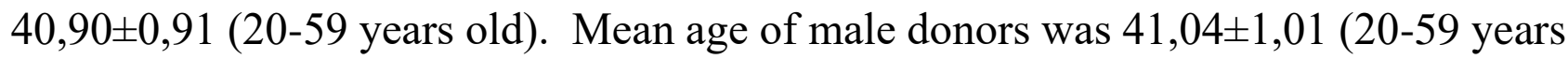
old). Mean age of female donors was 40,44 $\pm 2,07$ (22-58 years old). Groups of the examined donors were similar in terms of age and sex distribution. Research was approved by the Ethics Committee of Shupyk National Medical Academy of Postgraduate Education of the Health Minstry of Ukraine. The following methods were used: general blood tests, blood chemistry, specific blood chemistry, radioimmune and enzyme-immunoassay, atomic absorption spectroscopy, statistic methods. Devices and chemical agents used for the research were registered and certified in Ukraine. Devices were subjected to metrological monitoring in the due time. Hemoglobin measuring, erythrocyte, leukocyte, platelet count and calculation of RBC indices were performed in the laboratory of the State Enterprise Road Blood Transfusion Station of the Northwestern Railway on the automated analyzer PCE-210 (ERMA, Japan).

Determination of serum iron was performed according to beta-phenantroline method. Total iron binding capacity (TIBC) was evaluated by transferrin (TF) saturation with three-valence iron. Unsaturated (latent) iron binding capacity (UIBC) was calculated as difference between TIBC and iron concentration. Transferrin saturation coefficient (TSC) was calculated as serum iron (SI)/TIBC ratio. Serum TF was determined by TIBC value. Serum ferritin (FN) was evaluated by radioimmunoassay technique using ИРМО-ФЕРРИТИН set (Belarus). Mechanical resistance of erythrocytes was evaluated according to Marmont-Bianca method. Blood viscosity parameters, aggregation of erythrocytes and platelets were determined in accordance with S. Moiseev et al method (1990) - panel of methods allowing for evaluation of the main parameters that are determinative for blood viscosity properties 
- aggregation of platelets and erythrocytes, erythrocyte deformability, hematocrit. Optical transmission of erythrocytes (OTE) was determined in accordance with DanopMarikovaski method (1964). Physical and chemical parameters of erythrocyte membrane penetrability (PEMP) was evaluated in accordance with O. Kulapina et al. method (2006). Red blood cell distribution width (RDW) was determined automatically on automated hemo analyzer PCE-210 (ERMA, Japan). Effectiveness of erythropoiesis value (EEV) was evaluated in accordance with G. Kozinets et al. method (1988). All data obtained in the course of research were statistically processed. Research scope sample was analyzed by Student's t-test and Mann-Whitney nonparametric U-test, correlation and dispersion analyses. For data analysis, IBM SPSS Statistics 22.0 and Excel XP were used.

First-time blood donors pattern based on the results of laboratory, morphologic, biophysical and biochemical peripheral blood tests.

459 blood donors ( 231 men and 228 women) were examined. 160 of them (83 men and 77 women) were first-time donors and they made the control group (I), while 299 donors (148 men and 151 women) were regular blood donors donating for more than two years (no less than 2 times a year) - they made thestudy group (II). According to the age classification (WHO, 1991), first-time donors (control group, $n=160$ ) were divided into three subgroups: young donors - 48 (26 men and 22 women) aged 20-43, middle-aged donors -62 (30 men and 32 women) aged 35-44, ripe age donors ( 27 men and 23 women) aged 45-59.

Active donors ( $\mathrm{n}=299)$ were divided into 3 groups: $\mathrm{I}(\mathrm{n}=146)$ - donating from 2 to 5 years: young donors -41 ( 22 men and 19 women), middle-aged - 56 (29 men and 27 women), ripe age - 49 ( 25 men and 24 women); II ( $n=98)$ - donating for 6-9 years: young donors - 33 (13 men and 19 women), middle aged - 41 (16 men and 25 women), ripe age -24 (14 men and 11 women) and III ( $\mathrm{n}=55)$ donating for 10+ years: young donors -19 (11 men and 8 women), middle aged -19 ( 8 men and 11 women), ripe age - 17 (10 men and 7 women). The data is presented in Table 1. 
Table 1

Active Donors Pattern depending on donation career, age and $\operatorname{sex}(\mathbf{n}=299)$

\begin{tabular}{|c|c|c|c|c|c|c|c|}
\hline \multirow[t]{2}{*}{$\begin{array}{l}\text { Donation } \\
\text { career }\end{array}$} & \multicolumn{2}{|c|}{$\begin{array}{l}\text { Young age, } \\
20-34\end{array}$} & \multicolumn{2}{|c|}{$\begin{array}{l}\text { Middle age, } \\
35-44\end{array}$} & \multicolumn{2}{|c|}{$\begin{array}{l}\text { Ripe age, } \\
45-60\end{array}$} & \multirow[t]{2}{*}{$\begin{array}{l}\text { Total } \\
\text { (n) }\end{array}$} \\
\hline & $\begin{array}{l}\text { men } \\
\text { (n) }\end{array}$ & $\begin{array}{l}\text { women } \\
\text { (n) }\end{array}$ & $\begin{array}{l}\text { men } \\
\text { (n) }\end{array}$ & $\begin{array}{l}\text { women } \\
\text { (n) }\end{array}$ & $\begin{array}{l}\text { men } \\
\text { (n) }\end{array}$ & $\begin{array}{l}\text { women } \\
\text { (n) }\end{array}$ & \\
\hline \multirow[t]{2}{*}{$2-5$} & 22 & 19 & 29 & 27 & 25 & 24 & \multirow[t]{2}{*}{146} \\
\hline & \multicolumn{2}{|c|}{$(n=41)$} & \multicolumn{2}{|c|}{$(n=56)$} & \multicolumn{2}{|c|}{$(n=49)$} & \\
\hline \multirow[t]{2}{*}{$6-9$} & 13 & 19 & 16 & 25 & 14 & 11 & \multirow[t]{2}{*}{98} \\
\hline & \multicolumn{2}{|c|}{$(n=33)$} & \multicolumn{2}{|c|}{$(n=41)$} & \multicolumn{2}{|c|}{$(n=24)$} & \\
\hline \multirow[t]{2}{*}{$10+$} & 11 & 8 & 8 & 11 & 10 & 7 & \multirow[t]{2}{*}{55} \\
\hline & \multicolumn{2}{|c|}{$(n=19)$} & \multicolumn{2}{|c|}{$(n=19)$} & \multicolumn{2}{|c|}{$(n=17)$} & \\
\hline \multirow[t]{2}{*}{ Total } & 46 & 46 & 53 & 63 & 49 & 42 & \multirow[t]{2}{*}{299} \\
\hline & \multicolumn{2}{|c|}{$(n=92)$} & \multicolumn{2}{|c|}{$(n=116)$} & \multicolumn{2}{|c|}{$(n=91)$} & \\
\hline
\end{tabular}

In first-time donors, mean hemoglobin level was $138,88 \pm 0,95 \mathrm{~g} / \mathrm{l}$ : in men $142,72 \pm 0,81 \mathrm{~g} / 1(135 \mathrm{~g} / 1$ - $150 \mathrm{~g} / \mathrm{l})$, in women - 132,06 $\pm 0,89 \mathrm{~g} / 1$ (127 g/1 - $140 \mathrm{~g} / \mathrm{l})$. Hemoglobin level was higher in male than in female donors $(p<0,001)$. In first-time donors, erythrocyte count was, on an average, $4,63 \pm 0,03 \times 10^{12} / 1$. In the examined male donors it was, on an average, $4,76 \pm 0,03 \times 10^{12} / 1\left(4,5 \times 10^{12} / 1-5,0 \times 10^{12} / 1\right)$, in female $4,40 \pm 0,03 \times 10^{12} / 1\left(4,2 \times 10^{12} / 1-4,7 \times 10^{12} / 1\right)$. Erythrocyte count was higher in men than in women $(\mathrm{p}<0,001)$. In the examined male donors, leukocyte count was in the mean $6,86 \pm 0,21 \times 10^{9} / 1\left(4,4 \times 10^{9} / 1-8,6 \times 10^{9} / 1\right)$, in female $-6,79 \pm 0,29 \times 10^{9} / 1\left(8 \times 10^{9} / 1-\right.$ $\left.9,2 \times 10^{9} / 1\right)$. Average leukocyte count in the group of first-time donors was $6,83 \pm 0,17 \times 10^{9} / 1$. In first-time donors, platelet count was, on an average, $203,40 \pm 1,97 \times 10^{9} / 1$. In the examined male donors it was, on an average, $204,38 \pm 2,69 \times 10^{9} / 1\left(180 \times 10^{9} / 1-230 \times 10^{9} / 1\right)$, in female $-201,76 \pm 2,71 \times 10^{9} / 1\left(190 \times 10^{9} / 1\right.$ $\left.-210 \times 10^{12} / 1\right)$. Erythrocyte count was higher in men than in women $(\mathrm{p}<0,001)$. 
In the group of first-time donors, reticulocyte count was, on an average, $0,88 \pm 0,05 \%$. In the examined male donors, mean reticulocyte count was $0,87 \pm 0,05$, in female $-0,88 \pm 0,04 \%$. There were no significant age- or sex-dependent differences between mean leukocyte, platelet and reticulocyte counts in the examined first-time donors $(\mathrm{p}>0,05)$.

In the first-time donors, mean cell hemoglobin $(\mathrm{MCH})$ was, on an average, $30,63 \pm 0,25 \mathrm{pg}$ (27-33 pg). In female donors, mean $\mathrm{MCH}$ was $29,40 \pm 0,42 \mathrm{pg}$ (27-31 pg), in male - 31,13 $\pm 0,24$ pg (28-33 pg). There was no significant sex-dependent difference in $\mathrm{MCH}$ in the examined first-time donors ( $\mathrm{p}>0,05)$. In all first-time donors, mean corpuscular volume (MCV) was, on an average, 93,41 $\pm 0,91$ (84-97 fl). In female

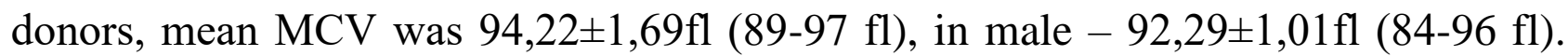
There was no significant sex-dependent difference in MCV in the control group ( $>00,05)$. In all first-time donors, mean corpuscular hemoglobin concentration

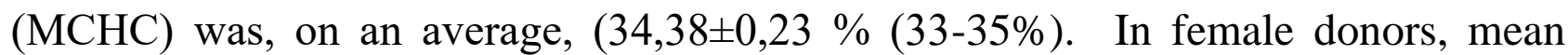

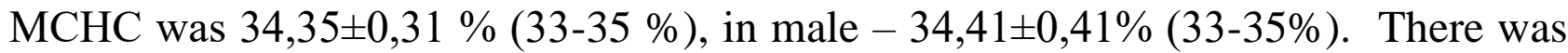
no significant age- or sex-dependent difference in $\mathrm{MCHC}$ in this group ( $\mathrm{p}>0,05)$.

We performed cytometry of peripheral blood erythrocytes of the first-time donors. Mean corpuscular diameter was, on an average, $7,192 \pm 0,06 \mathrm{mcm}^{3}$, micro- and

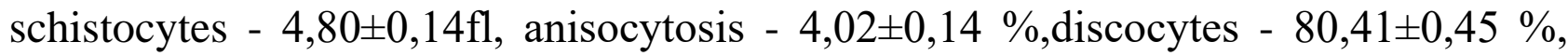
abnormal shape - $19,59 \pm 0,55 \%$. There was no significant age- and sex-related difference between average mean corpuscular diameter, micro- and schistocyte count, $\%$ of anisocytosis, discocytes and abnormally shaped erythrocytes in first-time donors ( $p>0,05$ ). In first-time donors, mean serum iron (SI) was $20,04 \pm 2,03 \mu \mathrm{mol} / 1$, and it was higher in male donors $(\mathrm{p}<0,01)$.

In fist-time donors, TIBS was, on an average, $57,25 \pm 2,49 \mu \mathrm{mol} / 1$. In the examined male donors, TIBS was, on an average, 56,52 $\pm 2,37 \mu \mathrm{mol} / 1$ (52,05 - 61,03 $\mu \mathrm{mol} / 1)$, in female $-58,55 \pm 2,20 \mu \mathrm{mol} / 1(54,87-62,05 \mu \mathrm{mol} / 1)$. TIBS was higher in females $(p<0,01)$. In the examined male donors, UIBS was, on an average, $35,77 \pm 4,07$ $\mu \mathrm{mol} / 1(28,05$ - 43,37 $\mu \mathrm{mol} / 1)$, in female - 39,78 $\pm 3,53 \mu \mathrm{mol} / 1$ (34,18 - 45,65 $\mu \mathrm{mol} / \mathrm{l})$. In general, the mean UIBC for the group of the first-time donors was $37,21 \pm 4,31$ 
$\mu \mathrm{mol} / \mathrm{l}$. UIBC was higher in females $(\mathrm{p}<0,01)$. In first-time donors, TSC was, on an average, $35,18 \pm 4,90 \%$. In the examined male donors, man TSC was $36,88 \pm 4,74 \%$ $(28,60-46,10 \%)$, in female $-32,17 \pm 3,63 \%(26,40-38,30 \%)$. TSC was higher in male donors $(\mathrm{p}<0,01)$. In first-term donors, serum TF was, on an average, 2,23 $\pm 0,10$ $\mathrm{g} / \mathrm{l}$. In the examined male donors, serum TF was $2,20 \pm 0,09 \mathrm{~g} / \mathrm{l}(2,03-2,38 \mathrm{~g} / \mathrm{l})$, in female $-2,28 \pm 0,09 \mathrm{~g} / \mathrm{l} \quad(2,14-2,42 \mathrm{~g} / \mathrm{l})$. Serum TF was higher in female donors $(\mathrm{p}<0,01)$. In the examined male donors, serum FN was, on an average, 24,91 $\pm 2,14$

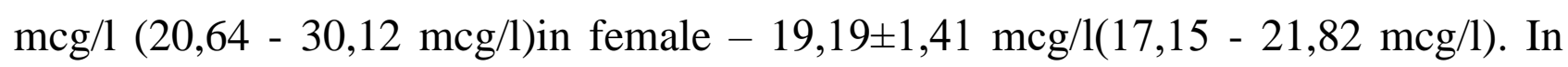
general, the mean serum FN in the group of first-time donors was $22,85 \pm 3,36 \mathrm{mcg} / \mathrm{l}$. Serum FN was higher in male donors $(\mathrm{p}<0,001)$. In young donors, serum iron was, on an average, $21,43 \pm 1,56 \mu \mathrm{mol} / 1(19,1-24,0 \mu \mathrm{mol} / \mathrm{l})$, in middle-aged donors $20,17 \pm 1,86 \mu \mathrm{mol} / 1(17,4-24,6 \mu \mathrm{mol} / 1)$, in ripe age donors - 18,03 $\pm 1,14 \mu \mathrm{mol} / 1(16,4$ 19,8 $\mu \mathrm{mol} / 1)$.

Serum iron level in young first-time donors was higher than in middle-aged $(p<0,05)$ and ripe age $(p<0,001)$ donors. The level of serum iron in middle-aged donors was higher than in the ripe age donors $(\mathrm{p}<0,01)$. Average level of serum TF in young

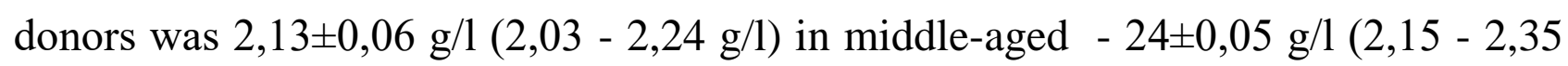
$\mathrm{g} / \mathrm{l})$, in ripe age $-2,35 \pm 0,05 \mathrm{~g} / \mathrm{l}(2,26-2,42 \mathrm{~g} / \mathrm{l})$. Average level of serum $\mathrm{FN}$ in young donors was $24,01 \pm 4,17 \mathrm{mcg} / \mathrm{ml}(17,21$ - 30,12 mcg/ml), in middle-aged donors $22,88 \pm 3,08 \mathrm{mcg} / \mathrm{ml}(17,49-26,55 \mathrm{mcg} / \mathrm{ml})$, in ripe age donors $-21,34 \pm 2,18 \mathrm{mcg} / \mathrm{ml}$ $(17,15-24,21 \mathrm{mcg} / \mathrm{ml})$. Serum FN in young donors was higher than in the ripe age $(\mathrm{p}<0,05)$. There was no significant difference in serum FN level between first-time young and middle-aged donors and middle-aged and ripe age donors.

In all first-time donors, RDW was 79,81 $\pm 0,81 \mathrm{fl}(79,01-80,71 \mathrm{fl})$. There was no significant sex-related difference in RDW in the examined first-time donors $(p>0,05)$. The margin of errors for mean values for erythrocyte populations varied between $0,4-4,1 \%$ of the reference value. In most cases, it did not exceed 1-2\%. According to the criteria approved for biology and medicine, accuracy achieved in the process of research is quite high. The data obtained is reliable and can be used both in practical work and as reference points. 
Infirst-time donors, OTE was 0,006 $\pm 0,001 \mathrm{~g} / \mathrm{ml}(0,005 \pm 0,001-0,007 \pm 0,001$ $\mathrm{g} / \mathrm{ml})$. There was no significant sex-related difference in OTE in the examined firsttime donors $(p>0,05)$. There was no significant sex-related difference in erythrocyte aggregation, platelet aggregation index and hematocrit in first-time donors $(p>0,05)$.

We established that in the group of first-time donors solid concentration in erythrocytes (\%) was 43,74 $\pm 0,11 \mathrm{~g}$ per $100 \mathrm{ml}$, solid content in erythrocyte was

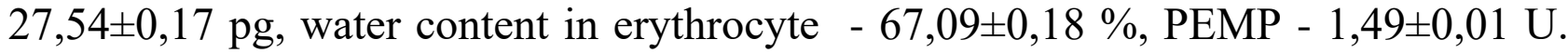
There was no significant sex-related difference in solid concentration in erythrocyte, solid content in erythrocyte, water content in erythrocyte and PEMP in first-time donors $(\mathrm{p}>0,05)$. We established that in the group of first-time donors erythrocyte fragmentation was, on an average, $1,74 \pm 0,09 \%(0,75$ - $3 \%)$. There was no significant sex-related difference in erythrocyte fragmentation in first-time donors $(p>0,05)$. While testing heat resistance of erythrocytes, there was no pink staining of plasma in any of 160 tested samples, which means that there was no thermal hemolysis.

We established that in the group of first-time donors 2-3-biphosphoglyceric acid (2,3-BPG) concentration in erythrocytes was $13,52 \pm 0,54 \mu \mathrm{mol} / \mathrm{g}$ of hemoglobin. In first-time female donors, 2,3-BPG concentration in erythrocytes was, on an average, $13,47 \pm 0,71 \mu \mathrm{mol} / \mathrm{g}$ of hemoglobin, in male donors it was respectively $13,64 \pm 0,63$ $\mu \mathrm{mol} / \mathrm{g}$ of hemoglobin.

We established that in the group of first-time donors adenosine triphosphoric acid concentration (ATP) concentration in erythrocytes was $3,28 \pm 0,17 \mu \mathrm{mol} / \mathrm{g}$ of hemoglobin. In first-time female donors, ATP concentration in erythrocytes was, on an average, $3,29 \pm 0,34 \mu \mathrm{mol} / \mathrm{g}$ of hemoglobin, in male donors it was respectively $3,27 \pm 0,21 \mu \mathrm{mol} / \mathrm{g}$ of hemoglobin.

In first-time donors, adenosine diphosphoric acid (ADP) concentration in erythrocytes was $1,21 \pm 0,08 \mu \mathrm{mol} / \mathrm{g}$ of hemoglobin. In first-time female donors, ADP concentration in erythrocytes was, on an average, $1,20 \pm 0,12 \mu \mathrm{mol} / \mathrm{g}$ of hemoglobin, in male donors it was respectively $1,22 \pm 0,09 \mu \mathrm{mol} / \mathrm{g}$ of hemoglobin.

In first-time donors, adenosine monophosphoric acid (AMP) concentration in erythrocytes was $0,40 \pm 0,03 \mu \mathrm{mol} / \mathrm{g}$ of hemoglobin. In first-time female donors, ADP 
concentration in erythrocytes was, on an average, $0,39 \pm 0,54 \mu \mathrm{mol} / \mathrm{g}$ of hemoglobin, in male donors it was respectively $0,39 \pm 0,07 \mu \mathrm{mol} / \mathrm{g}$ of hemoglobin.

Cumulative ATP + ADP + AMP concentration in erythrocytes of first-time donors was 4,89 $\pm 0,28 \mu \mathrm{mol} / \mathrm{g}$ of hemoglobin. In first-time female donors, ATP + ADP + AMP concentration in erythrocytes was, on an average, $4,90 \pm 0,54 \mu \mathrm{mol} / \mathrm{g}$ of hemoglobin, in male donors it was respectively $4,88 \pm 0,37 \mu \mathrm{mol} / \mathrm{g}$ of hemoglobin.

Results of the performed laboratory, morphologic, biochemical and biophysical tests: erythrocyte index determination, reticulocyte count, RDW, OTE, test for aggregation and penetrability of erythrocyte membranes, thermal, mechanical and acid resistance (of erythrocytes) testing, effectiveness of erythropoiesis value determination, study of energy metabolism in first-time donors erythrocytes demonstrated that the examined person making the control group of donors are practically healthy people whose test results are within normal limits for their age group.

Pattern of active blood donors donating for 2-5 years based on the results of laboratory, morphologic, biochemical and biophysical tests of peripheral blood.

In group I active donors hemoglobin concentration was, on an average, $138,18 \pm 8,98 \mathrm{~g} / \mathrm{l}$. There was no significant difference in hemoglobin concentration, erythrocyte and platelet count between Group I donors and control group donors $(p>0,05)$. In group I active donors, reticulocyte count was, on an average $0,88 \pm 0,05$ $\%$ :examined male donors $-0,87 \pm 0,05 \%$, femal donors $-0,88 \pm 0,04 \%$. There was no significant sex-related difference in the mean leuocyte, platelet and reticulocyte count in the examined group I active donors ( $p>0,05$ ). In group I active donors, mean MHC was $30,63 \pm 0,25 \operatorname{pg}(27$ - $33 \mathrm{pg})$. In female donors, MHC was, on an average $29,40 \pm 0,42 \mathrm{pg}(27-31 \mathrm{pg})$, in male donors - 31,13 $\pm 0,24 \mathrm{pg}$ ( 28 - $33 \mathrm{pg}$ ). There was no significant sex-related difference in MHC in the examined group I active donors

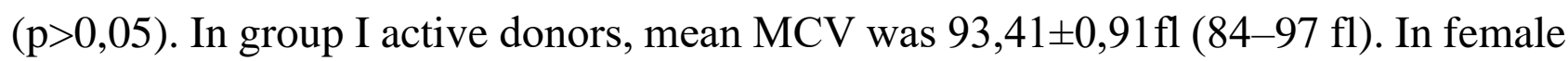

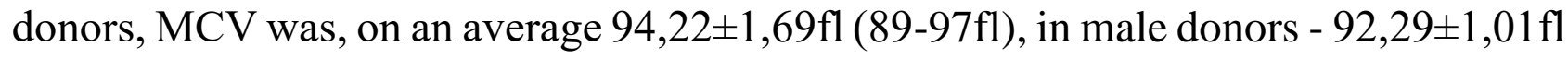
(84-96 fl). There was no significant sex-related difference in MCV in the examined group I active donors ( $\mathrm{p}>0,05)$. In group I active donors, mean MCHC was 34,38 $\pm 0,23$ 


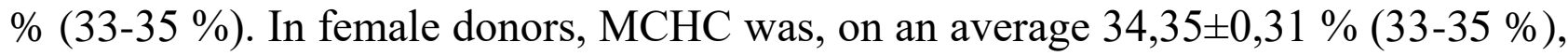

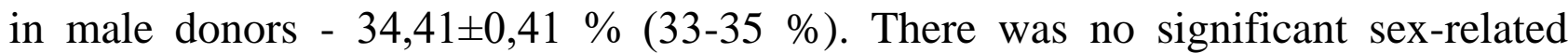
difference in $\mathrm{MCHC}$ in the examined Group I active donors ( $p>0,05)$. In young active donors, the results of the peripheral blood test were within the normal limits. It was established that mean hemoglobin concentration as well as erythrocyte and platelet count was higher in male donors $(\mathrm{p}<0,05)$, while average leucocyte count was the same in both sexes $(p>0,05)$. There was no significant difference in peripheral blood parameters between young active donors and control group donors ( $p>0,05)$.

In middle-aged active donors, the results of the peripheral blood test were within the normal limits. It was established that mean hemoglobin concentration as well as erythrocyte and platelet count was higher in male donors $(\mathrm{p}<0,05)$, while average leucocyte count was the same in both sexes $(p>0,05)$. There was no significant difference in peripheral blood parameters between middle-aged active donors and control group donors $(p>0,05)$ as well as between young and middle-aged active donors $(\mathrm{p}>0,05)$.

Extended peripheral blood test was performed for all ripe age active donors of study group I. Hemoglobin concentration was, on an average, 137,84 $\pm 7,90 \mathrm{~g} / \mathrm{l}$, erythrocyte count $-4,60 \pm 0,27 \times 10^{12} / 1$. $(\mathrm{p}<0,001)$. There was no sex-related significant difference in reticulocyte count between group I ripe age active donors $(p>0,05)$. There was no significant difference in reticulocyte count between group I ripe age active donors and control group donors ( $p>0,05)$. In group I ripe age active donors, the results of the peripheral blood test were within the normal limits. It was established that mean hemoglobin concentration as well as erythrocyte and platelet count was higher in male donors $(p<0,05)$, while average leucocyte count was the same in both sexes $(p>0,05)$. There was no significant difference in hemoglobin concentration, erythrocyte, reticulocyte and leukocyte count between young, middle-aged and ripe ageactive donors ( $p>0,05)$, while man platelet count in ripe age active donors was higher than in young and middle-aged donors $(\mathrm{p}<0,05)$. We performed cytometry of peripheral blood erythrocytes in this group of donors. Mean corpuscular diameter was, on an average,

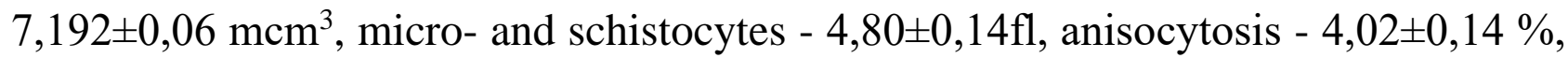


discocytes - 80,41 $\pm 0,45 \%$, abnormal shape - $19,59 \pm 0,55 \%$. There was no significant age- and sex-related difference between average mean corpuscular diameter, microand schistocyte count, $\%$ of anisocytosis, discocytes and abnormally shaped erythrocytes in group I donors $(\mathrm{p}>0,05)$.

In group I active donors, SI was $20,04 \pm 2,03 \mu \mathrm{mol} / 1$. In the examined male

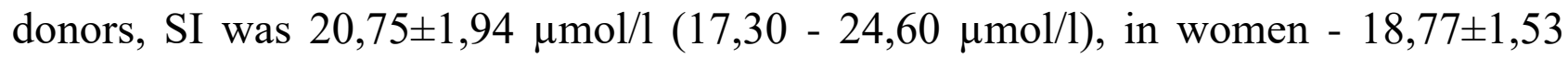
$\mu \mathrm{mol} / 1(16,40-21,30 \mu \mathrm{mol} / 1)$. SI was higher in male donors $(\mathrm{p}<0,01)$.

In group I active donors, TIBS was, on an average, $57,25 \pm 2,49 \mu \mathrm{mol} / 1$. In the examined male donors, TIBS was, on an average, 56,52 $\pm 2,37 \mu \mathrm{mol} / 1(52,05-61,03$ $\mu \mathrm{mol} / \mathrm{l})$, in female $-58,55 \pm 2,20 \mu \mathrm{mol} / 1(54,87-62,05 \mu \mathrm{mol} / 1)$. TIBS was higher in females $(\mathrm{p}<0,01)$. In group I active blood donors, UIBS was, on an average, $37,21 \pm 4,31 \mu \mathrm{mol} / 1$. UIBC was higher in females $(\mathrm{p}<0,01)$.

In group I active blood donors, TSC was, on an average, $35,18 \pm 4,90 \%$. In the examined male donors, man TSC was $36,88 \pm 4,74 \%(28,60-46,10 \%)$, in female $32,17 \pm 3,63 \%(26,40-38,30 \%)$. TSC was higher in male donors $(\mathrm{p}<0,01)$. In group I active blood donors, serum TF was, on an average, $2,23 \pm 0,10 \mathrm{~g} / 1$. In the examined male

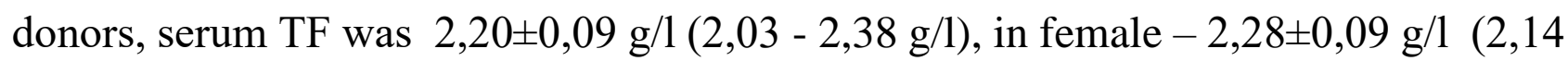
$-2,42 \mathrm{~g} / \mathrm{l})$. Serum TF was higher in female donors $(\mathrm{p}<0,01)$. In the examined male

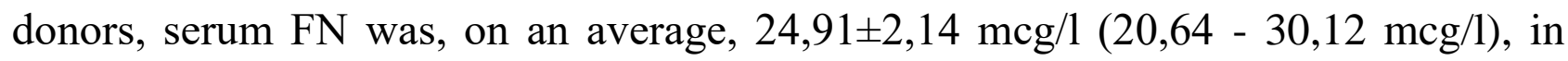
female $-19,19 \pm 1,41 \mathrm{mcg} / 1(17,15-21,82 \mathrm{mcg} / \mathrm{l})$. In general, the mean serum FN in Group I active blood donors was 22,85 3 3,36 mcg/l. Serum FN was higher in male

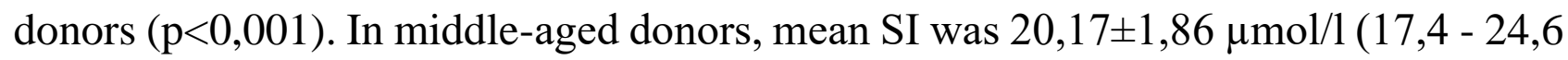
$\mu \mathrm{mol} / \mathrm{l})$. In ripe age donors, mean SI was $18,03 \pm 1,14 \mu \mathrm{mol} / 1(16,4-19,8 \mu \mathrm{mol} / \mathrm{l})$. SI in group I young donors was higher than in middle-aged $(\mathrm{p}<0,05)$ and ripe age $(\mathrm{p}<0,001)$ donors. SI in middle-aged donors was higher than in ripe age donors $(\mathrm{p}<0,01)$.

In young donors, TIBS was, on an average, 54,60 $1,54 \mu \mathrm{mol} / 1(52,05-57,44$ $\mu \mathrm{mol} / \mathrm{l})$. TIBS in ripe age donors was higher than in middle-aged $(\mathrm{p}<0,001)$ and young donors $(\mathrm{p}<0,001)$. TIBS in middle-aged donors was higher than in young donors 
( $\mathrm{p}<0,001)$. In middle-aged donors, UIBS was, on an average, $37,29 \pm 3,00 \mu \mathrm{mol} / 1(31,30$ $-42,60 \mu \mathrm{mol} / 1)$.

In group I ripe age active donors, UIBS was higher than in middle-aged $(\mathrm{p}<0,001)$ and young donors $(\mathrm{p}<0,001)$. UIBS in group I middle-aged active donors was higher than in young donors $(\mathrm{p}<0,001)$.

In young donors, TSC was, on an average $39,34 \pm 3,77 \%(33,9-46,1 \%)$, in

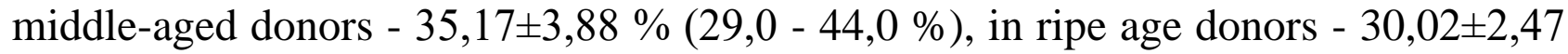
$\%(26,4-33,7 \%)$. TSC of young donors was higher than in middle-aged $(\mathrm{p}<0,01)$ and ripe age $(\mathrm{p}<0,001)$ donors. TSC of middle-aged donors was higher than in ripe age donors $(\mathrm{p}<0,001)$. In young donors, serum TF was, on an average, $2,13 \pm 0,06 \mathrm{~g} / 1(2,03$ - 2,24 g/l), in middle-aged donors - 2,24 $\pm 0,05 \mathrm{~g} / 1(2,15-2,35 \mathrm{~g} / \mathrm{l})$, in ripe age donors $-2,35 \pm 0,05 \mathrm{~g} / 1(2,26-2,42)$. In group I ripe age active donors, TF was higher than in young $(\mathrm{p}<0,001)$ and middle-aged $(\mathrm{p}<0,001)$ donors. In middle-aged donors, TF was higher than in young donors $(\mathrm{p}<0,001)$. In group I young active blood donors, serum FN was, on an average, $24,01 \pm 4,17 \mathrm{mcg} / \mathrm{ml}(17,21-30,12 \mathrm{mcg} / \mathrm{ml})$. In group I young active blood donors, FN level was higher than in ripe age donors $(\mathrm{p}<0,05)$. There was no significant difference between FN level in group one young active blood donors and middle-aged active donors as well as between middle-aged and ripe age active donors $(\mathrm{p}>0,05)$.

Main parameters of iron metabolism in Group I active blood donors were within normal limits except for elevated UIBS. Mean SI, TSC and FN were higher in male donors $(\mathrm{p}<0,05)$, while mean TIBS, UIBS and TF were similar $(\mathrm{p}>0,05)$. However, max levels of TIBS, UIBS and TF were elevated, while minimal levels of TSC and FN were low. Mean SI, TSC and TF in group I active donors were lower than in the control group ( $\mathrm{p}<0,05)$, while mean TIBS, UIBS and TF were higher than in the control group $(\mathrm{p}<0,05)$.

Our research revealed sex-dependent peculiarities of peripheral blood parameters and iron metabolism in active blood donors.

In all group I active blood donors, RDW was 79,81 $\pm 0,81 \mathrm{fl}(79,01-80,71 \mathrm{fl})$. There was no significant age-related difference in RDW between the examined active 
blood donors of group I ( $p>0,05)$ as well as between them and control group ( $p>0,05)$. In group I active blood donors, OTE was $0,006 \pm 0,001 \mathrm{~g} / \mathrm{ml}(0,005 \pm 0,001$ $0,007 \pm 0,001 \mathrm{~g} / \mathrm{ml})$. There was no significant sex-related difference in OTE and coefficients calculated from it between group I active blood donors $(p>0,05)$ as well as between them and control group ( $p>0,05)$.

There was no significant sex-related difference in erythrocyte aggregation, platelet aggregation index and hematocrit between group I active blood donors as well as between them and control group ( $p>0,05)$.

We established that in group I active blood donors solid concentration in erythrocytes (\%) was 43,74 $\pm 0,11 \mathrm{~g}$ per $100 \mathrm{ml}$, solid content in erythrocyte was $27,54 \pm 0,17 \mathrm{pg}$, water content in erythrocyte $-67,09 \pm 0,18 \%$, PEMP - 1,49 $\pm 0,01 \mathrm{U}$.

There was no significant sex-related difference in solid concentration in erythrocyte, solid content in erythrocyte, water content in erythrocyte and PEMP in group I active blood donors ( $>>0,05)$. We established that in group I active blood donors erythrocyte fragmentation was, on an average, 1,73 $\pm 0,12 \%(0,76-2,9 \%)$ $1,74 \pm 0,11 \%$ and $1,72 \pm 0,17 \%$ in male and female donors respectively. There was no significant sex-related difference in erythrocyte fragmentation between group I active blood donors as well as in comparison with control group ( $p>0,05)$.

We established that in group I active blood donors 2,3-BPG concentration in erythrocytes was $13,51 \pm 0,52 \mu \mathrm{mol} / \mathrm{g}$ of hemoglobin. In female donors from this group, 2,3 -BPG concentration in erythrocytes was, on an average, $13,45 \pm 0,71 \mu \mathrm{mol} / \mathrm{g}$ of hemoglobin, in male donors it was respectively $13,62 \pm 0,64 \mu \mathrm{mol} / \mathrm{g}$ of hemoglobin.

There was no significant difference in 2,3-BPG concentration in erythrocytes between group I active blood donors and control group donors ( $p>0,05)$.

We established that in group I active blood donors ATP concentration in erythrocytes was $3,29 \pm 0,17 \mu \mathrm{mol} / \mathrm{g}$ of hemoglobin. In active female donors, ATP concentration in erythrocytes was, on an average, $3,30 \pm 0,34 \mu \mathrm{mol} / \mathrm{g}$ of hemoglobin, andin male donors it was respectively $3,28 \pm 0,21 \mu \mathrm{mol} / \mathrm{g}$ of hemoglobin. In group I active blood donors, ADP concentration in erythrocytes was $1,22 \pm 0,08 \mu \mathrm{mol} / \mathrm{g}$ of hemoglobin. In female donors from this group, ADP concentration in erythrocytes 
was, on an average, $1,21 \pm 0,12 \mu \mathrm{mol} / \mathrm{g}$ of hemoglobin, and in male donors it was respectively $1,23 \pm 0,09 \mu \mathrm{mol} / \mathrm{g}$ of hemoglobin. In group I active blood donors, AMP concentration in erythrocytes was $0,41 \pm 0,03 \mu \mathrm{mol} / \mathrm{g}$ of hemoglobin. In female donors, ADP concentration in erythrocytes was, on an average, $0,42 \pm 0,08 \mu \mathrm{mol} / \mathrm{g}$ of hemoglobin, in male donors it was respectively $0,40 \pm 0,07 \mu \mathrm{mol} / \mathrm{g}$ of hemoglobin.

Cumulative ATP + ADP + AMP concentration in erythrocytes of Group I active blood donors was 4,89 $\pm 0,28 \mu \mathrm{mol} / \mathrm{g}$ of hemoglobin. In Group I active female donors, $\mathrm{ATP}+\mathrm{ADP}+\mathrm{AMP}$ concentration in erythrocytes was, on an average, $4,93 \pm 0,54 \mu \mathrm{mol} / \mathrm{g}$ of hemoglobin, in male donors it was respectively $4,91 \pm 0,37 \mu \mathrm{mol} / \mathrm{g}$ of hemoglobin.

Pattern of active blood donors donating for 6-9 years based on the results of laboratory, morphologic, biochemical and biophysical tests of peripheral blood.

In group II active donors hemoglobin concentration was, on an average, $138,88 \pm 6,91 \mathrm{~g} / \mathrm{l}$. In the examined male donors hemoglobin concentration was $142,72 \pm 4,60 \mathrm{~g} / \mathrm{l}(135-150 \mathrm{~g} / \mathrm{l})$, in female donors- $132,06 \pm 3,77 \mathrm{~g} / \mathrm{l}(127-140 \mathrm{~g} / \mathrm{l})$. Hemoglobin concentration was higher in male donors $(\mathrm{p}<0,001)$.

In group II active donors, erythrocyte count was, on an average, $4,63 \pm 0,23 \times 10^{12} / 1$. In the examined male donors, mean erythrocyte count was $4,76 \pm 0,15 \times 10^{12} / 1\left(4,5-5,0 \times 10^{12} /\right)$, in female donors $-4,40 \pm 0,13 \times 10^{12} / 1(4,2$ $\left.4,7 \times 10^{12} / 1\right)$. In group II active donors, platelet count was, on an average, $203,40 \pm 13,94 \times 10^{9} / 1$. In the examined male donors, mean platelet count was $204,38 \pm 15,23 \times 10^{9} / 1\left(180\right.$ до $\left.230 \times 10^{9} / 1\right)$, in female donors $-201,67 \pm 11,51 \times 10^{9} / 1(190$ до $\left.220 \times 10^{9} / 1\right)$. In group II active donors, reticulocyte count was, on an average

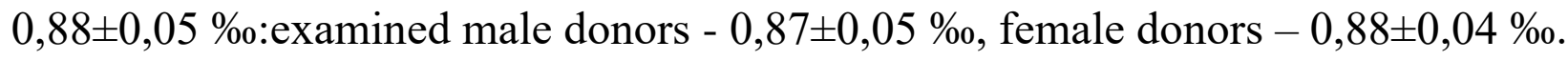

There was no significant sex-related difference in the mean leucocyte, platelet and reticulocyte count in the examined group II active donors ( $p>0,05)$. In group II active donors, mean MHC was 30,63 00,25pg(27 - $33 \mathrm{pg}$ ). In female donors, MHC was, on an average $29,40 \pm 0,42 \mathrm{pg}$ ( 27 - $31 \mathrm{pg}$ ), in male donors - 31,13 $\pm 0,24 \mathrm{pg}$ (28 - $33 \mathrm{pg}$ ). There was no significant sex-related difference in MHC in the examined group II active 
donors (p>0,05). In all group II active donors, mean MCV was 93,41 $\pm 0,91 \mathrm{fl}$ (84-97 $\mathrm{fl}$ ). In female donors, MCV was, on an average 94,22 $\pm 1,69 \mathrm{fl}$ (89-97fl), in male donors - 92,29 $\pm 1,01 \mathrm{fl}$ (84-96 fl). There was no significant sex-related difference in MCV in the examined group II active donors ( $>>0,05)$. In all group II active donors, mean MCHC was 34,38 $\pm 0,23 \%$ (33-35\%). In female donors, MCHC was, on an average $34,35 \pm 0,31 \%$ (33-35\%), in male donors - 34,41 $\pm 0,41 \%(33-35 \%)$. There was no significant age- and sex-related difference in MCHC in the examined group II active donors $(p>0,05)$. We performed cytometry of peripheral blood erythrocytes in this group of donors. Mean corpuscular diameter was, on an average, 7,01 $\pm 0,04 \mathrm{mcm}^{3}$,

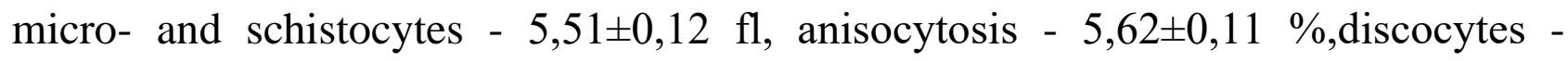
$72,01 \pm 0,25 \%$, abnormal shape $-28,98 \pm 0,75 \%$. In the examined group II active donors, we detected reduction of mean corpuscular diameter, discocyte percentage as well as increase of micro - and schistocytes, anocytosis and the number of abnormally shaped erythrocytes in comparison with the control group and the group donating for $2-5$ years $(p<0,05)$. In group II active donors, SI was $20,04 \pm 2,03 \mu \mathrm{mol} / 1$. In the

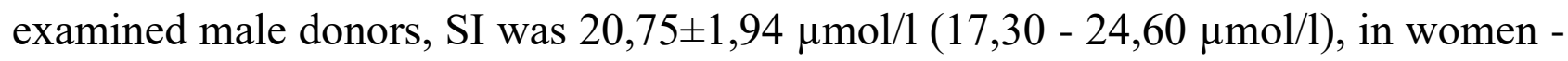
$18,77 \pm 1,53 \mu \mathrm{mol} / 1(16,40-21,30 \mu \mathrm{mol} / 1)$. SI was higher in male donors $(\mathrm{p}<0,01)$. In group II active donors, TIBS was, on an average, 57,25 $\pm 2,49 \mu \mathrm{mol} / 1$. In the examined male donors, TIBS was, on an average, $56,52 \pm 2,37 \mu \mathrm{mol} / 1(52,05-61,03 \mu \mathrm{mol} / 1)$, in female $-58,55 \pm 2,20 \mu \mathrm{mol} / \mathrm{l}(54,87-62,05 \mu \mathrm{mol} / \mathrm{l})$. TIBS was higher in females $(\mathrm{p}<0,01)$.

In the examined male donors, mean UIBS was $35,77 \pm 4,07 \mu \mathrm{mol} / 1(28,05-43,37$ $\mu \mathrm{mol} / \mathrm{l})$, in female donors $-39,78 \pm 3,53 \mu \mathrm{mol} / 1$ (34,18 - 45,65 $\mu \mathrm{mol} / \mathrm{l})$. Average UIBS in group II active blood donors was $37,21 \pm 4,31 \mu \mathrm{mol} / 1$. UIBC was higher in females $(\mathrm{p}<0,01)$.]

In group II active blood donors, TSC was, on an average, 35,18 $\pm 4,90 \%$. In the examined male donors, man TSC was $36,88 \pm 4,74 \%(28,60-46,10 \%)$, in female $32,17 \pm 3,63 \%(26,40-38,30 \%)$. TSC was higher in male donors $(\mathrm{p}<0,01)$. In group II active blood donors, serum TF was, on an average, $2,23 \pm 0,10 \mathrm{~g} / 1$. In the examined male donors, serum TF was $2,20 \pm 0,09 \mathrm{~g} / \mathrm{l}(2,03-2,38 \mathrm{~g} / \mathrm{l})$, in female $-2,28 \pm 0,09 \mathrm{~g} / \mathrm{l}$ 
$(2,14-2,42 \mathrm{~g} / \mathrm{l})$. Serum TF was higher in female donors $(\mathrm{p}<0,01)$. In the examined male donors, serum FN was, on an average, 24,91 $\pm 2,14 \mathrm{mcg} / \mathrm{l}(20,64-30,12 \mathrm{mcg} / \mathrm{l})$, in female $-19,19 \pm 1,41 \mathrm{mcg} / 1(17,15-21,82 \mathrm{mcg} / \mathrm{l})$. In general, the mean serum FN in group II active blood donors was 22,85 $\pm 3,36 \mathrm{mcg} / \mathrm{l}$. Serum FN was higher in male donors $(\mathrm{p}<0,001)$. In young donors, mean SI was21,43 $\pm 1,56 \mu \mathrm{mol} / 1(19,1-24,0$

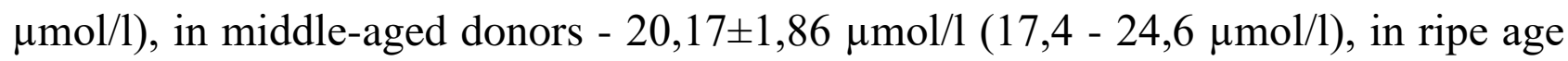
donors - 18,03 $\pm 1,14 \mu \mathrm{mol} / 1(16,4-19,8 \mu \mathrm{mol} / \mathrm{l})$.

SI in group II young donors was higher than in middle-aged $(\mathrm{p}<0,05)$ and ripe age $(\mathrm{p}<0,001)$ donors. SI in middle-aged donors was higher than in ripe age donors $(\mathrm{p}<0,01)$. In young donors, TIBS was, on an average, $54,60 \pm 1,54 \mu \mathrm{mol} / 1(52,05-57,44$ $\mu \mathrm{mol} / \mathrm{l})$, in middle-aged - 57,46 $\pm 1,40 \mu \mathrm{mol} / 1(55,13-60,26 \mu \mathrm{mol} / 1)$, in ripe age active donors from group II - 60,15 $\pm 1,34 \mu \mathrm{mol} / 1(57,95-62,05 \mu \mathrm{mol} / \mathrm{l})$. TIBS in ripe age donors was higher than in middle-aged $(\mathrm{p}<0,001)$ and young donors $(\mathrm{p}<0,001)$. TIBS in middle-aged donors was higher than in young donors $(\mathrm{p}<0,001)$. In group II young blood donors, UIBS was, on an average, 33,16 $\pm 2,90 \mu \mathrm{mol} / 1(28,05-37,31 \mu \mathrm{mol} / 1)$, in middle-aged donors - 37,29 $\pm 3,00 \mu \mathrm{mol} / 1(31,30-42,60 \mu \mathrm{mol} / 1)$, in ripe age donors $42,12 \pm 2,35 \mu \mathrm{mol} / 1(38,86-45,65 \mu \mathrm{mol} / 1)$. In Group II ripe age active donors, UIBS was higher than in middle-aged $(\mathrm{p}<0,001)$ and young donors $(\mathrm{p}<0,001)$. UIBS in group II middle-aged active donors was higher than in young donors $(\mathrm{p}<0,001)$. In group II young donors, TSC was higher than in middle-aged $(\mathrm{p}<0,01)$ and ripe age $(\mathrm{p}<0,001)$ donors. TSC of middle-aged donors was higher than in ripe age donors $(\mathrm{p}<0,001)$. In young donors, serum TF was, on an average, 2,13 $\pm 0,06 \mathrm{~g} / \mathrm{l}(2,03-2,24 \mathrm{~g} / \mathrm{l})$, in middle-

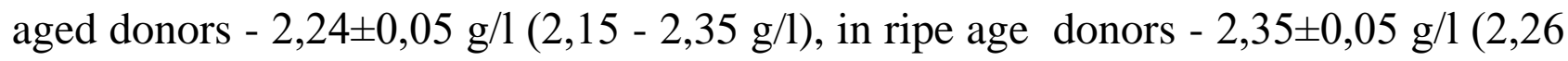
- 2,42 g/l). In group II ripe age active donors, TF was higher than in young $(\mathrm{p}<0,001)$ and middle-aged $(\mathrm{p}<0,001)$ donors. In middle-aged donors, TF was higher than in young donors $(\mathrm{p}<0,001)$. In group II young active blood donors, serum FN was, on an average, $24,01 \pm 4,17 \mathrm{mcg} / \mathrm{ml}(17,21-30,12 \mathrm{mcg} / \mathrm{ml})$, in middle aged donors $22,88 \pm 3,08 \mathrm{mcg} / \mathrm{ml}(17,49-26,55 \mathrm{mcg} / \mathrm{ml})$, in ripe age donors $-21,34 \pm 2,18 \mathrm{mcg} / \mathrm{ml}$ $(17,15-24,21 \mathrm{mcg} / \mathrm{ml})$. In Group II young active blood donors, FN level was higher than in ripe age donors $(\mathrm{p}<0,05)$. There was no significant difference in FN level 
between group II young active blood donors and middle-aged active donors as well as between middle-aged and ripe age active donors $(p>0,05)$.

In all group II active blood donors, RDW was 79,81 $\pm 0,81 \mathrm{fl}(79,01-80,71 \mathrm{fl})$. There was no significant sex-related difference in RDW between the examined active blood donors of group II ( $p>0,05)$. There is no significant difference in RDW between Group I and II active donors and first-time donors ( $p>0,05)$. In group II active blood donors, OTE was $0,006 \pm 0,001 \mathrm{~g} / \mathrm{ml}(0,005 \pm 0,001-0,007 \pm 0,001 \mathrm{~g} / \mathrm{ml})$. There was no significant sex-related difference in OTE between group II active blood donors $(p>0,05)$ as well as between them and control group $(p>0,05)$.

There was no significant sex-related difference in erythrocyte aggregation, platelet aggregation index and hematocrit between group II active blood donors $(\mathrm{p}>0,05)$.

We established that in group II active blood donors solid concentration in erythrocytes (\%) was 43,74 $\pm 0,11 \mathrm{~g}$ per $100 \mathrm{ml}$, solid content in erythrocyte was

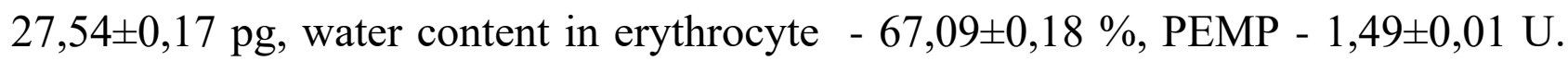
There was no significant sex-related difference in solid concentration in erythrocyte, solid content in erythrocyte, water content in erythrocyte and PEMP between group II active blood donors $(\mathrm{p}>0,05)$. We established that in group II active blood donors erythrocyte fragmentation was, on an average, $1,73 \pm 0,08 \%(0,76-2,9 \%)$. There was no significant sex-related difference in erythrocyte fragmentation between group II active blood donors $(\mathrm{p}>0,05)$.

It was established that in group II active blood donors EEV was, on an average, $0,070 \pm 0,0010 \cdot 10^{12} / 1$; in active female donors mean EEV was $0,069 \pm 0,0021 \cdot 10^{12} / 1$, and in male donors it was respectively $0,071 \pm 0,0019 \cdot 10^{12} / 1$. There was no significant sexrelated difference between group II active blood donors and in comparison with group $\mathrm{I}(\mathrm{p}>0,05)$.

We established that in group II active blood donors 2,3-BPG concentration in erythrocytes was $13,52 \pm 0,54 \mu \mathrm{mol} / \mathrm{g}$ of hemoglobin. In female donors from this group, 2,3-BPG concentration in erythrocytes was, on an average, $13,47 \pm 0,71 \mu \mathrm{mol} / \mathrm{g}$ of hemoglobin, in male donors it was respectively $13,64 \pm 0,63 \mu \mathrm{mol} / \mathrm{g}$ of hemoglobin. 
There was no significant sex-related difference in 2,3-BPG concentration in erythrocytes between group II active blood donors ( $p>0,05)$.

We established that in group II active blood donors ATP concentration in erythrocytes was $3,28 \pm 0,17 \mu \mathrm{mol} / \mathrm{g}$ of hemoglobin. In active female donors, ATP concentration in erythrocytes was, on an average, $3,29 \pm 0,34 \mu \mathrm{mol} / \mathrm{g}$ of hemoglobin, andin male donors it was respectively $3,27 \pm 0,21 \mu \mathrm{mol} / \mathrm{g}$ of hemoglobin. In group II active blood donors, ADP concentration in erythrocytes was $1,21 \pm 0,08 \mu \mathrm{mol} / \mathrm{g}$ of hemoglobin. In female donors from this group, ADP concentration in erythrocytes was, on an average, $1,20 \pm 0,12 \mu \mathrm{mol} / \mathrm{g}$ of hemoglobin, and in male donors it was respectively $1,22 \pm 0,09 \mu \mathrm{mol} / \mathrm{g}$ of hemoglobin. In group II active blood donors, AMP concentration in erythrocytes was $0,40 \pm 0,03 \mu \mathrm{mol} / \mathrm{g}$ of hemoglobin. In female donors, ADP concentration in erythrocytes was, on an average, $0,42 \pm 0,08 \mu \mathrm{mol} / \mathrm{g}$ of hemoglobin, in male donors it was respectively $0,39 \pm 0,07 \mu \mathrm{mol} / \mathrm{g}$ of hemoglobin.

Cumulative ATP + ADP + AMP concentration in erythrocytes of group II active blood donors was $4,89 \pm 0,28 \mu \mathrm{mol} / \mathrm{g}$ of hemoglobin. In group II active female donors, $\mathrm{ATP}+\mathrm{ADP}+\mathrm{AMP}$ concentration in erythrocytes was, on an average, $4,90 \pm 0,54 \mu \mathrm{mol} / \mathrm{g}$ of hemoglobin, in male donors it was respectively $4,88 \pm 0,37 \mu \mathrm{mol} / \mathrm{g}$ of hemoglobin. There was no significant sex-related difference in concentration of ATP, ADP and AMP and cumulative ATP + ADP + AMP concentration in erythrocytes between group II active blood donors ( $\mathrm{p}>0,05)$.

Pattern of active blood donors donating for more than 10 years based on the results of laboratory, morphologic, biochemical and biophysical tests of peripheral blood.

In group III active donors, hemoglobin concentration was, on an average, $138,18 \pm 8,98 \mathrm{~g} / \mathrm{l}$. In the examined male donors hemoglobin concentration was

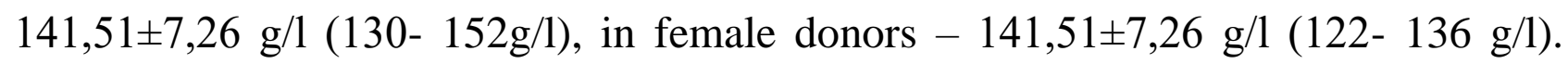
Hemoglobin concentration was higher in male donors $(\mathrm{p}<0,001)$. There was no significant difference in hemoglobin concentration between group III active donors and control group ( $p>0,05)$. In group III active donors, erythrocyte count was, on an average, $4,58 \pm 0,29 \times 10^{12} / 1$. In the examined male donors, mean erythrocyte count 
was $4,68 \pm 0,25 \times 10^{12} / 1\left(4,2-5,0 \times 10^{12} / 1\right)$, in female donors $-4,27 \pm 0,17 \times 10^{12} / 1(4,0$ $\left.4,6 \times 10^{12} / 1\right)$. Erythrocyte count was higher in male donors $(\mathrm{p}<0,001)$. There was no significant difference in erythrocyte count between group III active donors and control group donors $(\mathrm{p}>0,05)$. In the examined male donors, leukocyte count was, on an average, $5,97 \pm 1,10 \times 10^{9} / 1\left(4,0-8,0 \times 10^{9} / 1\right)$, in female donors $-5,69 \pm 1,03 \times 10^{9} / 1(4,0$ $\left.7,3 \times 10^{9} / 1\right)$. In general, in group III active donors leukocyte count was $5,91 \pm 1,08 \times 10^{9} / 1$. There was no significant sex-related difference in leukocyte count between group III active donors $(p>0,05)$ and between them and control group donors $(p>0,05)$. In group III active donors, platelet count was, on an average, $204,31 \pm 15,40 \times 10^{9} / 1$. In the examined male donors, mean platelet count was $205,90 \pm 14,99 \times 10^{9} / 1$ (180 до $\left.240 \times 10^{9} / 1\right)$, in female donors $-199,17 \pm 16,21 \times 10^{9} / 1\left(180\right.$ до $\left.230 \times 10^{9} / 1\right)$. There was nо significant sex-related difference in platelet count between group III active donors $(p>0,05)$ and between them and control group donors $(p>0,05)$. In group III active donors, reticulocyte count was, on an average $0,88 \pm 0,05 \%$ : examined male donors $0,87 \pm 0,05 \%$, female donors $-0,88 \pm 0,04 \%$. There was no significant sex-related difference in the mean leucocyte, platelet and reticulocyte count in the group III active

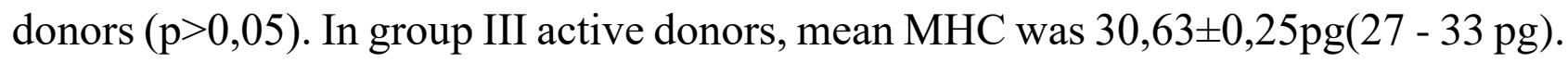

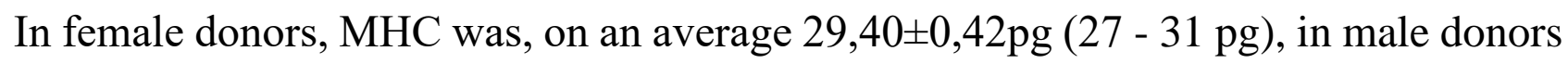
- 31,13 $\pm 0,24 p g$ (28 - 33 pg). There was no significant sex-related difference in MHC in the examined group III active donors ( $\mathrm{p}>0,05)$. In all group III active donors, mean MCV was 93,41 $\pm 0,91 \mathrm{fl}(84-97 \mathrm{fl})$. In female donors, MCV was, on an average

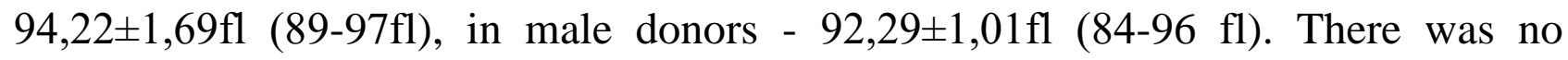
significant sex-related difference in MCV in the examined group III active donors

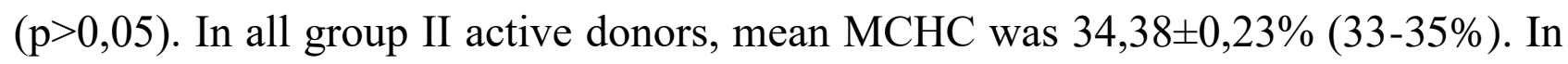

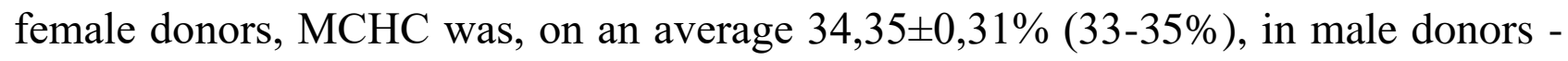
$34,41 \pm 0,41 \%(33-35 \%)$. There was no significant age- and sex-related difference in MCHC in the examined group III active donors ( $>>0,05)$.

In young active donors, the results of the peripheral blood test were within the normal limits. It was established that mean hemoglobin concentration as well as 
erythrocyte and platelet count was higher in male donors $(\mathrm{p}<0,05)$, while average leucocyte count was the same in both sexes $(p>0,05)$. There was no significant difference in the mean parameters of peripheral blood between active young donors and control group donors ( $\mathrm{p}>0,05)$.

In middle-aged active donors, the results of the peripheral blood test were within the normal limits. It was established that mean hemoglobin concentration and erythrocyte count was higher in male donors $(\mathrm{p}<0,05)$, while average leucocyte and platelet count was similar in both sexes $(p>0,05)$. There was no significant difference in the mean parameters of peripheral blood between active middle-aged donors and control group donors $(\mathrm{p}>0,05)$ as well as between young and middle-aged donors ( $>0,05)$. There was no sex-related difference in reticulocyte count between group III ripe age active donors $(p>0,05)$. There was no significant difference in reticulocyte count between group III ripe age active donors and control group donors ( $p>0,05)$. There was no sex-related difference in platelet count between group III ripe age active donors $(p>0,05)$. There was no significant difference in reticulocyte count between group III ripe active donors and control group donors ( $\mathrm{p}>0,05)$. Mean platelet count in the ripe age active donors was lower than in the young active donors $(p<0,01)$ and middle-aged active donors $(\mathrm{p}<0,05)$. In group III ripe age active donors, the results of the peripheral blood test were within the normal limits. It was established that mean hemoglobin concentration and erythrocyte count was higher in male donors $(\mathrm{p}<0,05)$, while average leucocyte and platelet count was similar in both sexes $(p>0,05)$. There was no significant difference in the mean parameters of peripheral blood between active ripe age donors and control group donors $(p>0,05)$. There was no significant difference in the mean hemoglobin concentration, erythrocyte, reticulocyte and leukocyte count between young and ripe age donors as well as between middle-aged and ripe age donors $(p>0,05)$, while platelet count in the ripe age donors was higher than in young and middle-aged donors $(\mathrm{p}<0,05)$. We performed cytometry of peripheral blood erythrocytes in this group of donors. Mean corpuscular diameter was, on an average, $6,31 \pm 0,03 \mathrm{mcm}^{3}$, micro- and schistocytes - $6,21 \pm 0,23 \mathrm{fl}$, anisocytosis $6,762 \pm 0,13 \%$, discocytes $-65,11 \pm 0,08 \%$, abnormal shape $-34,79 \pm 0,11 \%$. In the 
examined Group III active donors, we detected significant reduction of the mean corpuscular diameter, discocyte percentage as well as increase of micro - and schistocytes, anocytosis and the number of abnormally shaped erythrocytes in comparison with the control group and the group II $(\mathrm{p}<0,05)$. These changes are suggestive of latent iron deficiency (LID) development.

In group III active donors, SI was $20,04 \pm 2,03 \mu \mathrm{mol} / 1$. In the examined male

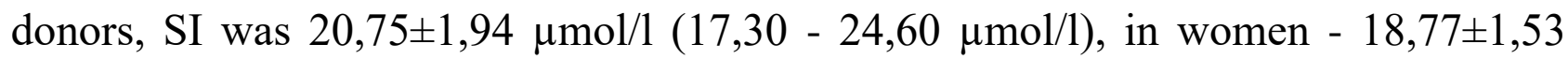
$\mu \mathrm{mol} / 1(16,40-21,30 \mu \mathrm{mol} / 1)$. SI was higher in male donors $(\mathrm{p}<0,01)$. In group III active donors, TIBS was, on an average, $57,25 \pm 2,49 \mu \mathrm{mol} / 1$. In the examined male donors, TIBS was, on an average, 56,52 $\pm 2,37 \mu \mathrm{mol} / 1(52,05-61,03 \mu \mathrm{mol} / 1)$, in female $-58,55 \pm 2,20 \mu \mathrm{mol} / 1(54,87-62,05 \mu \mathrm{mol} / 1)$. TIBS was higher in females $(\mathrm{p}<0,01)$. In the examined male donors, mean UIBS was $35,77 \pm 4,07 \mu \mathrm{mol} / 1(28,05-43,37 \mu \mathrm{mol} / 1)$, in female donors - 39,78 $\pm 3,53 \mu \mathrm{mol} / 1(34,18-45,65 \mu \mathrm{mol} / 1)$. Average UIBS in group II active blood donors was 37,21 $\pm 4,31 \mu \mathrm{mol} / 1$. UIBC was higher in females $(\mathrm{p}<0,01)$. In group III active blood donors, TSC was, on an average, $35,18 \pm 4,90 \%$. In the examined male donors, man TSC was $36,88 \pm 4,74 \%(28,60-46,10 \%)$, in female $32,17 \pm 3,63 \%(26,40-38,30 \%)$. TSC was higher in male donors $(\mathrm{p}<0,01)$. In group III active blood donors, serum TF was, on an average, $2,23 \pm 0,10 \mathrm{~g} / 1$. In the examined

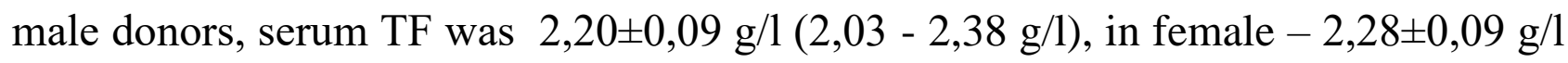
$(2,14-2,42 \mathrm{~g} / \mathrm{l})$. Serum TF was higher in female donors $(\mathrm{p}<0,01)$. In the examined male donors, serum FN was, on an average, 24,91 $\pm 2,14 \mathrm{mcg} / 1(20,64-30,12 \mathrm{mcg} / \mathrm{l})$, in female $-19,19 \pm 1,41 \mathrm{mcg} / 1(17,15-21,82 \mathrm{mcg} / \mathrm{l})$. In general, the mean serum FN in group II active blood donors was $22,85 \pm 3,36 \mathrm{mcg} / \mathrm{l}$. Serum FN was higher in male donors $(\mathrm{p}<0,001)$. In young donors, mean SI was $21,43 \pm 1,56 \mu \mathrm{mol} / 1(19,1-24,0$

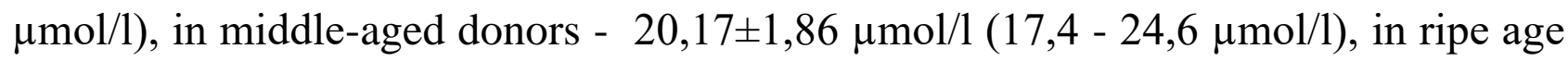
donors - 18,03 $\pm 1,14 \mu \mathrm{mol} / 1(16,4-19,8 \mu \mathrm{mol} / 1)$. SI in group III young donors was higher than in the middle-aged $(p<0,05)$ and ripe age $(p<0,001)$ donors. SI in middleaged donors was higher than in ripe age donors $(\mathrm{p}<0,01)$. In young donors, TIBS was, on an average, $54,60 \pm 1,54 \mu \mathrm{mol} / 1(52,05-57,44 \mu \mathrm{mol} / \mathrm{l})$, in middle-aged - 57,46 $\pm 1,40$

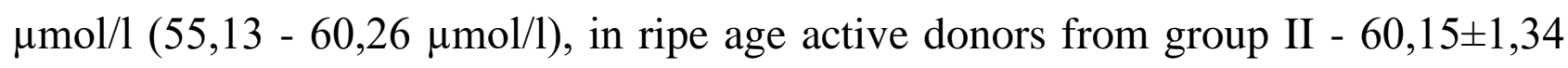


$\mu \mathrm{mol} / 1(57,95-62,05 \mu \mathrm{mol} / \mathrm{l})$. TIBS in ripe age donors was higher than in the middleaged $(p<0,001)$ and young donors $(p<0,001)$. TIBS in middle-aged donors was higher than in young donors $(\mathrm{p}<0,001)$. In group III young blood donors, UIBS was, on an average, 33,16 $\pm 2,90 \mu \mathrm{mol} / 1(28,05$ - 37,31 $\mu \mathrm{mol} / 1)$, in middle-aged donors $37,29 \pm 3,00 \mu \mathrm{mol} / 1(31,30-42,60 \mu \mathrm{mol} / 1)$, in ripe age donors - 42,12 $\pm 2,35 \mu \mathrm{mol} / 1$ (38,86 - 45,65 $\mu \mathrm{mol} / \mathrm{l})$. In group III ripe age active donors, UIBS was higher than in middle-aged $(\mathrm{p}<0,001)$ and young donors $(\mathrm{p}<0,001)$. UIBS in group II middle-aged active donors was higher than in young donors $(\mathrm{p}<0,001)$.

In young donors, TSC was, on an average 39,34 $\pm 3,77 \%(33,9-46,1 \%)$, in

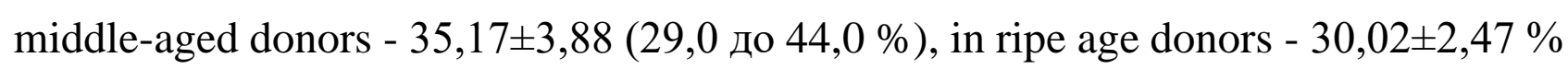
(26,4 до $33,7 \%)$.

In group III young donors, TSC was higher than in middle-aged $(\mathrm{p}<0,01)$ and ripe age $(\mathrm{p}<0,001)$ donors. TSC of middle-aged donors was higher than in ripe age donors $(\mathrm{p}<0,001)$. In young donors, serum TF was, on an average, $2,13 \pm 0,06 \mathrm{~g} / 1(2,03$ - 2,24 g/l), in middle-aged donors - 2,24 $\pm 0,05 \mathrm{~g} / 1$ (2,15 - 2,35 g/l), in ripe age donors - 2,35 $\pm 0,05 \mathrm{~g} / \mathrm{l}(2,26-2,42 \mathrm{~g} / \mathrm{l})$. In group III ripe age active donors, TF was higher than in young $(\mathrm{p}<0,001)$ and middle-aged $(\mathrm{p}<0,001)$ donors. In middle-aged donors, TF was higher than in young donors $(\mathrm{p}<0,001)$. In group III young active blood donors, serum FN was, on an average, 24,01 $\pm 4,17 \mathrm{mcg} / \mathrm{ml}(17,21-30,12 \mathrm{mcg} / \mathrm{ml})$, in middle aged donors - 22,88 $\pm 3,08 \mathrm{mcg} / \mathrm{ml}(17,49-26,55 \mathrm{mcg} / \mathrm{ml})$, in ripe age donors $21,34 \pm 2,18 \mathrm{mcg} / \mathrm{ml}(17,15-24,21 \mathrm{mcg} / \mathrm{ml})$. In group III young active blood donors, FN level was higher than in ripe age donors $(\mathrm{p}<0,05)$. There was no significant difference between FN level in group III young active blood donors and middle-aged active donors as well as between middle-aged and ripe age active donors $(p>0,05)$. Main parameters of iron metabolism in group III active blood donors were within normal limits except for elevated UIBS. Mean SI, TSC and FN were higher in male donors $(p<0,05)$, while mean TIBS, UIBS and TF were similar $(p>0,05)$. However, both in men and women max levels of TIBS, UIBS and TF were elevated, while minimal levels of TSC and FN were low. Mean SI, TSC and TF in group III active 
donors were lower than in the control group $(\mathrm{p}<0,05)$, while mean TIBS, UIBS and TF were higher than in the control group $(\mathrm{p}<0,05)$.

In all group III active blood donors, RDW was 70,28 1 ,93 fl $(69,01-73,71 \mathrm{fl})$. There was no significant sex-related difference in RDW between the examined active blood donors of group II ( $>>0,05)$, while there was significant difference in comparison with the control group $(\mathrm{p}<0,05)$. There was no significant sex-related difference in erythrocyte aggregation, platelet aggregation index and hematocrit between group III active blood donors $(\mathrm{p}>0,05)$. At the same time, erythrocyte aggregation in group III was significantly higher than in the control group as well as in groups I and II $(p<0,05)$. We established that in group III active blood donors solid concentration in erythrocytes (\%) was 44,25 $\pm 0,12 \mathrm{~g}$ per $100 \mathrm{ml}$, solid content in erythrocyte was $28,05 \pm 0,15 \mathrm{pg}$,

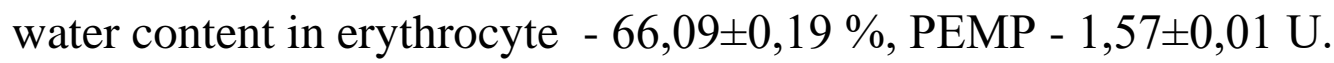

There was no significant sex-related difference in solid concentration in erythrocyte, solid content in erythrocyte, water content in erythrocyte and PEMP between group III active blood donors ( $p>0,05)$, however group III PEMP was significantly higher than in the control group $(\mathrm{p}<0,05)$. We established that in group III active blood donors erythrocyte fragmentation was, on an average, 1,73 $\pm 0,12 \%$ $(0,76-2,9 \%)-1,74 \pm 0,11 \%$ and $1,72 \pm 0,17 \%$ in males and females accordingly. While testing heat resistance of erythrocytes, there was no pink staining of plasma in any of 55 tested samples, which means that there was no thermal hemolysis.

It was established that in group III active blood donors EEV was, on an average, $0,070 \pm 0,0010 \cdot 10^{12} / 1$; in active female donors mean EEV was $0,069 \pm 0,0021 \cdot 10^{12} / 1$, and in male donors it was respectively $0,071 \pm 0,0019 \cdot 10^{12} / 1$.

We established that in group III active blood donors 2,3-BPG concentration in erythrocytes was $13,51 \pm 0,52 \mu \mathrm{mol} / \mathrm{g}$ of hemoglobin. In female donors from this group, 2,3-BPG concentration in erythrocytes was, on an average, $13,45 \pm 0,71 \mu \mathrm{mol} / \mathrm{g}$ of hemoglobin, in male donors it was respectively $13,62 \pm 0,64 \mu \mathrm{mol} / \mathrm{g}$ of hemoglobin.

We established that in group III active blood donors ATP concentration in erythrocytes was $3,29 \pm 0,17 \mu \mathrm{mol} / \mathrm{g}$ of hemoglobin. In active female donors, ATP 
concentration in erythrocytes was, on an average, $3,30 \pm 0,34 \mu \mathrm{mol} / \mathrm{g}$ of hemoglobin, and in male donors it was respectively $3,28 \pm 0,21 \mu \mathrm{mol} / \mathrm{g}$ of hemoglobin.

In group III active blood donors, ADP concentration in erythrocytes was $1,22 \pm 0,08 \mu \mathrm{mol} / \mathrm{g}$ of hemoglobin. In female donors from this group, ADP concentration in erythrocytes was, on an average, $1,21 \pm 0,12 \mu \mathrm{mol} / \mathrm{g}$ of hemoglobin, and in male donors it was respectively $1,23 \pm 0,09 \mu \mathrm{mol} / \mathrm{g}$ of hemoglobin. In group III active blood donors, AMP concentration in erythrocytes was $0,41 \pm 0,03 \mu \mathrm{mol} / \mathrm{g}$ of hemoglobin. In female donors, ADP concentration in erythrocytes was, on an average, $0,42 \pm 0,08 \mu \mathrm{mol} / \mathrm{g}$ of hemoglobin, in male donors it was respectively $0,40 \pm 0,07 \mu \mathrm{mol} / \mathrm{g}$ of hemoglobin.

Cumulative ATP + ADP + AMP concentration in erythrocytes of group III active blood donors was $4,92 \pm 0,28 \mu \mathrm{mol} / \mathrm{g}$ of hemoglobin. In group III active female donors, $\mathrm{ATP}+\mathrm{ADP}+\mathrm{AMP}$ concentration in erythrocytes was, on an average, 4,93 $\pm 0,54$ $\mu \mathrm{mol} / \mathrm{g}$ of hemoglobin, in male donors it was respectively $4,91 \pm 0,37 \mu \mathrm{mol} / \mathrm{g}$ of hemoglobin. There was no significant sex-related difference in concentration of ATP, ADP and AMP and cumulative ATP + ADP + AMP concentration in erythrocytes between group II active blood donors.

It has been established that donation career of over 10 years leads to development of abnormalities of the main cytometric parameters of peripheral venous blood (we detected significant reduction of the mean corpuscular diameter of erythrocytes, discocyte percentage and increase of micro - and schistocytes, anocytosis and the number of abnormally shaped erythrocytes in comparison with the control group and groups I and II $(\mathrm{p}<0,05)$ and differences in biochemical parameters characterizing iron metabolism - mean SI, TSC, FN and FE were significantly different $(\mathrm{p}<0,05)$ : they were the highest in group I donors $(19,88 \pm 2,43 \mu \mathrm{mol} / 1,34,05 \pm 4,09 \%, 17,95 \pm 2,83$ $\mathrm{mcg} / \mathrm{lta} 26,26 \pm 0,018 \mathrm{mcg} / \mathrm{g}$ respectively) and the lowest in group III $(16,22 \pm 1,23$ $\mu \mathrm{mol} / 1,16,19 \pm 4,94 \%, 12,78 \pm 1,73 \mathrm{mcg} / \mathrm{lta} 26,21 \pm 0,011 \mathrm{mcg} / \mathrm{g}$ respectively), while mean TIBS, UIBS and TF were the highest in group III donors $(104,87 \pm 16,68 \mu \mathrm{mol} / 1$, $88,65 \pm 17,46 \mu \mathrm{mol} / 1$ and 4,09 $\pm 0,65 \mathrm{~g} / 1$ respectively) and the lowest in group I donors $(58,42 \pm 2,81 \mu \mathrm{mol} / 1,38,54 \pm 3,19 \mu \mathrm{mol} / 1$ та $2,28 \pm 0,11 \mathrm{~g} / 1$ respectively). With the help 
of mathematical analysis, we established significant positive correlation between serum ferritin and iron in erythrocytes of peripheral venous blood $(r=0,941, p<0,05)$.

In the group of active donors donating for over 10 years, we detected significant increase in the number of transformed erythrocytes (stomatocytes, echinocytes etc.) $24,79 \pm 0,11 \%$ vs. $19,07 \pm 0,52 \%$ in the first-time donors and, consequently, decrease in the number of normal discocytes - $72,11 \pm 0,08 \%$ vs. $80,91 \pm 0,47 \%$ in first-time donors, significant decrease of the corpuscular diameter of erythrocytes $-6,31 \pm 0,03$ $\mathrm{mcm}^{3} \mathrm{vs}$. $\quad 7,22 \pm 0,04 \mathrm{mcm}^{3}$ in first-time donors, increased number of microcytes6,21 $\pm 0,23 \mathrm{fl}$ vs. 4,81 $\pm 0,11$ flin first-time donors, and higher anisocytosis $6,76 \pm 0,13 \%$ vs. $4,01 \pm 0,12 \%(\mathrm{p}<0,05)$.

Morphometric assay, cytometry, OTE and RDW tests demonstrated that active donors with donorship career of over 10 years had abnormalities of biophysical properties of erythrocytes. The following parameters were elevated in comparison with

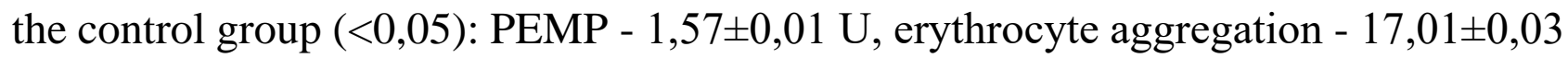
$\%$, OTE - 0,008 $\pm 0,003 \mathrm{~g} / \mathrm{ml}$, RDW - 70,28 $\pm 1,93 \mathrm{fl}$. These changes are secondary with LID and dynamic in the process of correction as they disappear with elimination of iron deficiency.

It has been proven that longer donorship career leads to rheologic abnormalities in the peripheral blood and affects erythrocyte aggregation, deformability, hematocrit and OTE $(\mathrm{P}<0,05)$. Active donors had increased number of light fractions of erythrocytes and reduced number of heavy fractions $(\mathrm{p}<0,05)$. In the group of active donors, correlation quotient between mean erythrocyte density and MCHC changes was $\mathrm{r}=0,81(\mathrm{p}<0,001)$.

Long donation career also results in abnormal energy metabolism in erythrocytes demonstrated by 2,3-BPG, ATP, ADP and AMP concentration changes. Active donors have unbalanced energy metabolism with increasing $2,3-\mathrm{BPG}(14,12 \pm 0,21 \mu \mathrm{mol} / \mathrm{g}$ of hemoglobin) and decreasing ATP $(3,01 \pm 0,05 \mu \mathrm{mol} / \mathrm{g}$ of hemoglobin), ADP $(1,11 \pm 0,05 \mu \mathrm{mol} / \mathrm{g}$ of hemoglobin), and AMP $(0,34 \pm 0,03 \mu \mathrm{mol} / \mathrm{g}$ of hemoglobin).

It was established that erythropoiesis efficiency in active female donors donating for over 10 years was, on an average, $0,069 \pm 0,0021 \cdot 10^{12} / 1$ and significantly lower than 
in male donors $(\mathrm{p}<0,05)$. This shows daily number of erythrocytes forming and appearing in one liter of peripheral blood of this category of donors.

\section{SUMMARY}

The study included 459 blood donors (225 men and 234 women): 299 active donors (148 men and 151women) donating regularly, at least 3 times a year, and 160 first-timedonors (83 men and 77 women) donating for the first time. Extended peripheral blood tests were performed for all the examined donors. We identified the main indicators of iron metabolism and iron content in erythrocytes of peripheral venous blood as well as the key parameters of erythrocytes characterizing carbohydrate metabolism. It was established that regular blood donations result in iron deficiency that can develop as latent iron deficiency or iron deficiency anemia, and that iron deficiency degree depends on donation career and number of donations. It has been proven that development of iron deficiency in blood donors is not always accompanied by changes in the peripheral blood and hemoglobin concentration used by the Blood Transfusion Service to evaluate iron metabolism of blood donors. Serum ferritin and transferrin, as well as iron content in the washed red blood cells of peripheral venous blood are the most significant parameters for detection of iron deficiency. Iron deficiency in blood donors is accompanied by secondary and non-specific abnormalities of carbohydrate metabolism in venous blood erythrocytes, the severity of which depth depends on iron deficiency degree. Active donors with donation career of over 10 year shave abnormal energy metabolism manifested as decrease of adenosine diphosphosphate acid and adenosinemonophosphate concentration. Possible mechanisms of the development of the diagnosed abnormalities shall be discussed. 


\subsection{Problems of formation of the public health system in Ukraine}

The elements of the public health system that exist in Ukraine today are inconsistent and needy optimization of existing resources and a significant increase in the efficiency of their management. Reform measures health systems have only deepened the crisis of preventive medicine. The reasons for this situation with the state of health of the population, there is a socio-economic crisis, unfavorable environmental situation, unhealthy nutrition, insufficient physical activity, high prevalence of smoking, alcohol consumption and drugs.

Public health system - a set of tools, procedures and measures implemented by governmental and non-governmental institutions to promote public health, prevent disease, increase the length of active and working age and promote a healthy lifestyle through the combined efforts of society as a whole.

Public health includes interdisciplinary approaches to epidemiology, biostatistics, and health care. Other important areas are environmental health, public health, psychohygiene, traffic safety, health economics, public policy, mental health, insurance medicine, occupational safety and health, etc.

Modern public health is the work of multidisciplinary public health teams, including physicians specializing in public health, communal medicine, infectious diseases, psychologists, epidemiologists, biostatists, medical microbiologists, and environmental health officials. public health inspectors, pharmacists, dentists, public health nurses, nutritionists and nutritionists, veterinarians, public health engineers, public health lawyers, sociologists, community development specialists, communication experts, bioethics, etc.

The concept of public health in Ukraine envisages the development of regional public health systems- creation of public health centers in each region. It is this new institution that must become regional coordinator of public health activities, to be flexible and able to fight both infectious and non-communicable diseases aimed at strengthening, protecting and preserving the health of the population, ensuring the 
definition of the social determinant of health and social justice to coordinate action call sectors of public administration.

Given the socio-political significance and economic value of individual and society -

public health, public health is considered one of the most important functions of modern state, because it is quantitative and qualitative indicators life expectancy and health of the population, a number of other indicators of social policy rich and developed countries of the world differ from the poor and underdeveloped [157]. There is so much importance to human health in the world it is important that this indicator is included in the index human development - a universal indicator level of development of society in a country.

In today's conditions, the formation and development of a public health system that would ensure the health of the population, prevent disease, increase the duration of active and working age and promote a healthy lifestyle through joint efforts is of particular importance. the whole society [161]. At the same time, the priority role should be given to the creation of an appropriate regulatory framework, adequate resource provision and modern effective management.

It is important to study the modern world experience of the functioning of public health systems, their development and improvement to justify the reform changes in Ukraine.

Population health is one of the greatest values, a necessary condition for the socio-economic development of the country. Ensuring the full life of the population, strengthening and maintaining health are among the most important goals of the world community, reflected in the principles of European policy.

The government has adopted the Concept for the Development of the Public Health System. This will help create a unified system of preventive medicine. The priority of the development of such a system is the principle that the interests of health should be taken into account in all areas of public policy. The concept defines the principles, directions, tasks, mechanisms and terms of building the public health system in order to form and implement an effective public policy to preserve and strengthen 
the health of the population. This concept defines the public health system as a set of tools, procedures and measures implemented by governmental and non-governmental institutions to strengthen the health of the population, prevent disease, increase the duration of active and working age and promote a healthy lifestyle by uniting the efforts of the whole society [161].

The public health system, as a basis for preventive medicine, should include basic measures in the field of health care and be aimed at preserving the health of the population and reducing the cost of medical care.

Ensuring the development of human resources in the field of public health requires radical changes, as there is no system of motivation, competitive selection and career growth. The current problem is the low level of wages, which makes it impossible to attract highly professional staff.

The solution of existing problems in accordance with the Concept of Public Health involves the implementation of: the creation of a multisectoral public health system with a coordinating role of the Ministry of Health; strengthening the role of the Minister of Health in the field of public health through the introduction of the principle of priority of preserving the health of the population in all areas of public authorities and defining at the legislative level the powers of the Minister to overcome threats and consequences of emergencies have a negative impact on the health of the population; ensuring the functioning. Center for Public Health of the Ministry of Health of Ukraine as a coordinator of public health programs and projects; entrusting the Center for Public Health of the Ministry of Health of Ukraine with functions to support management decisions in the field of public health, in particular to create and maintain a unified information and analytical system of medical information, methodological guidance of laboratory and analytical work of regional centers. public health.

Building a public health system in Ukraine is rapidly gaining momentum, the tasks of which are:

- cooperation with public and international organizations;

- monitoring the health of the population, assessment of social and economic factors that affect the health of the population; 
- development and implementation of a strategy for the formation of a conscious and responsible attitude of the population to their own health and personal safety;

- information support of health care institutions, education, mass media;

- creation of communication campaigns to promote the formation of a healthy lifestyle and motivate the population to maintain health;

- training of medical staff of public health institutions on public health;

- involvement of medical staff of health care institutions and public organizations in advocacy work on healthy lifestyles;

- introduction of rehabilitation systems based on technologies that provide, first of all, preservation and strengthening of health, disease prevention;

- organization of measures for the prevention of socially dangerous diseases (HIV / AIDS, tuberculosis);

- organization of immunization and surveillance programs for diseases that can be prevented by vaccination;

- prevention of infectious diseases by vaccination;

- comprehensive measures of epidemiological surveillance of infectious and non-infectious diseases, identification of risks to public health;

- coordination of activities and interaction of health care institutions regarding the collection, processing and analysis of information on the state of health of the population and resources of the health care system;

- collection and analysis of information for the formation of regional policy and strategic management in the field of public health [162].

The public health system is the basis of preventive medicine, which embodies the main systemic measures in the field of health care and aims to preserve both population and individual health of the population. Because the current system of medical care in Ukraine is not provides a preventive component, there is a need to identify new approaches and develop programs to solve problems in the field of public health and ensure the functioning of the Public Health Center of the Ministry of Health of Ukraine as a coordinator of these programs and projects. The established public health centers will ensure the preservation and strengthening of public health. 
According to the WHO, the main role in the public health system belongs to health workers. At the same time, the experience of the United States we have studied shows that volunteers and other organizations that do not require a special level of education, nurses, doctors with a bachelor's, master's or doctoral degree in public health can work in this field. $[161,163,165]$.

That is why the WHO recommends that higher education institutions organize master's, postgraduate and specialization with an emphasis on the following disciplines: global health, public health, environmental hygiene, occupational safety and health, toxicology, epidemiology, infectious diseases, health management , mental health, biostatistics, maternal and child health, nutrition, laboratory practice $[161,163$, $165]$.

Health components:

Physical health - the functioning of the human body and the state of health of each of its systems. It is important for us to know how our body should function, how to determine if we are in good health.

Mental health is our ability to receive information, our awareness of where to get the information we need, how to use it. We must be able to gather the necessary knowledge from a variety of sources and be able to use this information to make decisions about our body.

Emotional health is the ability to understand and express our feelings. Knowledge of how we feel and how others feel. Helps us express our feelings in a way that others can understand. It is important to feel comfortable, taking into account the range of emotions, and to know when people are good and when they are not.

Social health is how we feel as male or female, how we interact with other people. We need to understand what is really important to us in our relationships with friends, family, loved ones, and everyone we interact with. We need to develop skills that will help us in this relationship.

Personal health is the feeling of being a person. The feeling of developing one's "ego" ("ego" is a part of our essence that requires us to develop a sense of self and selfimprovement), is our hopes for achievement, our idea of success. Each of us finds 
unique ways of self-expression, depending on what we value and what we hope to achieve for ourselves and society. For example, some people find self-fulfillment in their work or career, others in family, and still others in activities for the benefit of others. We can determine for ourselves what brings pleasure to our own "ego".

Spiritual health is at the heart of health. Spiritual health is the core of our existence. This is the essence of our being (what we value and what is most important to us). Spirituality makes it possible to understand the relationship between the aspect of spiritual health and the other five.

Ukrainians must be provided with equal and timely access of citizens to highquality and safe blood components and preparations. The Blood Service will provide services for the procurement, processing, testing, storage and distribution of donor blood and blood components, as well as their proper clinical use. It will consist of the National Transfusion Center of the Ministry of Health, regional transfusion centers, their branches and hospital blood banks. The national register of donors, the establishment and equipping of interregional laboratory centers and blood centers with modern equipment, as well as the training of specialists, will be the next steps for the effective operation of the system.

In education, the development of public health and its further improvement will be ensured through the training and education of qualified personnel. National experts will be involved in the development and implementation of the public and postgraduate education program in the field of public health; advocacy, inclusion of the specialty "public health" in the list of fields of knowledge and specialties; and the development of a National Plan for the Development of Human Resources in the Public Health System.

And perhaps the most important area without which it is simply impossible to build an effective public health system is communication. Achieving results in the field of public health directly depends on the awareness and awareness of the population. That is why the Ministry of Health plans to develop programs of comprehensive prevention measures; to form a database on the state of health of the population and 
the environment of human life; and to conduct informational and educational campaigns to prevent disease and promote the benefits of a healthy lifestyle.

Therefore, a previous model was developed using the OneHealth Tool mental health care in Ukraine for the period from 2017 to 2030. It was calculated the cost of treatment and prevention measures, identified priority mental illnesses (depression, anxiety disorder, alcoholism, bipolar and psychotic disorders), including the cost of outpatient and primary care and resources for prevention programs (trainings), health and recreational activities.

The developed model shows that the expansion of the scale prevention and treatment of selected mental disorders provides until 2030 in total to return over UAH 4.7 million to the population of Ukraine. and prolong the duration of healthy life for 35 years. The total cost per capita will increase from $\$ 2.80$. (close 79 hryvnias) to 10.90 dollars. (about 305 hryvnias). That means for every dollar invested in prevention and improving the treatment of common mental disorders in Ukraine, we will get 2 dollars in restored productivity and added economic value.

The analysis of the data shows that the organization of public health services and their human resources differ significantly within the European region. Therefore, we should not focus on any one model of training - experts advise to work with international organizations that work closely with WHO and develop a policy of guidelines in training.

Such organizations include the Association of European Schools of Public Health (ASPHER) and the Public Health Accreditation Agency (APHEA). In particular, ASPHER has developed a list of competencies that master's graduates must achieve. To understand the needs for such staff, it is worth paying attention to the Policy Report prepared in cooperation with ASPHER, WHO and the European Observatory on Health Systems and Policies.

In connection with the above, we can conclude that in the formation of curricula should provide an increase in hours in these areas in graduation courses, as well as the inclusion in the program of sections on the study of environmental diseases, toxicology of the most commonly used and toxic chemicals. environments [162, 164, 165]. 
Achieving results in the field of public health directly depends on the awareness and awareness of the population. The main areas of further research are the development, together with the Ministry of Health of Ukraine, programs of comprehensive measures to prevent disease and promote the benefits of a healthy lifestyle, the formation of databases on public health and human environment. 


\section{SECTION 4. TECHNOLOGIES OF MEDICAL DIAGNOSTICS AND TREATMENT}

DOI 10.46299/ISG.2021.MONO.MED.III.4.1

\section{1 Нові підходи до діагностики та комплексного лікування алергічних ринітів, аденоїдиту в дитячому віці}

В даний час алергічні захворювання представляють глобальну загальносвітову проблему, так як відзначається щорічний приріст захворюваності на 1,5 - 2\%, з якою пов'язані значні медико соціальні та економічні втрати в усьому світі. Алергічні реакції, за даними різних авторів, реєструються більш ніж у 60\% населення планети, з них понад 30\% складають діти (Canonica G.W., Compalat E., 2009).

При цьому 5- 10\% дітей страждають на бронхіальну астму, 1-3\% - на атопічний дерматит, 20-40\% - на алергічний риніт, респіраторним алергозом.

За даними епідеміологічних досліджень деяких авторів, алергічними захворюваннями в Україні страждає кожен п'ятий житель країни, а у великих промислових центрах рівень захворюваності на алергічні хвороби серед населення досягає майже $60 \%$. В Україні останніми роками відзначається зростання алергічних захворювань як у дитячому віці, так і у дорослого населення. Примітно, що останніми роками відзначається значне зростання алергічних захворювань у дитячому та підлітковому віці на планеті. Наприклад, з 1960 р. по теперішній час захворюваність на атопічний дерматитом зросла у 8 разів (J.Spergel и соавт., 2003).

Гострі алергічні стани (анафілактичний шок, ангіоневротичний набряк, тяжкі, життєзагрозливі напади бронхіальної астми, гострі токсико-алергічні реакції) при неадекватне лікування забирають багато життів. Існують дані, які свідчать про те, що в Україні кількість викликів з щодо гострих алергічних станів неухильно зростає.

Таким чином, кількість пацієнтів 3 алергічними захворюваннями, нужденним у наданні висококваліфікованої медичної допомоги, зростає, і стає 
очевидною необхідність знання питань клініки та терапії невідкладних алергічних станів лікарями будь-яких спеціальностей.

Наявність алергічного компонента істотно знижує резистентність до впровадження інфекційних агентів, в тому числі таких, які призводять до інфекційного запалення придаткових пазух носа, носоглотки у дітей (Кузнєцова Л.В., 2012). Лікування пацієнтів з гострим риносинуситом, аденоїдитом, що мають обтяжений алергологічний анамнез, має ряд особливостей, які слід враховувати при виборі оптимальної етіопатогенетичної терапії.

Алергічний риніт, аденоїдит з синдромом постназального затікання - це патологія, яку повністю вилікувати неможливо, але діти 3 наявністю такої патології можуть жити повноцінним життям. Тому потрібно розуміти, що основним принципом патогенетичного лікування $\epsilon$ тривале застосування протизапальної терапії, спрямованої на контроль патології, в результаті чого у дитини відсутні нічні i денні прояви, немає необхідності в прийомі деконгестантів і топічних стероїдів, зберігається нормальна фізична і соціальна активність.

Дуже часто клінічний ефект від використання антигістамінних препаратів в поєднанні з топічними стероїдами не виправдовує очікування, так як не завжди приводив до полегшення симптомів (закладеність носа, хропіння, симптому постназального затікання, нічного підкашлювання).

Реплікація алергену в лімфоїдної тканини призводить до підвищення рівнів брадикинина, інтерлейкінів, простагландинів і гістаміну як медіаторів запалення (Skoner D.P. et al., 2001). Гістамін є біологічною активною речовиною, яка присутня в більшості тканин організму (в гранулах тучних клітин, базофілів, гістамінергічних нервових клітинах тощо.) і виконує функцію посередника в різних фізіологічних і патологічних реакціях.

Ефекти стимуляції Н1-гістамінових рецепторів включають: скорочення гладких м'язів (особливо трахеї і бронхів), посилення виділення слизу в дихальних шляхах, дилатацію та підвищення проникності капілярів, посилення вивільнення медіаторів запалення з нейтрофілів (Шкорботун В.А., Кубишкін 
А.В., 2013). Всі перераховані медіатори зумовлюють не тільки запуск запалення при риніті, а й підтримку хронічного запалення. Таким чином, при алергічних риносинуситах і аденоїдитах запускається каскад вищеописаних патологічних реакцій. (Gentile D.A., Skoner D.P., 2001., Кузнєцова Л.В., 2012.)

Лейкотрієни синтезуються з арахідонової кислоти, яка вивільняється при імунологічної стимуляції різних клітин, що беруть участь в запаленні. Цістеінілових лейкотрієни (ЛТС4, ЛТD4, ЛТЕ4) - важливі проастматичні медіатори, що зв'язуються з цистеїн - лейкотрієновими рецепторами в дихальних шляхах людини і викликають розвиток симптомів з боку дихальних шляхів, включаючи бронхоконстрикцію, порушення проникності стінок судин, виділення слизу i накопичення еозинофілів. Таким чином, під впливом найважливіших медіаторів - гістаміну і лейкотрієнів - починається хемотаксис клітин і формування запальної інфільтрації в слизовій оболонці верхніх дихальних шляхів. Надалі спостерігається взаємодія 3 імунною системою, розвиток проліферативно-фібропластичної реакції, хронізація запалення (Шкорботун В.А., Кубишкін А.В., 2013).

Важливо відзначити, що навіть в період ремісії алергічного риніту і аденоиїди та в верхніх дихальних шляхах зберігається так зване мінімального персистуючого запалення, яке саме по собі створює сприятливий фон для інвазії респіраторної інфекції. Мінімальним персистуючим запаленням являє собою безперервний запальний процес 3 мінімальною активністю, який може супроводжуватися повною відсутністю симптоматики у пацієнтів (Ricca V. Et al., 2000; Зайцева О.В., 2006).

Після відкриття нового класу медіаторів запалення - лейкотрієнів - виник новий напрям в лікуванні із застосуванням препаратів 3 антилейкотрієнових механізмів дії.

Блокатори рецепторів лейкотрієнів (монтелукаст) здатні гальмувати розвиток алергічної реакції i симптомів, асоційованих 3 продукцією лейкотрієнів. 
У нашій клініці використовувалася комбінація препаратів. Це був монтелукаст в поєднанні з одночасним прийомом антигістамінних препаратів (левоцетерезин). Всі препарати приймалися в вікових дозах.

У спостереженні брали участь пацієнти з діагнозом алергічний риніт, аденоїдит з синдромом постназального затікання. Критерієм виключення слугував прийом додаткових препаратів, що могло вплинути на результати лікування. Були виключені пацієнти, які за 2 тижні до початку спостереження брали деконгестантів, інтраназальні або системні кортикостероіди, інтраназальні препарати кромоглікату натрію.

Основна група складалася з 60 дітей різного віку (від 6 до 18 років), які приймали препарати монтелукаста і левоцетиризину у вікових дозуваннях.

До групи порівняння входило 40 дітей, які отримували антигістамінні препарати в поєднанні з топічними стероїдами (мометазон).

Діагноз грунтувався на скаргах, об'єктивному огляді, результати назоцітограмми (превалювання в мазку еозинофілів), підвищенні рівня Ig E i еозинофільного катіонного білка. Взаємодія алергенів з $\mathrm{IgE}$, фіксованими на поверхні опасистих клітин і базофілів, призводить до виділення з цих клітин медіаторів, що викликають алергічну реакцію (гістаміну, серотоніну). Процес дегрануляції опасистих клітин і базофілів людини в більшості випадків ініціюється перехресним зв'язуванням двох специфічних IgЕ-молекул за допомогою алергену.

Процес дегрануляції опасистих клітин і базофілів людини ініціюється перехресним зв'язуванням поверхневих IgE-рецепторів, в результаті чого починається фаза злиття мембрани гранул, що містять гістамін, і зовнішньої клітинної мембрани (Хаітова Р. М., 2009). В результаті мембрана гранул стає частиною клітинної мембрани.

Преформовані медіатори виділяються швидко (гістамін, гепарин, триптаза), а метаболіти арахідонової кислоти (AA) - лейкотрієн D4 (LTD4) та простагландин D2 (PGD2) - повільніше. Вміст гранул швидко розчиняється і 
секретується, причому після повної чи часткової. Дегрануляція клітина залишається життєздатною.

Деякі агенти здатні безпосередньо викликати дегрануляцію опасистих клітин: кодеїн, морфін, ванкоміцин, рентгеноконтрастні речовини, які використовуються для урографії, компоненти комплементу С3a та С5а. Такі гострі реакції, не пов'язані з IgЕ-антитілами, називаються анафілактоїдними.

Активація системи комплементу призводить до утворення проміжних продуктів активації (C3a, C2a, C2в, C4a, С5a та ін), які викликають вивільнення медіаторів з гладких клітин, базофілів, нейтрофілів та тромбоцитів.

Вивільнення медіаторів (насамперед гістаміну) призводить до розширенню та застою крові в капілярах, підвищенню проникності їх стінок, що сприяє згущенню крові та набряку навколишніх тканин, гіперсекреції залоз, спазму гладких м'язів тощо. Фізіологічні та патологічні ефекти гістаміну опосередковуються через мембранні рецептори Н1- та Н2-типу: підвищення судинної проникності (внаслідок ослаблення міжклітинних контактів ендотелію. в області венул), скорочення гладкої мускулатури, легенева вазоконстрикція, підвищення внутрішньоклітинної концентрації цГМФ, посилення слизовиділення у верхніх дихальних шляхах, посилення хемотаксису еозинофілів та нейтрофілів, активація Т-лімфоцитів, посилення продукції простагландинів F2 $\alpha$, E2, тромбоксану B2, лейкотрієнів та ін.

Серотонін здатний викликати констрикцію артеріол, бронхоконстрикцію, стимулювати перистальтику тонкої кишки. Вплив зазначених медіаторів алергії надалі призводить до вираженого спазму гладкої мускулатури внутрішніх органів, стазу, гемолізу, недостатності кровообігу, різкому підвищенню проникності судин та набряку органів та тканин. Цей тип реакцій протікає без участі комплементу. Шляхи, які ведуть до можливого контакту з алергенами, багато в чому визначають спосіб його презентації. Сенсибілізація до лікарського засобу, що спричинив розвиток анафілактичного шоку, що виникає в результаті застосування даного препарату 3 діагностичною або лікувальною метою у минулому у пацієнта. У дітей розвиток сенсибілізації може відбуватися при 
застосуванні якого-або лікарського препарату, або вживання певного алергенного продукту матір'ю під час вагітності чи грудного вигодовування.

Також причиною сенсибілізації пацієнта може стати контакт 3 лікарськими сполуками інгаляційним шляхом при проживання поблизу фармацевтичних підприємств. У деяких пацієнтів, переважно у дітей молодшого віку, алергія може бути наслідком надходження в організм фармакологічних засобів 3 харчовими продуктами, так як деякі 3 них використовуються як консервантів та стабілізаторів в даний час (Олехнович В.М. 2005).

Ряд алергенів також входить до складу вакцин. Наприклад, деякі вакцини приготовані на курячих ембріонах: вакцини від грипу, пріорікс; деякі вакцини містять сліди аміноглікозидів: живі кореві та паротитні вакцини; вакцини проти гепатиту В містять пекарські дріжджі. Розвиток алергічних реакцій на лікарські засоби, у тому числі анафілактичного шоку, можливо внаслідок перехресних реакцій, обумовлених наявністю загальних антигенних детермінант у деяких алергенів. Всі діти були проконсультовані дитячими алергологами.

Ефективність лікування визначалася за допомогою щоденників самоспостереження пацієнтів, де відзначалися суб'єктивні симптоми (відчуття закладеності носа, ринорея, затікання по задній стінці глотки, нічний кашель, хропіння).

Учасники оцінювали симптоми на 1, 3, 5, 10-й і 14-й день лікування за 3бальною шкалою (0 балів - симптоми відсутні, 1 бал - симптоми слабо виражені i не викликають роздратування, 2 бали - симптоми помірно виражені i викликають роздратування, 3 бали - різко виражені симптоми, які заважають щоденні діï).

Додатково оцінювалися дані об'єктивного обстеження, які включали оцінку загального стану пацієнта, риноскопічну картину і назоцітограмму.

Здійснювали моніторинг стану: фізикальне обстеження, електрокардіографію, пульсоксиметрію, контроль артеріального тиску, аускультацію, за необхідності - визначають центральний венозний тиск або тиск заклинювання в легеневої артерії. Паралельно з заходами, спрямованими на 
купірування алергії, виконували клінічний аналіз крові, дослідження кислотнолужної рівноваги, газового складу та електролітного балансу, коагулограми.

Результати оцінки проведеного лікування показали, що в основній групі значно зменшилися симптоми закладеності носа, виділення з порожнини носу, відчуття постназального затікання, нічний підкашлювання і хропіння вже на 3-ю добу в порівнянні з учасниками з контрольної групи.

\section{Висновки:}

1. Таким чином, спільне використання препаратів монтелукаст (в вікових дозуваннях 4 мг, 5мг, 10мг) і левоцетиризин (в таблетках 5 мг та у вигляді сиропів та крапель) раціонально об'єднує антигістамінну і антілейкотріенову дію, що забезпечує виражений лікувальний ефект у пацієнтів 3 діагнозом алергічний риніт, аденоїдит з синдромом постназального затікання.

2. Порівняльний аналіз динаміки лейкотрієнопосередних симптомів (закладеність носа, постаназальне затікання та ін.) показав найкращі результати в групі із застосуванням комбінації препаратів (монтелукаст і левоцетиризин) щодо групи порівняння, що одержувала антигистаминні препарати в поєднанні 3 топічними стероїдами (мометазон).

3. При комплексному застосуванні монтелукаста i левоцетиризину відбулося поліпшення основних клінічних проявів, 3 поліпшенням «нічних симптомів», показників кислородного обміну та газового складу крові, що знизило застосування деконгестантів.

4. Результати проведеного спостереження дозволяють рекомендувати цю комбінацію препаратів (монтелукаст у таблетках 4мг. 5 мг або 10 мг та левоцетерезина у таблентках 5 мг або у вигляді сиропа та крапель), які попереджають поліпрагмазію з її негативними наслідками. 


\section{SECTION 5. THEORETICAL MEDICINE}

DOI 10.46299/ISG.2021.MONO.MED.III.5.1

\subsection{Correction of ulcerogenic action of nonsteroidal anti-inflammatory drugs by using of cryopreserved placenta extract}

Today, the ulcerogenicity of nonsteroidal anti-inflammatory drugs is their major side-effect significantly limiting their clinical use. This is also an important medical and social problem, as these drugs are among the most widely used ones worlwide. The complexity of the pathogenesis of the lesion induced by nonsteroidal antiinflammatory drugs of the gastrointestinal tract necessitates a comprehensive approach to treat this pathology or to use the drugs of a polyvector mechanism of action. Classically, pharmacotherapy of this iatrogenic pathology is aimed at acid suppression, the use of gastrocytoprotectors and the drugs, restoring the content of prostaglandins in the mucous membrane of the specified group $[183,184,185,186,187,188,189$, $190,191]$.

While searching for the tools capable of increasing the resistance of the gastrointestinal tract mucous membrane to the damaging effects of nonsteroidal antiinflammatory drugs, our attention was drawn to the cryopreserved placenta extract which is a biotechnological agent designed at the Institute for Problems of Cryobiology and Cryomedicine of the National Academy of Sciences [192, 193, 194, 195, 196, 197, 198, 199, 200, 201, 202, 203, 204, 205, 206].

Studies have shown that during preventive administration the antiulcer activity of cryopreserved placenta extract was $69.1 \%$, and in acute indomethacin-induced gastropathy the ulcer index was 3.5 and 1.08 in control rats and those injected with placental cryoextract, respectively. In acute diclofenac sodium-induced gastropathy, the antiulcer activity of placental cryoextract was $92.1 \%$, and ulcerative defects of the gastric mucosa with the studied extract were found just in $28.6 \%$ of animals, which was 3.5 times lower than in the control rats. It should be noted that the most pronounced decrease of the diclofenac sodium ulcerogenic action was noticed when applied in a preventive combination, i.e. using the cryopreserved placenta extract and low 
temperatures; the expression index was 12.6 times lower than in rats with diclofenac sodium-induced ulcer-induced gastropathy, and its effectiveness was 1.5 times higher than that of esomeprazole [207].

The antiulcer activity of cryopreserved placenta extract in the treatment regimen in rats with subchronic meloxicam-induced gastropathy was $100 \%$, but ulcerative lesions of the gastric mucosa caused by meloxicam were found just in $74.1 \%$ of rats, indicating a low ulcerogenic potential of this nonsteroidal drug in stomach. The use of cryopreserved placenta extract in the treatment-and-prophylactic regimen was accompanied by comparable antiulcer activity in models of subchronic ibuprofeninduced and acetylsalicylic acid-induced gastropathies and made $72.8 \%$ and $70.6 \%$, respectively [208].

Evaluation of the effect of cryopreserved placenta extract on the condition of the distal gastrointestinal tract on the background of lesions induced by nonsteroidal antiinflammatory drugs showed that in the acute diclofenac sodium and indomethacininduced ulcerogenesis only small intestinal mucosa was affected. The condition of the colon remained macroscopically unchanged, which was probably due to the study timing. Preventive administration of cryopreserved placenta extract in both models of acute ulcerogenesis resulted in $100 \%$ reduction of the enterotoxic effects of both indomethacin and diclofenac sodium, confirming their enteroprotective properties.

During treatment regimen the use of cryopreserved placenta extract in the model of meloxicam-induced lesions of the small intestine led to $100 \%$ decrease of the ulcerogenic effect on the large intestine of the latter, and the number of ulcerative defects in the small intestine decreased 4.6 times compared with the group induced by ulcerogenesis without correction, and made $7.4 \pm 3.2$ and $33.7 \pm 1.7$ ulcers per $10 \mathrm{~cm}$ of small bowel length, respectively.

In therapeutic and prophylactic use of cryopreserved placenta extract, $100 \%$ decrease of the toxic effects of acetylsalicylic acid and the distal parts of the gastrointestinal tract was noted. The ibuprofen-induced ulcerogenesis model showed that the antiulcer activity of cryopreserved placenta extract in the small intestine was $78.4 \%$ and $72.3 \%$ in the large intestine $[208,209]$. 
The findings suggest the presence of pronounced entero- and colonoprotective activity in cryopreserved placenta extract in gastrointestinal tract ulcerative lesions induced by non-steroidal anti-inflammatory drugs. The most pronounced antiulcer activity in the gastrointestinal tract distal parts was found in the prophylactic cryopreserved placenta extract in the model of diclofenac sodium-induced ulcerogenesis and in treatment and preventive use of the cryopreserved placental acid extract on the ulcer background.

Biochemical studies of the gastric mucosa homogenates showed that prophylactic use of cryopreserved placenta extract in rats with diclofenac sodium-induced gastropathy increases the activity of the antioxidant system in mucosa, indicating a rise in in catalase activity by $40.0 \%$ as compared with the control group. Modulation of antioxidant-prooxidant homeostasis is one of the mechanisms of gastrocytoprotective action of the combined effect of low temperatures and cryopreserved placenta extract. This is demonstrated by a significant $(\mathrm{p}<0.05)$ increase in the antioxidant-prooxidant index by 2.2 times versus the rats with diclofenac sodium-induced gastropathy.

In addition, it was found that administration of cryopreserved placenta extract enhanced the activity of prostaglandin synthases in rats with diclofenac sodiuminduced gastropathy 2.0 times relative to those of the control group, that eliminated iatrogenic prostaglandin deficiency in the gastric mucosa.

Evaluation of the effect of cryopreserved placenta extract on lipoxygenase mechanisms of inflammation showed that one of them as for its anti-inflammatory activity is the inhibition of this pathway of arachidonic acid metabolism. This was shown by a significant $(\mathrm{p}<0.05)$ suppression of zymosan-induced inflammation in rats by $78.8 \%$ and $74.8 \%$ for 120 and $180 \mathrm{~min}$, respectively. This was similar to monotherapy with the studied cryoextract, most likely due to weaker effect of the studied nonsteroidal anti-inflammatory drug on the lipoxygenase pathway of arachidonic acid metabolism [210, 211].

A comprehensive study of the effect of cryopreserved placental extract on therapeutic properties of nonsteroidal anti-inflammatory drugs in a model of experimental rheumatoid arthritis in rats showed that the combined use of diclofenac 
sodium and cryopreserved placental extract had more pronounced anti-inflammatory activity versus monotherapy. This is evidenced by an $8.7 \%$ greater reduction in the volume of the damaged limb of rats with diclofenac sodium and cryopreserved placental extract than with diclofenac sodium alone. In addition, it was found that the combined use of diclofenac sodium and cryopreserved placenta extract was accompanied by an increase in the threshold of pain sensitivity with mechanical irritation of the limb by $13.8 \%$ higher if compared with diclofenac sodium monotherapy. In addition, the combined use of diclofenac sodium and cryopreserved placental extract was accompanied by a more pronounced $10.7 \%$ analgesic activity if compared with diclofenac sodium monotherapy adjuvant arthritis as for disability in rats versus DN monotherapy, which was significantly higher $(\mathrm{p}=0.01)$ by $14.1 \%$ rise in the threshold of pain sensitivity in rats with adjuvant arthritis on day 28 of the experiment.

Hematological studies showed that the combined use of cryopreserved placenta extract and diclofenac sodium was accompanied by a more pronounced leveling of inflammation signs by hematological parameters, i.e. erythrocyte sedimentation rate decreased by $72.2 \%$ ( $p<0.001$ ), and the number of leukocytes decreased by $54.8 \%$ $(\mathrm{p}<0.001)$ relative to the rats with adjuvant arthritis without treatment. In addition, it was found that the combined use of cryopreserved placenta extract and diclofenac sodium led to a complete elimination of signs of anemia of chronic inflammation - the level of hemoglobin and erythrocytes was significantly ( $\mathrm{p}<0.001)$ increased by 17.6 $\%$ and $36.8 \%$, respectively, in the rats with adjuvant arthritis with no treatment [212].

Blood biochemical studies have shown that administration of diclofenac sodium and cryopreserved placental extract to the rats with adjuvant arthritis resulted in normalization of malonic dialdehyde levels, indicating a reduction in the symptoms of arthritis-induced oxidative stress. There was also a significant $(p=0.01)$ rise in the level of superoxide dismutase by $30.6 \%$ relative to the values in the control group rats. Enhanced anti-inflammatory properties of DN on the background of the combined use of diclofenac sodium from cryopreserved placenta extract, namely the level of reactive protein decreased $(\mathrm{p}<0.001)$ by $61.1 \%$ relative to untreated rats, and the level of 
seromucoid significantly $(\mathrm{p}<0.01)$ decreased by $17,1 \%$ relative to rats of the diclofenac sodium monotherapy group. It was shown that the level of alanine aminotransferase was significantly $(\mathrm{p}<0.01)$ lower by $38.9 \%$, and aspartate aminotransferase was lower $(\mathrm{p}<0.01)$ by $37.9 \%$ compared to the animals treated with diclofenac sodium, which was $16.7 \%(\mathrm{p}=0.02)$ and $17.2 \%(\mathrm{p}<0.001)$, respectively, lower than in control rats with untreated adjuvant arthritis. The observed changes in aminotransferases demonstrate the ability of cryopreserved placenta extract to level not only cytolytic syndrome induced by adjuvant arthritis, but also diclofenac sodiuminduced. Moreover, it was found that the combined use of cryopreserved placenta extract and diclofenac sodium was accompanied by normalization of the level of total lipids and phospholipids in the serum of rats on the background of experimental rheumatoid arthritis. Thus, the content of phospholipids in the phospholipid pool increased significantly $(\mathrm{p}=0.02)$ by $22.6 \%$ compared to the animals with adjuvant arthritis with no treatment [213].

The obtained research data made it possible to conclude that cryopreserved placenta extract had an antiulcer activity in the gastrointestinal tract lesions induced by nonsteroidal anti-inflammatory drugs, and the combined use of these drugs was accompanied by an increase in their therapeutic properties. 


\section{REFERENCES}

1. MV Vlasenko, NI Kravchuk, NA Kravchuk, ZP Nizhynskaya-Astapenko. Diliatory cardiomyopathy: indirect disease or complication of tierotoxicose. Problems of endocrine pathology. 2017;3: 29-37. doi.org/10.21856/j-PEP.2017.3.04

2. OG Nesukay. Modern approaches to the diagnosis and treatment of cardiomyopathy: what's new? Health of Ukraine of the 21st century. 2020;7(476):8-9.

3. Mezincescu A, Karthikeyan VJ, Nadar SK. Ranolazine: A true pluripotent cardiovascular drug or jack of all trades, master of none? Sultan Qaboos University Med J [Internet]. 2018 [cited 2020 Sep 30];18(1):e13-e23. Available from: https://www.ncbi.nlm.nih gov/ pmc/ articles/ PMC5892807/ pdf / squmj1802-e13 23.pdf. DOI: 10.18295/squmj.2018.18.01.003.

4. De Ferrari GM et al. Ranolazine in the treatment of atrial fibrillation: Results of the dose ranging RAFFAELLO. Heart Rhythm. 2015;12 (5):872-878. doi: 10.1016/j.hrthm.2015.01.021.

5. Muntean DM, Kohajda Z. Atrial remodeling in permanent atrial fibrillation: mechanisms and pharmacological implications. J Clin Exp Cardiolog. 2013;4(11):212.

6. Pop-Busui R, Boulton AJM, Feldman EL, et al. Diabetic neuropathy: a position statement by the American Diabetes Association. Diabetes Care. 2017; 40: 136-54.

7. Serhiyenko V.A., Serhiyenko A.A. Cardiac autonomic neuropathy: risk factors, diagnosis and treatment. World J Diabetes. 2018; 9: 1-24.

8. Lonsdale D, Marrs C. The autonomic nervous system and its functions. In: Lonsdale D, Marrs C, eds. Thiamine Deficiency Disease, Dysautonomia, And High Calorie Malnutrition. 1st ed. Oxford: Elsevier, 2017: 27-57.

9. Boghdadi MA, Afify HE, Sabri N, et al. Comparative study of vitamin B complex combined with alpha lipoic acid versus vitamin B complex in treatment of diabetic polyneuropathy in type 2 diabetic patients. Clin Exp Pharmacol. 2017; 7: 241.

10. Oyenihi AB, Ayeleso AO, Mukwevho E, et al. Antioxidant strategies in the management of diabetic neuropathy. Biomed Res Int. 2015; 2015: 515042.

11. American Diabetes Association. Standards of medical care in diabetes-2017. Clin. Diabetes. 2017; 35(1): 5-26.

12. Moss CJ, Mathews ST. Thiamin status and supplementation in the management of diabetes mellitus and its vascular comorbidities. Vitam Miner. 2013;2: 111. 
13. Pácal L, Kuricová K, Kaňková K. Evidence for altered thiamine metabolism in diabetes: is there a potential to oppose gluco- and lipotoxicity by rational supplementation? World J Diabetes. 2014; 5: 288-95.

14. Luong KV, Nguyen LT. The impact of thiamine treatment in the diabetes mellitus. J Clin Med Res. 2012; 4: 153-60.

15. Sandireddy R, Yerra VG, Areti A, et al. Neuroinflammation and oxidative stress in diabetic neuropathy: futuristic strategies based on these targets. Int $\mathbf{J}$ Endocrinol. 2014; 2014: 674987.

16. Serhiyenko V, Hotsko M, Snitynska O, et al. Benfotiamine and type 2 diabetes mellitus. MOJPH. 2018; 7: 00200.

17. Spallone V. Might genetics play a role in understanding and treating diabetic polyneuropathy? Diabetes Metab Res Rev. 2017; 33: e2882.

18. Mirza S, Hossain M, Mathews C, et al. Type 2-diabetes is associated with elevated levels of TNF-alpha, IL-6 and adiponectin and low levels of leptin in a population of Mexican Americans: a cross-sectional study. Cytokine. 2012; 57: 13642.

19. Valdes-Ramos R, Guadarrama-Lopez AL, Martinez-Carrillo BE, et al. Vitamins and type 2 diabetes mellitus. Endocr Metab Immune Disord Drug Targets. 2015; 15: 54-63.

20. Hrebenyk M.V., Kotsiuba O.I. Optymizatsiia likuvannia diastolichnoi sertsevoi nedostatnosti $\mathrm{u}$ patsiientiv iz hipertonichnoiu khvoroboiu $\mathrm{v}$ umovakh komorbidnosti z hiperurykemiieiu. Visnyk naukovykh doslidzhen. 2016. N 3. S. 1113.

21. Nasledov A.D. Matematycheskye metodы psykholohycheskoho yssledovanyia. Analyz y ynterpretatsyia dannыkh: ucheb. posob. Sankt-Peterburh: Rech, 2012. 392 s.

22. Pro zatverdzhennia ta vprovadzhennia medyko-tekhnolohichnykh dokumentiv zi standartyzatsii medychnoi dopomohy pry stabilnii ishemichnii khvorobi sertsia. Nakaz MOZ Ukrainy vid 02.03.2016 № 152. URL: http://www.moz.gov.ua/ua/portal/dn_20160302_0152.html.

23. Tashchuk V.K., Vasek Obeid Al Salama Mukhamed. Komorbidnist, sertsevo-sudynna patolohiia i likuvannia hiperurykemii - chy zapobihaie zakhvoriuvanniu alopurynol? (ohliad literatury). Bukovynskyi medychnyi visnyk. 2016. T. 20, № 2. S. 209-212.

24. Bang D, Xu J, Keenan R, Pike V, Lehmann R, Tenner C, et al. Cardiovascular Disease Prevalence in Patients with Osteoarthritis, Gout, or Both. Bull Hosp Jt Dis. 2016 Jun;74(2):113-8.

25. Kuwabara M. Hyperuricemia, Cardiovascular Disease, and Hypertension. Pulse. 2015;3:242-52. 
26. Okazaki H, Shirakabe A, Kobayashi N, Hata N, Shinada T, Matsushita M, et al. Are atherosclerotic risk factors associated with a poor prognosis in patients with hyperuricemic acute heart failure? The evaluation of the causal dependence of acute heart failure and hyperuricemia. Heart Vessels. 2017 Apr;32(4):436-445. doi: 10.1007/s00380-016-0893-z.

27. Shahin L, Patel KM, Heydari MK, Kesselman MM. Hyperuricemia and Cardiovascular Risk. Cureus. 2021; 13(5): e14855. doi: 10.7759/cureus.14855.

28. Saito Yu, Tanaka A, Node K, Kobayashi Yo. Uric acid and cardiovascular disease: A clinical review. J Cardiol. 2021;78(1):51-57. doi: 10.1016/j.jjcc.2020.12.013.

29. Shahin L., Patel KM, Heydari MK, Kesselman MM. Hyperuricemia and Cardiovascular Risk. Cureus. 2021;13(5):e14855. https://doi: 10.7759/cureus.14855.

30. Wei Y, Cheng Ji D. Uric acid and cardiovascular disease: an update from molecular mechanism to clinical perspective. Frontiers in Pharmacology. 2020;11:582680. https://doi: 10.3389/fphar.2020.582680.

31. Winder M, Owczarek AJ, Mossakowska M, Broczek K, Grodzicki T, Wierucki $Ł$, Chudek J. Prevalence of Hyperuricemia and the Use of Allopurinol in Older Poles-Results from a Population-Based PolSenior Study. International Journal of Environmental Research and Public Health. 2021;18(2):387. https://doi: 10.3390/ijerph18020387.

32. Ciccullo A, Borghetti A, Zileri Dal Verme L, Tosoni A, Lombardi F, Garcovich M, et al. Neutrophil-to-lymphocyte ratio and clinical outcome in COVID19: a report from the Italian front line. Int J Antimicrob Agents. 2020;56(2):106017. DOI: 10.1016/j.ijantimicag.2020.106017.

33. Rudyk YuS, Pyvova SM. COVID-19 i zakhvoriuvannia sertsevo-sudynnoi systemy: $\mathrm{u}$ fokusi - sertseva nedostatnist [COVID-19 and diseases of the cardiovascular system: the focus is heart failure]. Zdorov'ia Ukrainy. 2021; 4 (497):4244. (in Ukrainian).

34. Mai F, Del Pinto R, Ferri C. COVID-19 and cardiovascular diseases. J Cardiol. 2020;76(5):453-458.: 10.1016/j.jjcc.2020.07.013.

35. Sattar Y, Ullah W, Rauf H, Virk H, Yadav S, Chowdhury M, et al. COVID19 cardiovascular epidemiology, cellular pathogenesis, clinical manifestations and management. Int J Cardiol Heart Vasc. 2020; DOI: 29:100589.: 10.1016/j.ijcha.2020.100589.

36. Naz A, Billah M. COVID-19 and Coronary Heart Disease. Encyclopedia. 2021; 1(2):340-349. DOI: https://doi.org/10.3390/encyclopedia1020028. 
37. Hemmat N, Derakhshani A, Bannazadeh Baghi H, Silvestris N, Baradaran B, De Summa S. Neutrophils, Crucial, or Harmful Immune Cells Involved in Coronavirus Infection: A Bioinformatics Study. Front. Genet. 2020;11:641. DOI: 10.3389/fgene.2020.00641.

38. Feng X, Li S, Sun Q, Zhu J, Chen B, Xiong M, et al. Immune-Inflammatory Parameters in COVID-19 Cases: A Systematic Review and Meta-Analysis. Front Med (Lausanne). 2020;7:301. DOI:10.3389/fmed.2020.00301.

39. Gatti A, Radrizzani D, Viganò P, Mazzone A, Brando B. Decrease of NonClassical and Intermediate Monocyte Subsets in Severe Acute SARS-CoV-2 Infection. Cytometry A. 2020 S; 97(9):887-890. DOI: 10.1002/cyto.a.24188.

40. Lopez M.J., Mohiuddin S.S. StatPearls. StatPearls Publishing; Treasure Island, FL, USA: 2020. Biochemistry, Essential Amino Acids.

41. Gambardella J, Khondkar W, Morelli MB, Wang X, Santulli G, Trimarco V. Arginine and Endothelial Function. Biomedicines. 2020;8(8):277.DOI: 10.3390/biomedicines8080277.

42. Cziráki A, Lenkey Z, Sulyok E, Szokodi I, Koller A. L-Arginine-Nitric Oxide-Asymmetric Dimethylarginine Pathway and the Coronary Circulation: Translation of Basic Science Results to Clinical Practice. Front Pharmacol. 2020;11:569914. DOI: 10.3389/fphar.2020.569914.

43. Medina-Leyte DJ, Zepeda-García O, Domínguez-Pérez M, GonzálezGarrido A, Villarreal-Molina T, Jacobo-Albavera L. Endothelial Dysfunction, Inflammation and Coronary Artery Disease: Potential Biomarkers and Promising Therapeutical Approaches. Int J Mol Sci. 2021;22(8):3850. DOI: 10.3390/ijms22083850.

44. Colunga Biancatelli RML, Berrill M, Catravas JD, Marik PE. Quercetin and Vitamin C: An Experimental, Synergistic Therapy for the Prevention and Treatment of SARS-CoV-2 Related Disease (COVID-19). Front Immunol. 2020;11:1451. DOI: 10.3389/fimmu.2020.01451.

45. Pawan KA, Chandan A, Gerald B. Quercetin: Antiviral Significance and Possible COVID-19 Integrative Considerations. Natural Product Communications. 2020;15(12): 1934578X2097629. DOI: 10. 1177/1934 578X 20976293.

46. Коваленко СВ. Досвід застосування методів синдромно-патогенетичної терапії при пневмонії, спричиненій COVID-19, в умовах пульмонологічного відділення. Здоров'я України 21 сторіччя. 2020; 13-14:481-4

47. Басаргина Е.Н. Миокардит у детей: трудности диагностики и лечения. Педиатрия.- М.-2015. Том 94, №2.- С.1-9. 
48. Березнева Н.А., Арсеньева Е.Н., Юрявичус А.И. и соавт. Состояние ренин-ангиотензин-альдостероновой системы у детей с дилатационной и гипертрофической кардиомиопатией // Тезисы Всероссийского конгресса «Детская кардиология». - М. — 2012. - С.86-88.

49. World Health Organization. Serum ferritin concentrations for the assessment of iron status and iron deficiency in populations.Vitamin and Mineral Nutrition Information System.Geneva, World Health Organization, 2011 (WHO/NMH/NHD/MNM/11.2).

50. World Health Organization. World health statistics 2013. http://www.who.int/about/licensing/copyright_form/en/index.html/

51. Саперова Е. В., Вахлова И. В. Врожденные пороки сердца у детей: распространенность, факторы риска, смертность. Вопросы современной педиатрии. 2017; 16 (2): 126-133. doi: 10.15690/vsp.v16i2.1713.

52. Inman M, Daneman D, Curtis J, Sochett E, Clarke A, Dunger DB, Deanfield J, Mahmud FH. Social Determinants of Health Are Associated with Modifiable Risk Factors for Cardiovascular Disease and Vascular Function in Pediatric Type 1 Diabetes. J Pediatr. 2016 Oct; 177:167-172.

53. Rusconi P., Wilkinson J.D., Sleeper L.A., Lu M., et al.; for the Pediatric Cardiomyopathy Registry Investigators. Differences in Presentation and Outcomes between Children with Familial Dilated Cardiomyopathy and Children with Idiopathic Dilated Cardiomyopathy: A Report from the Pediatric Cardiomyopathy Registry Study Group. Circ Heart Fail. 2017; 10: e 002637.

54. Габрусенко С. А. Современные подходы к лечению больных гипертрофической кардиомиопатией/ С. А. Габрусенко, Ю. В. Сафрыгина, В. Г. Наумов и др. Лечащий врач. 2004; № 2: 32-37.

55. Вайханская Т.Г. и соавт. Дилатационная кардиомиопатия: новый взгляд на проблему//Российский кардиологический журнал. 2019; 24(4):35-47.

56. Сдвигова Н.А., Басаргина Е.Н. и соавт. Актуальность генетической верификации некомпактной кардиомиопатии у детей: клинические случаи. Вопросы современной педиатрии. 2018; 17 (2): 157-165.

57. Шляхто Е.В. Кардиология. Национальное руководство. Краткое издание [Электронный ресурс] / Шляхто Е.В. - М. : ГЭОТАР-Медиа, 2019. - 816 c. - ISBN 978-5-9704-4876-2 .

58. Salim S. Virani, Alvaro Alonso, Emelia J. Benjamin, Marcio S. Bittencourt, et al. Heart Disease and Stroke Statistics-2020 Update: A Report From the American Heart Association. Circulation Volume 141, Issue 9, 3 March 2020; Pages e139-e596. https://doi.org/10.1161/CIR.0000000000000757.

59. Михайлов В.С. и соавт., Клин.и эксперимент. хир. Журн. им. акад. Б.В. Петровского.- 2018. - № 1. - С.70-76. 
60. Сухарева Г.Э. Диагностика различных вариантов кардиопатий у детей. Новый взгляд на старую проблему. Учебно-методическое пособие. С.-Петербург, 2017.- 95 c.

61. Rusconi P., Wilkinson J.D., Sleeper L.A., Lu M., et al.; for the Pediatric Cardiomyopathy Registry Investigators. Differences in Presentation and Outcomes between Children with Familial Dilated Cardiomyopathy and Children with Idiopathic Dilated Cardiomyopathy: A Report from the Pediatric Cardiomyopathy Registry Study Group. Circ Heart Fail. 2017; 10: e002637. doi: 10.1161/CIRCHEARTFAILURE.115.002637.

62. Леонтьева И.В. Проблемы современной диагностики и лечения дилатационной кардиомиопатии у детей//Рос.вестн.перинатол. и педиатр 2018; 63:(2): 7-15. DOI: 10.21508/1027-4065-2018-63-2-7-15. 2020

63. Caforio, Alida LP. Myocarditis. Pathogenesis, Diagnosis and Treatment.

64. Kumar S., Baldinger S.H. et al. Long-Term Arrhythmic and Nonarrhythmic Outcomes of Lamin A/C Mutation Carriers. Journal of the American College of Cardiology. Volume 68, Issue 21, 29 November 2016, Pages 2299-2307.

65. Ponikowski P., Voors A.A., Anker S.D., Bueno H., Cleland JG.F, Coats AJ.S et al. 2016 ESC Guidelines for the diagnosis and treatment of acute and chronic heart failure: The Task Force for the diagnosis and treatment of acute and chronic heart failure of the European Society of Cardiology (ESC). Developed with the special contribution of the Heart Failure Association (HFA) of the ESC. European Heart Journal. 2016; 37(27):2129-200. DOI:10.1093/ eurheartj/ehw128.

66. Bakeet M.A. et al. Childhood Cardiomyopathies: A Study in Tertiary Care Hospital in Upper Egypt. Electronic Physician, 25 Nov 2016, 8(11):3164-3169

67. Elliott P., Anastasakis A., Borger M., Borggrefe M., Cecchi F., Charron P. et al. 2014 ESC Guidelines on diagnosis and management of hypertrophic cardiomyopathy The Task Force for the Diagnosis and Management of Hypertrophic Cardiomyopathy of the European Society of Cardiology (ESC). Eur Heart J 2014; 35(39): 2733-2779. DOI: 10.1093/eurheartj/ehu284.

68. Алиева А.М., Резник Е.В., Гасанова Э.Т., Жбанов И.В., Никитин И.Г. Клиническое значение определения биомаркеров крови у больных с хронической сердечной недостаточностью// Архивъ внутренней медицины. 2018.- № 5. - С.333-345.

69. Дупляков Д.В. Мутации сердечных тропонинов, ассоциированные с кардиомиопатиями. Кардиология: новости, мнения, обучение. 2019.-Т.7, №3. C.8-17. 
70. Копьева К.В. и соавт. Новые маркеры сердечной недостаточности: значение для диагностики и прогнозирования NT-PROBNP и интерлейкиновых рецепторов - членов семейства ST2// Комплексные проблемы сердечнососудистых заболеваний. 2018; 7 (1): 94-101.

71. Медведева Е. А. и соавт. Молекулярные биомаркеры в диагностике, стратификации риска и прогнозировании хронической сердечной недостаточности// Российский кардиологический журнал 2016, 8 (136): 86-91.

72. Хамитова А.Ф., Дождев С.С., Загидуллин Ш. З., Ионин В.А., Гареева Д.Ф., Загидуллин Н.Ш. Значение сывороточных биомаркеров в прогнозировании развития сердечной недостаточности и смертности. Артериальная гипертензия. 2018; 24(1):101-107.

73. Хафизов Р.Р. и соавт. «Новые» биомаркеры при инфаркте миокарда с подъемом сегмента ST//Практическая медицина.2014; 6(82):48-52.

74. Braunwald E.B. The Management of Heart Failure: The Past, the Present, and the Future. Circ Heart Fail 2008; 1: 58-62. DOI: 10.1161 /CIRCHEARTFAILURE.107.752162.

75. Хамитова А.Ф., Загидуллин Ш.З., Лакман И.Р., Гареева Д.Ф., Загидуллин Н.Ш. Отдаленные сердечно-сосудистые события в зависимости от биомаркерного профиля у пациентов с инфарктом миокарда//Российский кардиологический журнал. 2019; 24(3):24-31.

76. Kimie Ohkubo, Ichiro Watanabe, Yasuo Okumura, et al. Usefulness of High Sensitivity C-Reactive Protein in Predicting Recurrence of Atrial Fibrillation after Electrical Cardioversion. J Nihon Univ Med Ass. 2015; 74(5):233-7.

77. Lavie CJ, Milani RV, Verma A, O'Keefe JH. C-reactive protein and cardiovascular disease: is it ready for primetime? Am J Med Sci. 2009; 338:486-492.

78. Westerlind A., Wahlander H., Lindstedt G., Lundberg P.A., Holmgren D. Clinical signs of heart failure are associated with increased levels of natriuretic peptide types B and A in children with congenital heart defects or cardiomyopathy // Acta. Paediatr. - $2004-93$ (3). - P. 340-5.

79. Алиева А.М., Резник Е.В., Гасанова Э.Т., Жбанов И.В., Никитин И.Г. Клиническое значение определения биомаркеров крови у больных с хронической сердечной недостаточностью// Архивъ внутренней медицины. 2018.- № 5. - С.333-345.

80. Дупляков Д.В.. Мутации сердечных тропонинов, ассоциированные с кардиомиопатиями. Кардиология: новости, мнения, обучение. 2019.-Т.7, №3.C.8-17. 
81. Копьева К.В. и соавт., Новые маркеры сердечной недостаточности: значение для диагностики и прогнозирования NT-PROBNP и интерлейкиновых рецепторов - членов семейства ST2// Комплексные проблемы сердечнососудистых заболеваний. 2018; 7 (1): 94-101. DOI: 10.17802/2306-1278-2018-7-194-101.

82. Амелюшкина В.А., Коткина Т.И., Титов В.Н. Биохимические маркеры пораженного миокарда. Клин.мед. 2000; 5:9-13.

83. Ripoll-Vera T., Gamez J.M., Govea N., Gomez Y. et al. Clinical and prognostic profiles of cardiomyopathies caused by mutations in the troponin $\mathrm{T}$ gene // Rev. Esp. Cardiol. (Engl. ed.). 2016. Vol. 69, N 2. P. 149-158.

84. Pinto YM, Elliott PM, Arbustini E, et al. Proposal for a revised definition of dilated cardiomyopathy, hypokinetic non-dilated cardiomyopathy, and its implications for clinical practice: a position statement of the ESC working group on myocardial and pericardial diseases. Eur Heart J. 2016; 37(23): 1850-8.

85. Короткова А.А., Титов В.Н., Стараведов И.И. Прогностическая роль кардиального тропонина I у больных с острым синдромом без подъема ST. Кардиология. 2002; 4: 19-22.

86. Бокерия Е.Л. Фетальные и неонатальные аритмии (клиника, диагностика, лечение): Автореф. дисс. ... докт.мед. наук. М., 2012: 48 с.

87. Бокерия О.Л. Ионные каналы и их роль в развитии нарушений ритма сердца / О.Л. Бокерия, А.А. Ахобеков // Анналы аритмологии. - 2014. - Т. 11, № 3. - С. 176-184;

88. Галышева Н.В. Оптимизация подходов к диагностике патологии сердца у новорожденных»: Автореф. дисс. ... канд. мед.наук. Екатеринбург, 2009.

89. Слобин П.И. Клинико-биохимические особенности адаптации сердечной деятельности при врожденных пороках сердца у новорожденных: Автореф. дисс. ... канд. мед.наук. Астрахань, 2000.

90. Шматкова Ю.В. Клиническое значение динамики содержания тропонина I, миоглобина и цитокинов при хронической сердечной недостаточности у детей: Автореф. дисс. ...канд. мед.наук. М., 2006.

91. Шматкова Ю.В., Бершова Т.В., Басаргина Е.Н., Баканов М.И., Гасанов А.Г., Монаенкова С.В., Иванов А.П., Арсеньева Е.Н. Иммунохимические медиаторы повреждения миокарда $\mathrm{y}$ детей $\mathrm{c}$ хронической сердечной недостаточностью. Педиатрия. - 2008. - Том 87, №2.- С.6-9.

92. Березнева Н.А., Арсеньева Е.Н., Юрявичус А.И. и соавт. Состояние ренин-ангиотензин-альдостероновой системы у детей с дилатационной и гипертрофической кардиомиопатией // Тезисы Всероссийского конгресса «Детская кардиология». - М. — 2012. - С.86-88. 
93. Драпкина О.М., Шепель Р.Н. Теломеры и хроническая сердечная недостаточность. Кардиология. 2014; 54(4):60-7.

94. Дремина Н.Н., Шурыгин М.Г., Шурыгина И.А. Эндотелины в норме и патологии // Международный журнал прикладных и фундаментальных исследований. - 2016. - № 10-2. - С. 210-214;

95. Кисленко О.А., Котлукова Н.П., Рыбалко Н.А. Диагностическое значение различных маркеров миокардиальной дисфункции у детей грудного возраста с патологией сердечно-сосудистой системы. Педиатрия.- 2011.- Т.90 (5).-C.6-11

96. Cook A.B., Toli E ., Gomez Y . et. al. From rest to stressed: endothelin1levels in young healthy smokers and non-smokers // Metabolism, 2015; 64(9):110311.

97. Davenport A.P. Endothelin // Pharmacol Rev. - 2016. - Vol. 68, № 2. - P. 357-418.

98. Davignon J, Ganz P. Role of endothelial dysfunction in atherosclerosis. Circulation. 2004; 109(Suppl 1): III27-III32.

99. Teerlink J.R. Endothelins: Pathophysiology and treatment implications in chronic heart failure // Current Heart Failure Reports. - 2005. - Vol. 2. - P.91-97.

100. Гомазков О.А. Система эндотелиновых пептидов: механизмы эндоваскулярных патологий // Кардиология. - 2000. -№ 1. -С. 32-39.

101. Шурыгин М.Г. Значение повышения продукции эндотелина при инфаркте миокарда // Фундаментальные исследования. - 2015. - № 1. - С. 12811287.

102. Tanowitz H.B. Role of endothelin 1 in the pathogenesis of chronic chagasic heart disease // Infect Immun. - 2005. - Vol. 73. - P. 2496-2503.

103. Hiyama T.Y. Endothelin-3 expression in the subfornical organ enhances the sensitivity of $\mathrm{Na}(\mathrm{x})$, the brain sodium-level sensor, to suppress salt intake // Cell Metab. - 2013. - Vol. 17, № 4. - P. 507-519.

104. Шурыгин М.Г. Экспрессия эндотелина при экспериментальном инфаркте миокарда в условиях измененной концентрации фибробластического и вазоэндотелиального факторов роста // Бюл. ВСНЦ СО РАМН. - 2013. - № 1 (89). - C. 125-129.

105. Полонецкий О.Л., Плонецкий Л.3. Дисфункция эндотелия и атеросклероз// Медицинские новости. - 2012. - №6. - С. 6-11.

106. Павленко Т.А. Содержание эндотелина в слезной жидкости больных глаукомой и пролиферативной диабетической ретинопластией / Т.А. Павленко, Н.Б. Чеснокова // Вестник офтальмологии. - 2013. - Т.129, № 4. -С. 20-23. 
107. Liefeldt L. Effects of transgenic endothelin-2 overexpression on diabetic cardiomyopathy in rats // Eur J Clin Invest. - 2010. - Vol. 40, № 3. - P. 203-2010.

108. Осипова О.А., Власенко М.А., Годлевская О.М., Суязова С.Б. Цитокины в развитии и прогрессировании хронической сердечной недостаточности. Вестник новых медицинских технологий - 2012 - Т. XIX, № 2 - C. 322-327.

109. Терещенко С.Н., Скворцов А.А., Щедрина А.Ю. и соавт. Диагностическая значимость иммунологических маркеров у больных воспалительной кардиомиопатией // Росс.кардиол.журнал. 2017. №2 (142): 22-30.

110. Bozkurt, B. Biomarkers of inflammation in heart failure./B. Bozkurt, D. L. Mann, A. Deswal // Heart fail. rev.- 2010.- Vol. 15, N 4.- P. 331-341.

111. Pro inflammatory cytokines in heart failure: double-edged swords / M. Hedayat [et al.] // Heart Fail Rev.- 2010.- Vol. 15, N 6.-P. 543-562.

112. Черешнев В.А., Гусев Е.Ю. Иммунологические и патофизиологические механизмы системного воспаления. Медицинская иммунология 2012; 14(1-2): 9-20)

113. Серебренникова С.Н., Семинский И.Ж., Семенов Н.В. и др. Интерлейкин-1, интерлейкин-10 в регуляции воспалительного процесса//Сибирский медицинский журнал.- 2012.-№ 8.-С.5-7.

114. Tinsley J.H., South S., Chiasson V.L., et al. Interleukin-10 reduces inE ammation, endothelial dysfunction, and blood pressure in hypertensive pregnant rats // Am. J. Physiol. Regul. Integr. Comp. Physiol. — 2010. — Vol. 298, №3. - P. 713719.

115. Васюк, Ю.А. «Цитокиновая» модель патогенеза хронической сердечной недостаточности и возможности нового терапевтического подхода в лечении декомпенсированных больных /Ю.А. Васюк [и др.] // Рациональная Фармакотерапия в Кардиологии. - 2006. - №4. - С.63-70.

116. Маткасымова А.Т., Муратов А.А., Кудаяров Д.К., Болотбекова А.Ж. Особенности иммунного статуса у детей с неревматическим миокардитом и кардиомиопатией//Вестник Кыргызско-Российского славянского университета. 2014; 14(4): 128-131.

117. Закирова Н.Э., Закирова А.Н. Роль иммуновоспалительных реакций и дисфункции эндотелия в ремоделировании миокарда и прогрессировании ишемической болезни сердца // Рациональная фармакотерапия в кардиологии 2014; 10(5):488-494.

118. Белюк С.Н., Снежицкий В.А. Роль иммунной активации и системного воспаления в патогенезе хронической сердечной недостаточности и подходы к лечению // Журнал ГрГМУ.- 2010.- № 4.-С.32-35. 
119. Levine, B. Elevated circulating levels of tumor necrosis factor in severe chronic heart failure / B. Levine [et al.] // New Engl J Med.- 1990. - Vol. 323. - P. 236-241.

120. Хамитова А.Ф., Дождев С.С., Загидуллин Ш. З., Ионин В.А., Гареева Д.Ф., Загидуллин Н.Ш. Значение сывороточных биомаркеров в прогнозировании развития сердечной недостаточности и смертности. Артериальная гипертензия. 2018; 24(1):101-107.

121. Хазова Е.В., Булашова О.В., Ослопов В.Н. и др. Фактор некроза опухоли $\alpha-$ маркер системного воспаления у пациентов с сердечной недостаточностью // Практическая медицина.- 2017. - №2 (103).- С.24-27.

122. Басаргина Е.И., Сенцова Т.Б., Гориславец Н.В. и соавт. Значение цитокинов при кардиомиопатиях у детей // Тезисы Всероссийского конгресса «Детская кардиология». - 2002. - С.83.

123. Юрьева Э.А., Воздвиженская Е.С., Алимина Е.Г., Леонтьева И.В. Лабораторные маркеры поражения миокарда при сердечно-сосудестой патологии у детей // Российский вестник перинатологии и педиатрии, 6, 2016; 61:6.82-88

124. Борзилова Ю.А., Болдырева Л.А., Шлык И.В. Васкулоэндотелиальные факторы роста (VEGF): роль и местов патологических процессах. Вестник офтальмологии. 2016; 4: 98-102.

125. Li X. Revaluation of the role of VEGF-B suggests a restricted role in the revascularization of the ischemic myocardium. Arterioscler Thromb Vasc Biol. 2008; 28:1614-1620.

126. Koch S., Tugues S., Li X., Gualandi L., Claesson-Welsh L. Signal transduction by vascular endothelial growth factor receptors. Biochem. J. 2011; 437 (2): $169-83$.

127. Koch S., Claesson-Welsh L. Signal Transduction by Vascular Endothelial Growth Factor Receptors. Cold Spring Harb Perspect Medv.2(7); 2012 Jul.

128. Selim KM, Sahan D, Muhittin T. Increased levels of vascular endothelial growth factor in the aqueous humor of patients with diabetic retinopathy. Indian $\mathrm{J}$ Ophthalmol. 2010; 5(5):375-379.

129. Кузьмин А.Г., Липатов Д.В., Чистяков Т.А. и др. Сосудистый эндотелиальный фактор роста в жидкости передней камеры у больных с диабетической ретинопатией, катарактой и неоваскулярной глаукомой. Сахарный диабет. 2010; (3):32-36.

130. Fujinaga H.L., Baker C.D., Ryan S.L., Markham N.E., Seedorf G.J., Balasubramaniam V. et al. Hyperoxia disrupts vascular endothelial growth factor-nitric oxide signaling and decreases growth of endothelial colony-forming cells from preterm infants. Am. J. Physiol. Lung. Cell. Mol. Physiol. 2009; 297 (6): 1160—9. 
131. Zhang F, Tang Z, Hou X. VEGF-B is dispensable for blood vessel growth but critical for their survival, and VEGF-B targeting inhibits pathological angiogenesis. Proc Natl Acad Sci USA. 2009; 106(15):6152-6157.

132. Островская А.С. Актуальные аспекты лечения острых респираторных заболеваний у детей: препараты топического действия при ринофарингите/ A.C. Островская, С.А. Иваничкин // Вопросы современной педиатрии. - 2012. - №11 (5).- C.160-166.

133. Юлиш Е.И. Факторы местного иммунитета при респираторных инфекциях и методы их активации /Е.И. Юлиш// Здоровье ребенка.-2010.-№5 (26).- C.63-67.

134. Косенко И. М. Местная иммунокорригирующая терапия при тонзиллитах и фарингитах у детей /И. М. Косенко// Российская оториноларингология №5 (48) 2010.- С. 107-116.

135. Мустафаев Д.М. Иммуномодулирующая терапия в ЛОР-практике / Д.М. Мустафаев, В.И. Егоров// Медицинский совет.- 2016.-№18.- С.94-100.

136. Мельников О.Ф. Иммунология хронического тонзиллита /О.Ф. Мельников, Д.И. Заболотный, В.В. Кищук и др.- К.: Логос, 2017.- 192 с.

137. Горбаль Н.М.Особливості продукції IFN- $\alpha$ у хворих на рецидивуючу герпесвірусну інфекцію 1-го та 2-го типів / Н.М. Горбаль, К.Е. Іщейкін, Г.О. Потьомкіна, І.Г. Гайдучок, І.Й. Кріль, В.В. Чоп’як // Семейная медицина. - 2019. - №3. - C.37-42.

138. Кетлинский С.А. Цитокины/ С.А. Кетлинский, А.С.Симбирцев.- СПБ: ООО «Издательство Фолиант», 2008.- 552 с.

139. Агаєв Н. А. Збірник методик для діагностики негативних психічних станів військовослужбовців: Методичний посібник / Н. А. Агаєв, О. М. Кокун, І. О. Пішко, Н. С. Лозінська, В. В. Остапчук, В. В. Ткаченко. - К. : НДЦ ГП ЗСУ, 2016. $-234 \mathrm{c}$.

140. Батищева Г. О. Музикотерапія як метод психокорекції / Г. О. Батищева // Профілактика і терапія засобами мистецтва: [наук.(метод. посіб.] ; Під заг. ред. О. І. Пилипенка. - К. : А.Л.Д., 1996. - 231 с.

141. Блінов О. А. Види та напрямки психологічної допомоги психотравмованим військовослужбовцям / О. А. Буряк // Вісник Національного університету оборони України. - 2014. - 4 (41). - С. 168-173.

142. Буряк О. О. Шляхи та методи реабілітації осіб з «військовим синдромом» та посттравматичним стресовим розладом / О. О. Буряк, М. I. Гіневський, Г. Л. Катеруша // Збірник наукових праць Харківського університету Повітряних Сил. - 2015. - № 3. - С. 137-141. 
143. Киндрас Г. П. Влияние посттравматических расстройств на адаптацию воинов-ветеранов войны в Афганистане / Г. П. Киндрас, А. М. Тураходжиев // Социальная и клиническая психиатрия. - 1992. - Т. 2, № 1. - С. 33-36.

144. Кокун О. М. Психологічна робота 3 військовослужбовцями учасниками АТО на етапі відновлення: Методичний посібник / О. М. Кокун, Н. А. Агаєв, І. О. Пішко, Н. С. Лозінська, В. В. Остапчук. - К. : НДЦ ГП ЗСУ, 2017. $-282 \mathrm{c}$.

145. Лесков В. О. Соціально-психологічна реабілітація військовослужбовців із районів військових конфліктів : автореф. дис. на здобуття наук. ступеня канд. психол. наук : спец. 19.00.09 / В. О. Лесков. - Хмельницький, 2008. -22 c.

146. Лікування та реабілітація комбатантів - миротворців із посттравматичним стресовим розладом / [О. Г. Сиропятов, О. К. Напрєєнко, Н. О. Дзеружинська та ін.]. - К. : О. Т. Ростунов, 2012. - 76 с.

147. Мульована Л. І. Методи психологічної допомоги учасникам АТО / Л. I. Мульована // Молодий вчений. - 2014. - № 10. - С. 114-116.

148. Стаднік I. В. Психологічні особливості переживання посттравматичного стресового розладу (ПТСР) учасниками зони антитерористичної операції (АТО) / І. В. Стаднік, М. І. Мушкевич // Психологія: реальність і перспективи. - 2015. - Вип. 4. - С. 244-248.

149. Сухарева Г. Е. Психогенные типы реакций военного времени / Г. Е. Сухарева // Невропатология и психиатрия. - 1943. - Т. 12. - № 4. - С. 3-10.

150. Цихоня В. Пам'ятка про посттравматичний стресовий розлад / В. Цихоня // Мистецтво лікування. - 2014. - № 7-8 (113-114). - С. 57-58.

151. Ботос, Л. Донорство: залучення донорів крові та іiі компонентів: навчальний посібник / Л. Ботос, Д. А. Оу, Д. Галлеем [та ін.]. К. - Вашингтон. 2014. $200 \mathrm{c}$.

152. Видиборець, С. В. Донорство крові та метаболізм заліза: монографія / С. В. Видиборець, Ю. Ю. Дерпак, О. В. Сергієнко. Вінниця-Бориспіль: ТОВ «Меркьюрі-Поділля». 2012. 144 с.

153. Видиборець, С. В. Організація трансфузіологічної допомоги в закладах охорони здоров'я: керівництво для лікарів / С. Видиборець, О. Волок, О. Добро вольський [та ін.]. К. - Вашингтон. 2018. 224 с.

154. Дерпак, Ю. Ю. Диагностика нарушений обмена микроэлементов у активных доноров крови / Ю. Ю. Дерпак, С. В. Выдыборец. Гематология. Трансфузиология. Восточная Европа. 2018. Т. 4. № 3. С. 482-487.

155. Дерпак, Ю. Ю. Клиническое значение и лабораторная диагностика изменений трансферрина у регулярных доноров крови / Ю. Ю. Дерпак. Гематология. Трансфузиология. Восточная Европа. 2018. Т. 4. № 2. С. 189-193. 
156. Стенлі, Д. Менеджмент якості в службі крові: навчальний посібник / Д. Стенлі, О. Волок, С. Гайдукова [та ін.]. К. - Вашингтон. 2017. 308 с.

157. Kulhinskyi, Ye. (2016). Priorytetni napriamy derzhavnoi polityky zberezhennia hromadskoho zdorovia Ukrainy [Priority directions of the state policy of preservation of public health of Ukraine]. Derzhavne upravlinnia ta mistseve samovriaduvannia - State Administration and Local Self-Government, 3, 84-91 [in Ukrainian].

158. Moskalenko, V.F. (2009). Kontseptualni pidkhody do formuvannia suchasnoi pro $\square$ laktyktychnoi stratehii $\mathrm{v}$ okhoroni zdorovia: vid pro $\square$ laktyky medychnoi do pro $\square$ laktyky sotsialnoi [Conceptual approaches to the formation of a modern preventive strategy in health care: from medical prevention to social prevention]. Kyiv: Avicenna [in Ukrainian].

159. Nakaz MOZ Ukrainy vid 18.09.2015 № 604 "Pro utvorennia derzhavnoi ustanovy "Tsentr hromadskoho zdorovia Ministerstva okhorony zdorovia Ukrainy" [Order of the Ministry of Health of Ukraine dated September 18, 2015 No. 604 "On Establishment of a State Institution " Center for Public Health of the Ministry of Health of Ukraine"]. Retrieved from: https://zakon.rada.gov.ua/rada/show/v0604282-15 [in Ukrainian].

160. Kniazevych, V.M. (Ed.). (2009).Okhorona zdorovia Ukrainy: stan, problemy, perspektyvy [Health care in Ukraine: status, problems, prospects]. Kyiv [in Ukrainian].

161. Rozporiadzhennia Kabinetu Ministriv Ukrainy vid 30 lystopada 2016 r. No. 1002-r "Pro skhvalennia Kontseptsii rozvytku systemy hromadskoho zdorovia" [Ordinance of the Cabinet of Ministers of Ukraine of November 30, 2016 No. 1002-p "On Approval of the Concept of Development of the Public Health System"]. Retrieved from: https://www.kmu.gov.ua/ua/ npas/249618799 [in Ukrainian].

162. Uhoda pro asotsiatsiiu mizh Ukrainoiu ta Yevropeiskym Soiuzom. Uriadovyi portal [Association Agreement between Ukraine and the European Union. Government portal].

Retrieved from: https://www.kmu.gov.ua/storage/app/media/ugodaeuassociationagreementbody.pdf 13 [in Ukrainian]

pro-asociaciyu/00ukraine-

163. Крюков А.І., Туровський А.Б. Антибактеріальна терапія гострого середнього отиту і синуситу у дорослих в амбулаторній практиці // PM3 -No 21, 2012 p, C.1188-1191

164. Canonica G.W., Compalati E. Minimal persistent inflammation in allergic rhinitis: implications for current treatment strategies. Clin. Exp. Immunol. -2009.158(3): 260-271.

165. Кузнєцова Л. В. Особливості терапії ГРВІ у пацієнтів 3 алергічними захворюваннями // Укр.медичний часопис.-No 6 (92) - XI / XII 2012. 
166. Тарасова Г.Д. Особливості лікування ускладнених форм алергічного риніту // Лікуючий лікар. -2008.-No4.- c.28-33.

167. Шкорботун В.А., Кубишкін А.В. Патогенетичне обгрунтування комбінованої терапії при алергічного риніту // Укр.медичний часопис. - No 2 (94) - III/IV 2013.

168. Gentile D.A., Skoner D.P. Viral rhinitis. // Curr. Allergy Asthma Rep., 2001.- 1(3). - 227-234.

169. Даніличева І.В. Деякі аспекти способу життя хворих на поліноз // Consilium Medicum. - 2003.- No 5(4)c.- 223-225.

170. Зайков С.В. Сучасні уявлення про лікування полінозу // Клин. іммнол. аллергол. Інфектол. - 2008.-No 3(14)c.- 49-54.

171. Дідковський Н.А., Малашенкова І.К. Клініка, діагностика, лікування полінозу: фокус на лоратадин (Кларідол) // РМЗ (Російський медичний журнал). -2013.-No 9.-c. 454-459.

172. Зайцева О.В. Гострі респіраторні інфекції у пацієнтів 3 алергією // Лікуючий лікар. - 2006.- No9.-с. 13-16.

173. Skoner D.P., Gentile D.A., Fireman P. et al. Urinary histamine metabolite elevations during experimental influenza infection. Ann. Allergy Asthma Immunol. 2001.- No 87(4).-p. 303-306.

174. Ricca V., Landi M., Ferrero P. et al. Minimal persistent inflammation is also present in patients with seasonal allergic rhinitis// J. Allergy Clin. Immunol. 2000.- No105(1 Pt. 1).-p. 54-57.

175. Day J.H., Ellis A.K., Rafeiro E. Levocetirizine: a new selective H1 receptor antagonist for use in allergic disorders// Drugs Today (Barc).- 2004.- No 40(5).p. 415421.

176. Nettis E., Calogiuri G.F., Di Leo E. et al. Once daily levocetirizine for the treatment of allergic rhinitis and chronic idiopathic urticaria. J. Asthma Allergy.-2008.No 2.-p.17-23.

177. Walsh G.M. A review of the role of levocetirizine as an effective therapy for allergic disease. Expert. Opin. Pharmacother. - 2008.- No 9(5).-p. 859-867.

178. Щербак I. Б. Акценти антигистамінной терапії: левоцетиризин //Укр.медичний часопис. -2012.-No 3 (89) - V/VI и.

179. Brozek J L. Allergic Rhinitis and its Impact on Asthma (ARIA) guidelines: 2010 Revision / J L. BrozekJ Bousquet, CE. Baena-Cagnani [et al] // J Allergy Clin Immunol. - 2010. - Vol.126. - P.466-76

180. Аллергология: Руководство для практич. врачей - 2-е изд., испр. и доп. / Под ред. Р. М. Хаитова, Н.И.Ильиной. М.: ГЭОТАР-Медиа, 2009. 256 с. 
181. Аллергология и иммунология: Клинические рекомендации для педиатров - 2-е изд., испр. и доп. / Под ред. А.А.Баранова, Р. М. Хаитова. М.: Союз педиатров России, 2010. 248 с.

182. Олехнович В.М. Клиника и терапия неотложных состояний в аллергологии и их профилактика. М.: Медицинская книга, 2005.96 с.

183. Каратеев АЕ. Использование нестероидных противовоспалительных препаратов в реальной клинической практике: новые возможности. Consilium Medicum. 2018;20(9):88-94. DOI: http://doi.org/10.26442/2075-1753_2018.9.88-94

184. Шостак НА, Клименко АА, Демидова НА, Аничков ДА. Безопасность селективных нестероидных противовоспалительных препаратов: анализ данных последних лет. Клиницист. 2020;14(1-2):91-9. DOI: https://doi.org/10.17650/18188338-2020-14-1-2-91-99

185. Довгань ЕB. Результаты исследования PRECISION: удалось ли ответить на вопрос, насколько безопасны коксибы в сравнении с «традиционными» нестероидными противовоспалительными препаратами у пациентов с высоким риском развития сердечно-сосудистых осложнений? Современная ревматология. 2017;11(3):129-31.

186. Бондаренко ОА, Агибалов АН. Лекарственно-индуцированные поражения верхних отделов пищеварительного тракта: профилактика и лечение. Сучасна гастроентерологія. 2019;2(106):55-65. DOI: http://doi.org/10.30978/MG2019-2-55

187. Вялов СС. Противовоспалительная терапия и гастротоксичность: реальные возможности профилактики. Российский медицинский журнал. 2014;22:1644-8.

188. Гладких Ф. В., Степанюк Н. Г. Сучасні шляхи послаблення ульцерогенності нестероїдних протизапальних засобів: досягнення, невирішені питання та шляхи оптимізації. Запорожский медицинский журнал. 2014. № 2. С. 82-86. DOI: https://doi.org/10.14739/2310-1210.2014.2.25437

189. Степанюк Н. Г., Гладких Ф. В. Характеристика ускладнень фармакотерапії на тлі застосування НПЗ3 за даними спонтанних картповідомлень у Подільському регіоні за 2013 рік. Клінічна фармація, фармакотерапія та медична стандартизація. 2014. № 1-2 (22-23). С. 30-34. Режим доступу: http://clinpharm.meduniv.lviv.ua/FILES/kffms_1-2_2014/all.pdf

190. Степанюк Н. Г., Гладких Ф. В., Басараб О. В. Аналіз побічних реакцій на тлі застосування анальгетиків-антипіретиків та нестероїдних протизапальних засобів, які призначались лікарями закладів охорони здоров'я Подільського регіону у 2015 році. Галицький лікарський вісник. 2016. № 2 (23). С. 60-63. Режим доступу: http://ojs.ifnmu.edu.ua/index.php/gmj/article/view/545

191. Гладких Ф. В., Чиж М. О. Нестероїдні протизапальні засоби: сучасне уявлення про механізми ушкодження травного тракту, недоліки препаратів 
патогенетичного лікування та перспективи біологічної терапії НПЗ3-індукованої езофагогастроентероколонопатії. Гастроентерологія. 2020. № 4. C. 253-266. DOI: https://doi.org/10.22141/2308-2097.54.4.2020.216714

192. Гольцев АН, ред. Плацента: криоконсервация, клиническое применение. Харьков; 2013. 268 с.

193. Гулида МО, Мирошниченко ЕВ, Берёзка НИ, Гарячий ЕВ. Применение экстракта плаценты в комплексном лечении больных ревматоидным артритом. Експериментальна i клінічна медицина. 2014;1(62):168-71.

194. Капустянська АА. Застосування препарату «Кріоцелл-кріоекстракт плаценти» в комплексному лікуванні загострення подагричного артриту 3 метаболічним артритом. Актуальні проблеми сучасної медицини: Вісник Української медико-стоматологічної академії. 2010;10.2(30):54-8.

195. Гулида МО, Мирошниченко ЕВ, Берёзка НИ, Гарячий ЕВ. Применение экстракта плаценты в комплексном лечении больных ревматоидным артритом. Експериментальна i клінічна медицина. 2014;1(62):168-71.

196. Капустянська АА. Застосування препарату «Кріоцелл-кріо-екстракт плаценти» в комплексному лікуванні загострення подагричного артриту 3 метаболічним артритом. Актуальні проблеми сучасної медицини: Вісник Української медичної стоматологічної академії. 2010;10(30):54-8.

197. Шепітько КВ. Дослідження ступеня зв'язування лектинів у слизовій оболонці дванадцятипалої кишки при введенні кріоконсервованої плаценти на тлі гострого асептичного запалення очеревини у щурів. Клінічна анатомія та оперативна хірургія. 2015;14(1):57-61.

198. Шепітько КВ. Характеристика гемомікроциркуляторного русла слизової оболонки дванадцятипалої кишки при трансплантації кріоконсервованої плаценти на тлі гострого асептичного запалення очеревини у щурів. Світ медицини та біології. 2015;2(49):151-5.

199. Грищенко НГ, Грищенко ВИ, Смольянинова ЕИ, Чернишенко ЛГ, Волкова НА. Влияние криоэкстракта плаценты на индукцию суперовуляции у лабораторных мышей с хроническим воспалением яичников. Проблеми кріобіології. 2010;20(3):327-37.

200. Луценко НС, Прокопюк ОС, Бондаренко ИА, Гераскина ЛР, Евтарева ИА. Применение криоконсервированной плацентарной ткани при изоиммунизации беременных женщин. Проблемы криобиологии. 2008;18(3):316-8.

201. Прокопюк ВЮ, Трифонов ВЮ, Прокопюк ОС, Черемський АК, Зуб ЛІ. Клінічна ефективність прегравідарної підготовки жінок з антифосфоліпідним синдромом. Педіатрія, акушерство та гінекологія. 2011;(2):78-81. 
202. Рєпін МВ, Марченко ЛМ, Говоруха ТП, Васькович АМ, Строка ВI, Кондаков II, Брусенцов ОФ. Вплив попереднього введення кріоекстрактів плаценти різного походження на морфофункціональний стан нирок щурів при моделюванні гострої ниркової недостатності. Експериментальна і клінічна медицина. 2017;2(75):37-43.

203. Ковалев ГА, Высеканцев ИП, Ищенко ИО, Абрафикова ЛГ, Олефиренко АА, Сандомирский БП. Влияние криоконсервированной сыворотки кордовой крови и экстракта плаценты на заживление холодовых ран. Проблемы криобиологии и криомедицины. 2015;25(1):57-66.

204. Лихицкий АА. Влияние криоконсервированной плацентарной ткани на остеогенез в эксперименте при переломе нижней челюсти. Клінічна стоматологія. 2016;1(14):37-41.

205. Шепитько КВ, Шепитько ВИ, Юрченко ТН, Строна ВИ. Влияние криоконсервированной плацентарной ткани на течение стабильной стенокардии. Вестник неотложной и восстановительной медицины. 2012;13(1):146-9.

206. Кондаков ИИ, Юрченко ТН. Морфологические аспекты действия криоконсервированной плаценты при экспериментальном атеросклерозе. Вестник неотложной и восстановительной медицины. 2012;13(1):68-71.

207. Гладких Ф. В., Чиж М. О. Антиульцерогенна дія кріоконсервованого екстракту плаценти та ефект впливу низьких температур при ушкодженні травного тракту диклофенаком натрію в експерименті. Східноукраїнський медичний журнал. 2021. 9 (3) 284-94. DOI: https://doi.org/10.21272/eumj.2021;9(3):284-294

208. Гладких Ф. В., Чиж М. О. Модуляція мелоксикам-індукованих змін секреторної та моторної активності шлунка шляхом застосування кріоекстракту плаценти. Праці Наукового Товариства ім. Т. Г. Шевченка. Медичні науки. 2021. № 64 (1). C. 84-94. DOI: https://doi.org/10.25040/10.25040/ntsh2021.01.08. Режим доступу: https://mspsss.org.ua/index.php/journal/article/view/400

209. Гладких Ф. В. Макроскопічна оцінка протективної дії кріоконсервованого екстракту плаценти при ібупрофен-індукованій гастроентероколонопатії. Гастроентерологія. 2021; 55 (3): 25-32. DOI: https://doi.org/10.22141/2308-2097.55.3.2021.241587

210. Гладких Ф. В. Експериментальне дослідження впливу кріоконсервованого екстракту плаценти на протизапальну активність диклофенаку натрію. Innovative Biosystems and Bioengineering. 2021. № 5 (3). С. 144-.52. DOI: https://doi.org/10.20535/ibb.2021.5.3.237505. Режим доступу: http://ibb.kpi.ua/article/view/237505

211. Гладких Ф. В., Чиж М. О. Характеристика механізмів протизапальної дії кріоконсервованого екстракту плаценти та диклофенаку натрію за їх 
нарізного введення. Сучасні медичні технології. 2021. 3 (50): 41-47 DOI: https://doi.org/10.34287/MMT.3(50).2021.8

212. Гладких Ф. В. Оцінка лікувального ефекту комбінованого застосування кріоконсервованого екстракту плаценти та диклофенаку натрію при експериментальному ревматоїдному артриті за гематологічними показниками. Медична наука України. 2021. 17 (3): 15-21. DOI: https://doi.org/10.32345/2664-4738.3.2021.02

213. Гладких Ф. В., Чиж Н. А., Манченко А. А., Белочкина И. В., Михайлова И. П. Влияние криоконсервированного экстракта плаценты на отдельные биохимические показатели лечебной эффективности и токсичности диклофенака натрия при адъювант-индуцированном артрите в эксперименте. Фармация и фармакология. 2021. № 9 (4). С. 278-293. DOI: https://doi.org/10.19163/2307-9266-2021-9-4-278-293. Режим доступу: https://www.pharmpharm.ru/jour/article/view/879 